Portland State University

PDXScholar

$11-4-1993$

\title{
Cities and Automobile Dependence: An Empirical Examination of Density and Automobile Dependence Relationship and Their Underlying Factors
}

Musaad Abdullah Al-Mosaind

Portland State University

Follow this and additional works at: https://pdxscholar.library.pdx.edu/open_access_etds

Part of the Urban Studies and Planning Commons

Let us know how access to this document benefits you.

\section{Recommended Citation}

Al-Mosaind, Musaad Abdullah, "Cities and Automobile Dependence: An Empirical Examination of Density and Automobile Dependence Relationship and Their Underlying Factors" (1993). Dissertations and Theses. Paper 4675.

https://doi.org/10.15760/etd.6559

This Dissertation is brought to you for free and open access. It has been accepted for inclusion in Dissertations and Theses by an authorized administrator of PDXScholar. Please contact us if we can make this document more accessible: pdxscholar@pdx.edu. 
AN ABSTRACT OF THE DISSERTATION of Musaad Abdullah Al-Mosaind for the Doctor of Philosophy in Urban Studies presented November 4, 1993.

Title: Cities and Automobile Dependence: An Empirical

Examination of Density and Automobile Dependence Relationship and Their Underlying Factors.

APPROVED BY MEMBERS OF THE DISSERTATION COMMITTEE:
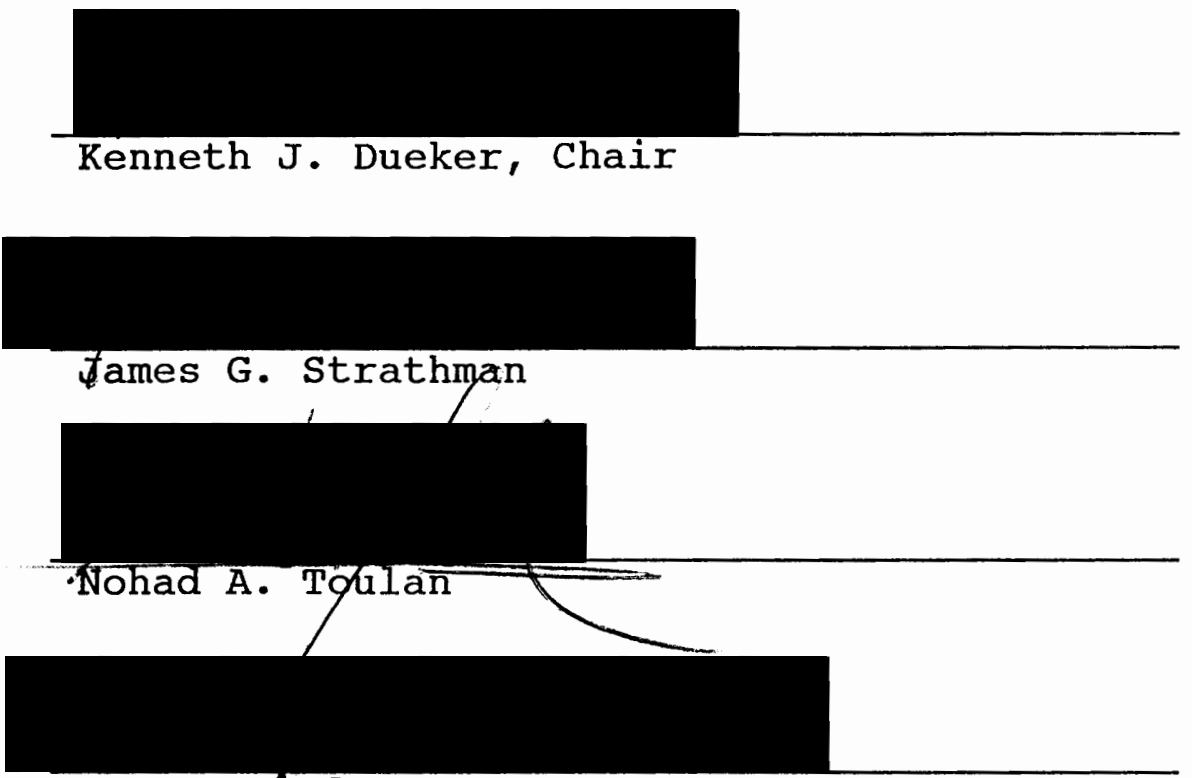

Seymour/fdler

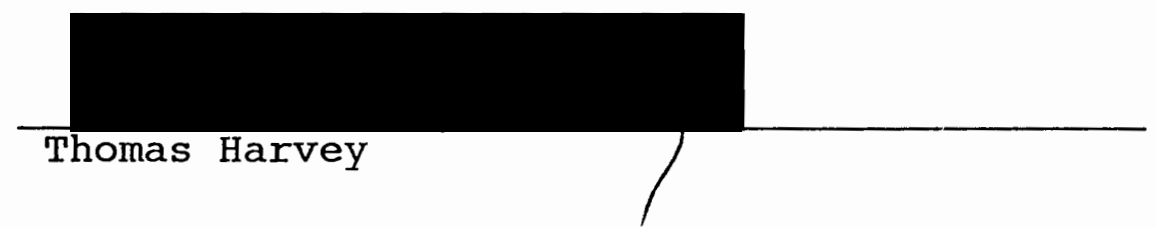

Over the last several decades, low-density development and increasing levels of automobile dependence have become two of the major problems facing many urban areas. While they have significantly improved urbanites' mobility, 
freedom, and social contacts, and have expanded the ranges of economic activities, they have also brought numerous problems and externalities. Mitigating their negative externalities through appropriate policies necessitates the examination of their relationship and the effect of other urban elements.

This research examines the relationship between density and automobile dependence and its underlying factors within cities. It examines the effects of quantifiable factors at three levels of analysis: regional, zonal, and household. Several hypotheses and sub-hypotheses concerning density and automobile dependence relationship and its underlying factors are examined.

The research findings confirm most of the study hypotheses. With respect to the strength and direction of the relationship between population density and automobile dependence measured in per capita VMT, most of the models constructed confirm the existence of a strong simultaneous relationship between density and VMT. Further, the analysis shows that other land use, economic, demographic, and transportation factors are also important determinants of density and VMT. At different levels of analysis, different factors are more important in explaining density and automobile dependence than others. Finally, the estimated optimal densities tend to be more than double the existing average densities of the study cases. 
The research conclusions suggest several theoretical and policy implications to guide future policies in land use and transportation. 
CITIES AND AUTOMOBILE DEPENDENCE:

AN EMPIRICAL EXAMINATION OF DENSITY AND AUTOMOBILE DEPENDENCE RELATIONSHIP AND THEIR UNDERLYING FACTORS

by

MUSAAD ABDULLAH AL-MOSAIND

A dissertation submitted in partial fulfillment of the requirements for the degree of

DOCTOR OF PHILOSOPHY

in

URBAN STUDIES

Portland State University

1993 
TO THE OFFICE OF GRADUATE STUDIES:

The members of the Committee approve the dissertation of Musaad Abdullah Al-Mosaind presented November 4, 1993.

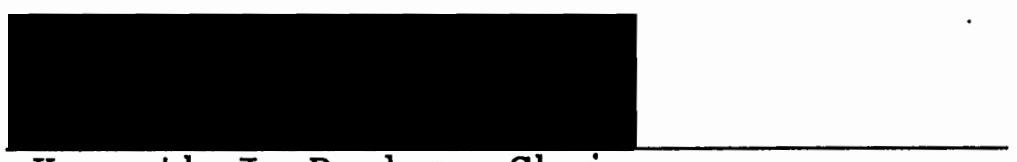

Kenneth J. Dueker, Chair

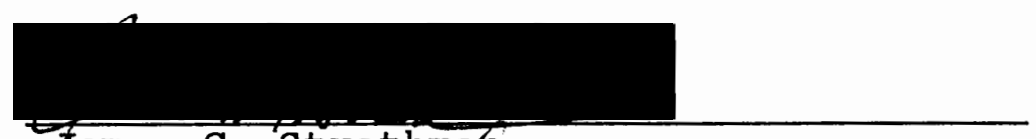

James G. Strathmgin
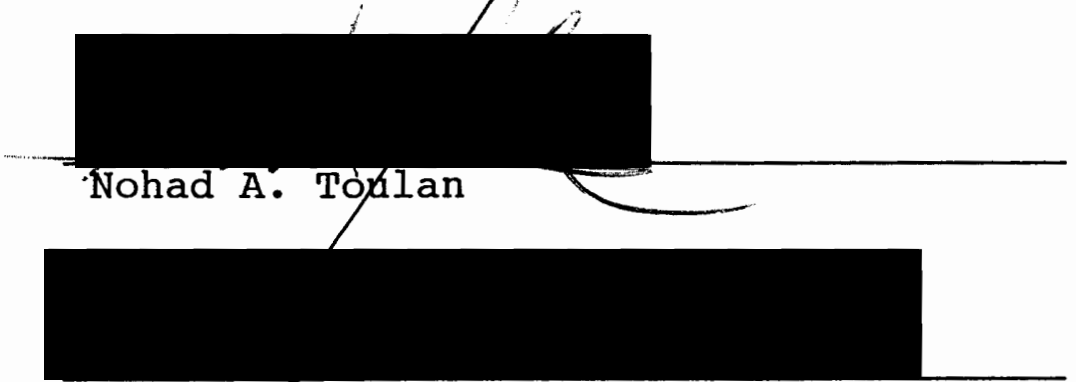

Seymour fader

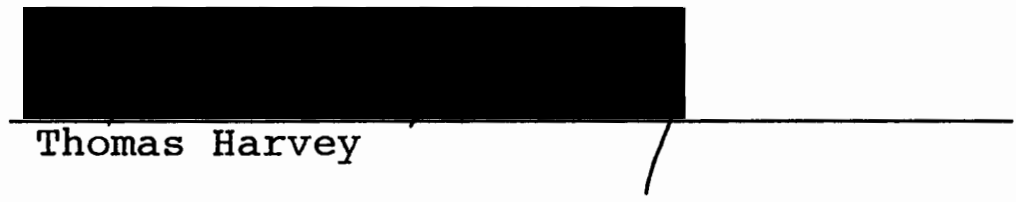

APPROVED :

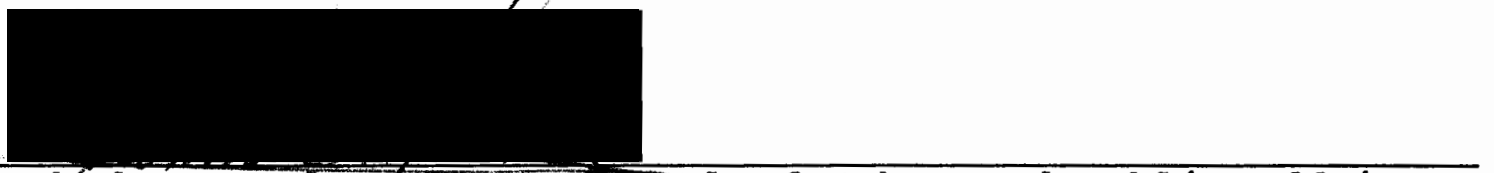

Nohad A. Toulan, Dean, S\&Kool of Urban and Public Affairs

Roy W. Kqch, Vice Provost for Graduate Studies and Research 


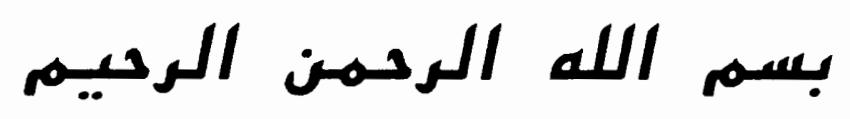

In the name of Rllah, Most Gracious, Most Merciful.

Proclaim! ( or Read!) In the name of thy Lord and Cherisher; Who create-

Created man, out of $\mathrm{B}$ leech-like clot:

Proclaim! And thy Lord is Most Bountiful

He Who taught (The use of) the Pen,-

Taoght man that Which he Knew not.

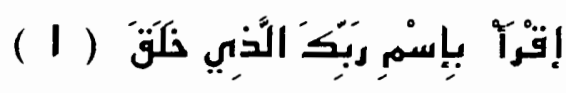

ذَكَّ الإنسانْ هـن علٍٍَّ ( )

إقْرَاً وَربتُكُ الأكَرَمُ ( )

الَّبِي علَّمَ بِالقَمْمِ (

علَّمَ الإنسانَ ما لَمْ يَعَلْمَ (0 ) 
To my Parents, for their love and faith in me.

To my Brothers and Sisters, for their support and encouragement.

To my Wife and my Daughter, Hatoon, for their patience, support, and devotion. 


\section{ACKNOWLEDGEMENTS}

This dissertation would not have been completed without the guidance of Allah (Subhanaho Wa-Taala) and of those who contributed so much and deserve special recognition.

I would like to express my deep appreciation to my advisor and committee Chair, Dr. Kenneth J. Dueker, for his valuable advice and encouragement throughout my doctoral program and dissertation process. Dr. Dueker has been a strong motivator inside and outside the class. Sincere appreciation and gratitude is also extended to Dr. James G. Strathman for his constructive comments and advice, especially in the technical aspects of this work. I also wish to thank all the other members of my dissertation committee, Dr. Nohad A. Toulan, Dr. Seymour Adler, and Dr. Thomas Harvey, for their guidance and encouragement.

In addition, a special thanks goes to King Saud University for its financial support throughout my graduate studies. Some of the research data were not possible without the help of my close friend Abdul Rahman Messeinid from ADA and Keith Lawton and Dick Walker from Metro of Portland.

Finally, I am greatly indebted to my parents, my wife, my daughter, my entire family, and my friends for their continuous love, support, and encouragement. 
TABLE OF CONTENTS

PAGE

ACKNOWLEDGEMENTS $\ldots \ldots \ldots \ldots \ldots \ldots \ldots \ldots \ldots \ldots$ iv

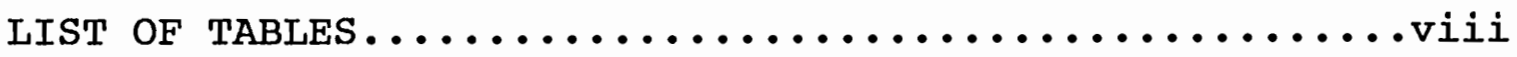

LIST OF FIGURES $\ldots \ldots \ldots \ldots \ldots \ldots \ldots \ldots \ldots \ldots \ldots \ldots \ldots \ldots \ldots$

CHAPTER

I INTRODUCTION...................... 1

Research Objectives................. 6

Definitions..................... 8

Organization of the study............. 9

II LITERATURE REVIEW................. 10

A Historical Perspective of Transportation and Urban Development.............. 10

Transportation and Land Use Interaction

Theories....................... 16

Theoretical Perspectives on the Relationship

Between Density and Automobile Dependence 20

The Simultaneity Concept

Other Contributors to the Simultaneous Relationship

Empirical Studies of Density and Automobile

Dependence..................... 34

Concluding Remarks.................. 39 
III RESEARCH METHODOLOGY............... 41

Approaches Examining Density and Automobile

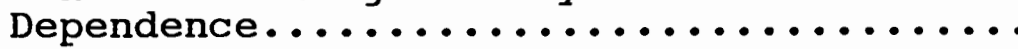

Aggregate Approach

Disaggregate (Household) Approach

Statistical Techniques for Examining Density

and Automobile Dependence Relationship... 45

Single Equation Systems

System Equation Methods

Research Design.................... 48

Statement of the Problem

Study Scope and Sample

Research Hypotheses

Research Models

Data Sources

International (Intercity) Comparisons: Land

Use and Travel Patterns............. 64

Variations in Urban Development Patterns

Variations in Transportation Systems and Summary Travel Patterns

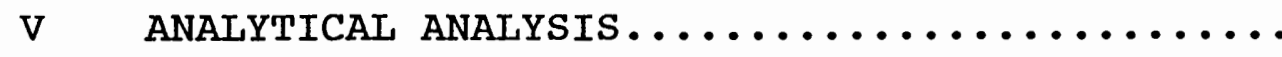

The Design of Empirical Analysis......... 75

Specification Strategies

The Relationship Between Density and VMT and The Effects of Other Factors at the Regional Level.................. 79

The Relationship Between Density and VMT and The Effects of Other Factors at the

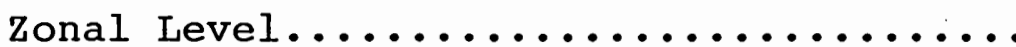

Results of the Portland Model

Results of the Ar-Riyadh Model 
The Relationship Between Density and VMT and The Effects of other Factors at the Household Level.................... 94

Results For New York Model Results For Snowbelt Cities Model Results for Sunbelt Cities Model Portland Zonal and Household Models Summary

Optimal Density Analysis................ 111

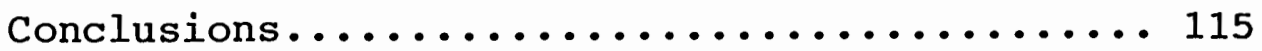

VI RESEARCH FINDINGS................... 118

Density and Automobile Dependence Relationship 118

Other Factors Affecting Density and

Automobile Dependence.............. 122

Land Use Factors

Economic Factors

Demographic Factors

Transportation Provision Factors

Conclusions......................... 127

VII DISCUSSIONS AND RESEARCH IMPLICATIONS....... 129

Generalizability of the study............. 130

Research Limitations................... 130

Theoretical Implications................ 132

Planning and Policy Implications.......... 135

Suggestions for Further Research........... 142

SELECTED BIBLIOGRAPHY.......................... 145 APPENDICES

A DEVELOPMENT AND TRAVEL PATTERNS IN WORLD CITIES ................... 157

B SUMMARY STATISTICS OF THE RESEARCH MODELS .... 161

C RESULTS OF AUXILIARY HOUSEHOLD MODELS . . . . . 167 


\section{LIST OF TABIES}

TABLE

PAGE

I

II

III

IV

V

VI

VII

VIII

IX

$\mathrm{X}$

XI

XII

XIII

XIV

XV

XVI

XVII
Definitions and Measurements of Regional Models Variables.............. 59

Definitions and Measurements of Portland Model Variables............... 60

Definitions and Measurements of Ar-Riyadh Model Variables................ 61

Definitions and Measurements of Household Models Variables................

Variations in Urban Development Patterns

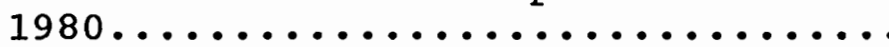

Variations in Population and Employment Densities 1980

Variations in Travel Patterns 1980..... 69

Variations in Modal split 1980........ 71

Variations in Transportation Provision 1980

Results of the Pooled Regional Model.... 82

Results of the 1980 Regional Model...... 83

Elasticities of Regional Models........ 85

Results of Portland Zones Model........ 89

Results of Ar-Riyadh Zones Model....... 92

Results of the Household Model for

Metropolitan New York........... 96

Results of the Household Model for

Snowbelt Cities................ 99

Elasticities of the Household Models

for snowbelt Cities............. 102 
XVIII Results of the Household Model for Sunbelt Cities................ 104

$\mathrm{XIX}$

Elasticities of the Household Models for Sunbelt Cities............... 107

$\mathrm{XX}$

Elasticities of the Three Household Models.................... 110

$\mathrm{XXI}$

Estimations of Optimal Densities for the Study Models.............. 113

XXII

Variations in Urban Development Patterns

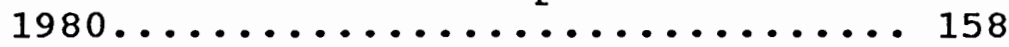

XXIII

Variations in Travel Patterns

(Per Capita) 1980.............. 159

XXIV

Variations in Transportation Provision

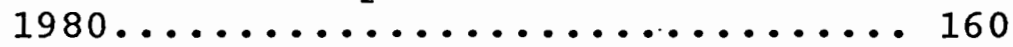

$\mathrm{XXV}$

XXVI

XXVII

Summary Statistics for the Pooled Regional Model............... 162

Summary Statistics for the 1980 Regional Model............... 162

$X X V I$

Summary statistics for the Portland Zonal Model................. 163

XXVIII Summary Statistics for the Ar-Riyadh Zonal Model................. 163

XXIX Summary Statistics for New York Household Model................ 164

XXX Summary Statistics for Snowbelt Cities Household Model.............. 165

XXXI Sumary Statistics for Sunbelt Cities Household Model.............. 166

XXXII Results of the Household Model for Metropolitan Chicago........... 168

XXXIII Results of the Household Model for Metropolitan Boston............ 169

XXXIV Results of the Household Model for Metropolitan Los Angeles......... 170 


\section{LIST OF FIGURES}

FIGURE

PAGE

1. Transportation and Land Use Cycle.... 19

2. Variations in Development and Travel

Patterns.................... 65

3. Variations in Modal Split.......... 72 
CHAPTER I

\section{INTRODUCTION}

The mobility of urban populations worldwide is the greatest in history. Over the past several decades, automobility has increased significantly, reflecting remarkable increases in automobile ownership and automobile trips and miles of travel. Since World War II, automobile ownership has rapidly increased not only in developed countries but also in developing countries. Between 1950 and 1986 , the number of automobiles in use worldwide increased from 53 million to 386 million, a 17 percent annual increase (Renner, 1988). In the developing world, the number has increased 14.5 percent annually since 1970 (Lowe, 1990). These rates reflect the growing dependence of urban population on the automobile in both developed and developing countries.

High automobile ownership represents a growing trend toward increased automobile use worldwide, especially in the developed world. Automobile travel has increased rapidly, while transit use has decreased at a similar but slower rate (Owen, 1972). In terms of passenger kilometers per capita, automobile travel has increased 20 percent in the U.S., 17 to 60 percent in Western Europe, and 110 to 180 percent in 
Eastern Europe between 1970 and 1985 (Pucher, 1990). Transit share of urban travel is declining steadily in almost all cities of the developed world (Pucher, 1990). The growing dependence on the automobile is apparent in many cities of North America, Europe, Australia, and even Asia. Coupled with high automobile dependence, a growing trend toward low-density living is spreading over the landscape. Urban densities have been falling over time, especially in the developed world (Gomez-Ibanez, 1991). In most world cities, the desire for spacious living coupled with increases in real personal incomes and drops in transportation costs have been identified as major motivator of population decentralization (Meyer and Gomez-Ibanez, 1980; Webster et al., 1986). For instance, between 1960 and 1980, net population densities have declined, on average, by 45, 38, and 13 percent in Australian, European, and prominent Asian cities, respectively (modified from Newman. and Kenworthy, 1989b) .

In fact, automobile dependence and low-density developments are not without costs to individuals and society at large. The human costs of the automobile are severe. In 1988 alone, road accidents accounted for more than one-quarter of a million fatalities and seven million injuries or permanent disabilities worldwide (Lowe, 1990). At the social scale, the automobile demands a large amount of space in terms of streets and highways, parking lots, and 
other automobile-related facilities. It competes with other essential urban activities, disrupts existing neighborhoods, and damages the environment (Owen, 1976). Further, the automobile has created two separate societies: those who have an access to the automobile and those who do not. For those unable to afford or unable to drive an automobile, many advantages of urban living are unattainable because they are out of reach, and those who do not own automobiles have to contend with it and bear much of the social costs (Owen, 1972).

These social costs include traffic congestion, energy consumption, and water and air pollution. In fact, most world cities are experiencing high levels of traffic congestion that result in losses in both time and productivity (Downs, 1992). Further, per passenger kilometer, automobiles consume more than five times the energy of a standard transit mode (Lowe, 1990). Because of its high energy consumption, the automobile is a major air and water polluter in cities. Traffic congestion and air pollution have become serious concerns that affect the movement of people and goods and contribute to the greenhouse and global warming effects (Downs, 1979; Lowe, $1990)$.

Meanwhile, the automobile has increased the span of human and urban activities and interactions and has become an indispensable element of our cities. The majority of 
urbanites have achieved an unprecedented personal mobility in terms of speed, flexibility, reliability, availability, and comfort (Altshuler, 1979; Downs, 1979). In fact, the automobile has created the opportunity for disadvantaged groups to improve their mobility levels. Early results of the U.S. 1990 Nationwide Personal Transportation Study show that women and the poor were the major beneficiaries of increased urban mobility during the 1980s (U.S. DOT, 1992a). Furthermore, the automobile is the most efficient mode in small and middle-size cities and in low-density areas (Gordon and Richardson, 1989; Altshuler, 1979). Increased mobility has expanded the radius of economic activities and in turn the economic vitality of cities.

Similarly, low-density development has its own social and environmental costs. It has been criticized as being inefficient in terms of infrastructural provision costs, energy resources, and land consumption (Parker, 1993). In addition, low-density and urban sprawl can be inequitable, limiting access to employment and main transportation modes by the poor, and thus, segregating social classes and ethnic groups (Altshuler, 1979). These potential costs of lowdensity living were subject to intensive examinations by opponents and proponents of urban development control verses market and individual preferences (see Altshuler, 1979; Newman and Kenworthy, 1989b; Real Estate Research Corporation (RERC), 1974; Gordon and Richardson, 1989). 
Proponents of low-density living argue that it has several advantages and its potential costs have been exaggerated. They argue that low-density development increases business productivity, responds to a prevailing preference for most urban residents worldwide, and can be efficient with the decentralization of employment in close proximity to population (Gordon and Richardson, 1989). They also argue that its potential costs are overstated (Altshuler, 1979; RERC, 1974). In fact, Muller (1975) argues that high-density development may cause high rather that low public expenditure. These studies argue for the need to balance both costs and the residents' desires for spacious living.

The advantages of low-density, automobile-dependent cities ought to be balanced against their costs. A conflict between the desire for spacious living and enhanced accessibility of workplaces and other amenities is apparent in many parts of the world (Webster et al., 1988). Urban sprawl and extensive reliance on the automobile may neither be efficient nor desirable for the vitality of contemporary cities. An efficient system of cities would encourage an appropriate balance of development and travel patterns that relies on several locational and travel choices to support residents' needs and preferences. Travel choices would include a combination of public and private transportation modes (Vuchic, 1984; Owen, 1976; Gakenheimer, 1978; Townroe, 
1974). As Gakenheimer (1978: 13-14) stated:

The automobile and public transportation should complement one anothex rather than compete with each other. Both should serve as elements of one integrated urban transportation system whose purpose is not just to move people but also to enhance the quality of the city and to contribute to the broader community objectives.

Such combinations of urban development and transport technologies should be related to existing and future urban form and activities (Vuchic, 1984).

Over the past three decades, trends in density and travel patterns may have been mutually reinforcing and can be tracked closely with several important factors. These factors are broad, variable, interrelated, and somewhat complex. They can be found within several outlooks of urban development. An examination of the factors that encourage low-density living and automobile travel is needed. Such an approach would increase our understanding of the nature of the density-automobile dependence relationship and the complex effects of other contributors. This research attempts to identify and examine the interrelationship of density and automobile dependence and the contribution levels of these factors in cities.

\section{RESEARCH OBJECTIVES}

The primary objective of this dissertation is to examine the density-automobile dependence relationship and the factors that underlie it within cities. The problem is 
complex, and the contributing factors are numerous. Some of these factors are measurable and tangible, while others are intangible and subjective.

This research argues that quantifiable factors are important determinants of density and automobile dependence. Given the complexity of the problem, the list includes numerous underlying variables. These variables can be grouped into multiple categories. Such analysis would incorporate three levels of spatial aggregations: an urban region level and a zonal (traffic zone) level and a disaggregate (household) level. It aims to examine intercity and intra-city variations in density and automobile dependence for comparison.

The dissertation will address four specific issues. First, a current examination of the density-automobile dependence relationship will improve our understanding of its nature. Second, land use and transportation scholars should find the study conclusions fruitful, compared to other studies, due to the study's treatment of the densityautomobile dependence relationship. Third, several research questions concerning other underlying factors will strengthen the theoretical and empirical aspects of the density-automobile dependence relationship. Finally, the research conclusions will help in devising several land use and transportation policies that deal with current problems of urban development and travel patterns. Exploration of 
these issues would enrich the land use-transportation literature and be of great help to planners and policymakers.

\section{DEFINITIONS}

Automobile Dependence. As a term, automobile dependence has been used frequently in the transportation literature. The term was denoted to represent an excessive reliance on the automobile, in terms of number of trips and amount of use, over other modes of travel (see Lowe, 1990; Owen, 1972;

Renner, 1988; and Newman and Kenworthy, 1989b) The word "dependence" implies certain consequences, either positive, negative, or both, that can not be captured by other terms such as use or utilization. Dependence is more comprehensive than the word use in relating to the problem of excessive reliance on the automobile.

Land Use. In this dissertation, the term "land use" is used as a general term and a specific one. It includes everything from urban form at the larger scale to density of a parcel at the smallest scale. "Urban form," "city structure," "urban development patterns," and "land use patterns" are all used to represent land use in its general meaning. More specific connotations include the terms "land use," or merely "use," to describe the type of activity that exists at the parcel level. 
ORGANIZATION OF THE STUDY

The study is organized into chapters. Chapter I, the introduction, defines the general scope of the problem, the study objectives, and the study outlines. Chapter II gives a brief review of related literature. It reviews the role of the historical relationship between transportation and land development. Land use and transportation interaction theories and effects are reviewed. The chapter concludes with a brief review of empirical studies of density and automobile dependence. Chapter III presents the methodology used for this research in terms of approaches for problem examination and research design. Chapter IV presents a comparative analysis of density and automobile dependence for world cities. The effects of several parameters on density and automobile dependence are also examined. Chapter $V$ presents the empirical analysis of the simultaneous relationship between density and automobile dependence, other influences of density and automobile dependence, and a formal conclusion. Chapter VI presents the major research findings and conclusions, and Chapter VII discusses their theoretical and policy implications. 
CHAPTER II

\section{IITERATURE REVIEW}

This chapter presents a theoretical perspective on the relationship between transportation and land development in urban areas. The first section provides a historical context of urban development and its relationship with changes in transportation technology. Special attention is given to the automobile revolution in cities. The second section includes a theoretical examination of the interaction between transportation and land use. Third, the contributing factors to the simultaneous relationship between density and automobile dependence are examined. Fourth, the previous empirical work in density and automobile dependence is analyzed and discussed.

A HISTORICAL PERSPECTIVE OF TRANSPORTATION AND URBAN DEVELOPMENT

Transportation is as old as urban settlements. It played an earlier indispensable role in the location and growth of urban settlements. Goods were transported to cities developed at good land and water connections from nearby rural areas by way of land transportation and from further areas by way of waterways (Pederson, 1980). The emergence and the rapid growth of cities have both been 
reflected in an enhanced movement system for goods and people.

For instance, advances in inter- and intra-city goods movement technologies have allowed cities to grow and attract migrants from other areas. Several thousands of years ago, the invention of the wheel slightly increased the radius of economic activities. Human and animal carts were the only available means for goods transport. During the nineteenth century, industrialization and the expansion of cities encouraged developments in water canals and rail transportation which stimulated growth in industrial cities (Webster et al., 1986). Goods movement was no longer a growth constraint (Pederson, 1980).

The twentieth century has witnessed the evolution of road and truck transportation to accommodate rapid economic growth and changes in locational advantages. This eased the locational constraints of many urban activities, especially manufacturing (Webster et al., 1986). The growth of major cities and their activities' distribution reflect these rapid changes in goods movement and urban development.

Similarly, as urban areas began to grow, developments of mechanized transportation have increased the radius of people movement and, hence, city size. Prior to the nineteenth century, city structure was characterized by high intensity developments, mixed uses, and primitive means of transportation such as walking, human carts, and animal 
carts (Daniels and Warnes, 1980). City functions were integrated as a result of the limited transportation means. Mechanization of urban transportation that accompanied the industrialization process has influenced urban development patterns. The invention of the steel wheel for the horsecar early in the nineteenth century increased the outward movement of affluent residents to new areas outside the compacted city (Hall, 1991). Similarly, steam commuter rails encouraged the development of urban pockets around rail stations outside the urban core (Pederson, 1980). Both technologies allowed Iimited suburban extensions of the city (Ha11, 1991).

In the late nineteenth century, the electric car, streetcar, or tram and the electric rail were invented and put into service. These provided cheap, reliable service for most income groups. The streetcar became an American symbol and a major facilitator of the massive suburbanization in U.S. cities. Tramway in Europe played a similar role by moving people within the expanding city for shorter trips, while railroads facilitated the outward spread of development along their corridors (Daniels and Warnes, 1980; Hall, 1991). The two technological breakthroughs were a major facilitator of suburban developments.

Following these breakthroughs, a new transportation technology, the motor bus, was invented. The bus became 
fully operational early in the twentieth century. Its flexible routing and scheduling permitted infill developments between rail and streetcar lines while modestly expanding the city to new areas further out (Daniels and Warnes, 1980). The rapid increase of motorbus use, coupled with the rapid growth of automobile ownership, led to the decline and eventual demise of streetcars and rail transit (Pederson, 1980). Other world cities followed the western example, and the motorbus and the automobile became the two dominant modes of intra-urban travel (Hanson, 1989).

The automobile was invented in the mid-1880s in Germany and France. Its use was hampered by its high cost and speed restrictions in the U.S. and Europe (Altshuler et al., 1986; Daniels and Warnes, 1980). In the 1920s, automobile ownership surged as cars became affordable for more segments of society (Meyer and Gomez-Ibanez, 1981). The Great Depression in the U.S., followed shortly by the second World War, halted automobile production and ownership till the end of the war. Then, the automobile population increased rapidly worldwide. Rising real incomes, huge governmental subsidy for suburban developments, massive highway and motorway construction projects, and cheap, abundant oil fueled automobile ownership and expansions (Renner, 1988; Altshuler et al., 1986; Pederson, 1980). The automobile revolution is still spreading at staggering rates in developing countries, whereas some developed nations are 
experiencing a saturation in the automobile market (Owen, 1978). The automobile moved cities of the Western world, and later most world cities, into unprecedented development patterns.

The automobile and its related facilities have facilitated changes in the structure and patterns of urban development. It increased the relative accessibility of different city activities that had been less accessible by other transportation technologies. These changes led to massive changes in the structure and patterns of urban development. Unprecedented urban sprawl, infill developments, and ribbon developments were made possible by the automobile revolution.

Similarly, massive suburbanization and rapid expansion of Western cities transformed urban structure and movement patterns. This transformation was fueled by increases in real personal income, urban population increases, changes in household composition, and declines in real transportation costs (Meyer and Gomez-Ibanez, 1981). The new development patterns were not supportive of public transit, contributing to the rapid decline of transit patronage. The automobile, with its flexible mobility and other advantages, has become the most popular form of transportation in newly developed areas. These patterns have expanded rapidly in the developed world and are followed today by developing nations. 
In fact, improvements in transportation technologies exerted great impact on urban development in terms of segregation of different land uses and city size. Pederson (1980: 9) contends that the natural segregation of urban land uses since the mid-1800s was a product of improved urban transportation means. Dispersal of urban activities from the urban core to periphery was made possible by improvements in travel technology from primitive to mechanized. Suburbanization of population and then employment was facilitated by rail and bus services and, later, the automobile. Trucks played a similar role in the decentralization of manufacturing. During the past century, transportation innovations exerted greater impact on urban development because changes in transportation technologies outpaced changes in urban development (Hall, 1991). Recently, transportation systems impact on urban development have been limited to locations with enhanced accessibility and mobility of their residents.

On the other hand, Daniels and Warnes (1980:2-3) suggest that improvements in transportation technology followed changes in urban structure. The location and distribution of different land uses have been important factors in predicting transportation demand. The type and intensity of land use affect the number of trips and the trip lengths within the city. During this century, urban development has outpaced intra-urban transportation 
development and, in turn, has exerted the greater impact (Hall, 1991). The existing transportation technology is still the same as at the turn of the century. Urban travel patterns have become a function of city structure (Thompson, 1977; Hall, 1991).

In summary, the relationship between transportation systems and urban development is still debatable. The next section explores theoretically the nature of this relationship.

TRANSPORTATION AND LAND USE INTERACTION THEORIES

The relationship between transportation and land use has long been recognized. Since World War II, land usetransportation studies have been conducted in most U.S. cities (Brown et al., 1972). Highway planning studies to forecast traffic volumes were first based on traffic projections. However, this technique was inadequate. It was replaced by projections of urban growth rate that would affect traffic, especially in suburbia (Brown et al., 1972). This process constituted the base for future studies that linked land use with traffic.

In terms of type and amount, land use activities were recognized as a major factor affecting trips generated. This was exemplified in a landmark study of transportation and land use conducted in Detroit (1953). The procedures include travel forecast that is based on the relationships 
between travel and land use in combination with land use forecast. The well-known four-step transportation modelling steps were first introduced in the 1953 Detroit study. Later, Mitchell and Rapkin (1954) provided a theoretical justification for which study that was adopted in subsequent transportation studies (Brown et al., 1972). They developed a unidirectional model of transportation and land use, and argue that traffic is a function of land use. The location and intensity of land uses affects the demand for transportation or trip making and in turn affect the location of transportation facilities (Mitchell and Rapkin, 1954)

However, this approach has been widely criticized, as tends to ignore the distributional effect of transportation system improvements on the location and intensity of land use. Recognizing this, Alonso (1964), Mills (1972), Muth (1969), and Wingo (1961) concluded that land use and transportation relationship is indeed simultaneous. Within this framework, The Lowry model was developed in the $1960 \mathrm{~s}$. The model was the foundation of integrated land use and transportation models. Elaborative models of the Lowry framework were hampered by complexity and computational difficulties and were widely criticized (Webster et al., 1986). They include, for instance, TOPAZ (1970), ITLUP (1971), EMPIRIC (1972), LILT (1974), DORTMUND (1977), CALUTAS (1978), and OSAKA (1981). Some of these models are 
predictive models of urban system behavior, while others are "optimizing" or normative models for certain community objectives (Webster et al., 1988). These integrated models attempt to overcome some of these computational difficulties but they are still far from being fully adopted.

The interdependent relationship is better characterized as a transportation-land use cycle. Accessibility of urban activities increases its development potentials, while the type and distribution of urban activities determines the demand for transportation. Transportation networks and facilities consume lands, distribute activities, and weaken accessibility constraints for urban growth. Figure 1 shows a simplified version of the complex, interactive relationship between transportation and land use.

Improvements in transportation facilities would enhance accessibility of an area and, in turn, the value of its lands. High land values would encourage the intensification of development thus increasing traffic generation in the area. More demand for transportation facilities would necessitate improvements and expansions. The cycle continues with more improvements and land use changes until no further development of the land is possible. This means the transportation system affects land use activities while land use distribution impacts transportation demand. 


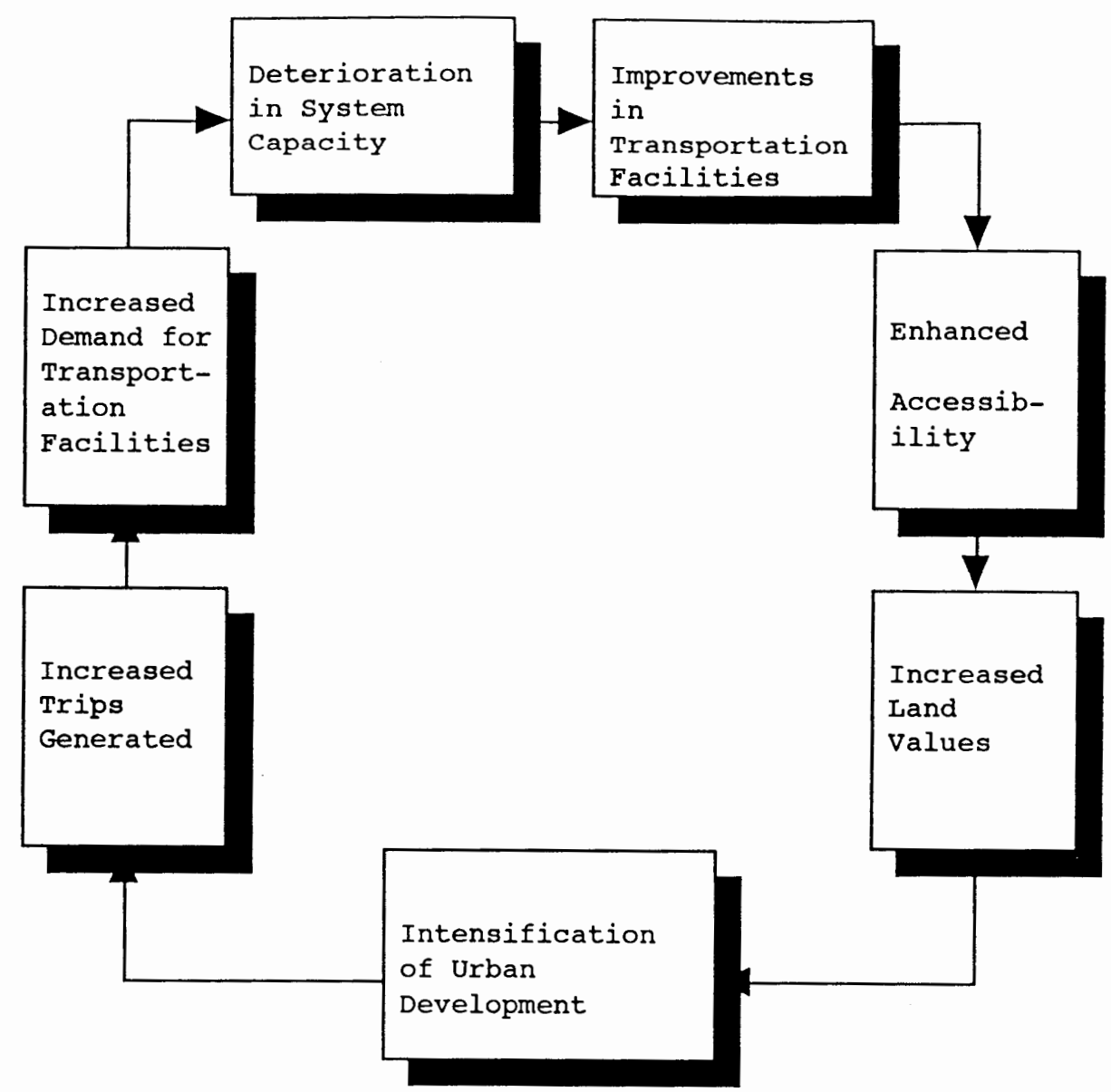

Figure 1. Transportation and Land Use Cycle. Source: Adapted from V. Stover and F. Koepke, 1988 .

The next section will examine more thoroughly the effect of land use and city structure in the demand and use of the dominant mode: the automobile. Similarly, the effects of increased automobile dependence in cities on urban development patterns represented by population density is also examined. Both factors inevitably affect each other. Because of their importance, land use and other important effects on the density-automobile dependence simultaneous relationship are examined. 
THEORETICAL PERSPECTIVES ON THE RELATIONSHIP BETWEEN DENSITY AND AUTOMOBILE DEPENDENCE

This section will present the theoretical perspectives that affect the relationship between density and automobile dependence. Density and automobile dependence is measured in terms of population density and Vehicle Miles of Travel (VMT), respectively. The simultaneity notion of density and automobile dependence will be examined. The effect of each element on the other will be addressed independently as a one-way relationship. Then, the mutual effect of both measures will be reviewed.

\section{The Simultaneity Concept}

As previously stated, the interrelationship between density and automobile dependence is complex and debatable. Our ability to predict the direction and the rate or magnitude of this relationship is in fact limited. Recent studies of this relationship have, to a certain extent, identified the inter-dependence nature of this relationship. However, these studies have held different views regarding the magnitude of change in each factor due to the other.

\section{Vehicle Miles of Travel (VMT) Affects Density. VMT} measures the mobility level of city residents. Number of trips produced in an area, along with their lengths, measures the extent of automobile use in the city. High per capita VMT means a high level of automobile dependence 
compared to other modes. Some scholars argue that increased mobility of urban residents through automobiles has shifted locational advantages from central to suburban locations and fostered preferences for low-density living (Webster et al., 1986). In addition to increased congestion in central cities and good road connections in suburban areas, the automobile has made suburban locations attractive for development. Similarly, in most world cities, the decentralization of population to suburban locations was a product of increasing preferences for privacy and spacious living fostered by increased auto-mobility. This, in turn, led to a spread of development toward less developed, lowdensity areas.

Density Affects VMT. Population density measures the degree of compactness of a city in terms of urban growth and development. Density of development is strongly related to automobile travel (Newman and Kenworthy, 1989a, 1989b, 1992; Mahamassani, Baaj, and Tong, 1988; Pucher, 1988). Lowdensity development encourages automobile travel for two reasons: it makes mass transit operation infeasible, thus limiting the mobility choices to automobile driving, and it makes driving more comfortable due to low congestion levels. Conversely, high-density development constrains automobile driving due to the increased congestion level, while enhancing the potentiality of walking and public rides (Kain, 1985). Similarly, a high-density, compact city 
shortens trip lengths compared to a low-density, dispersed city. Therefore, density of development would affect the number of automobile trips, and their lengths, at the city or neighborhood level (Keyes, 1982).

Simultaneous Relationship. The previous discussion of the mutual effects of density and VMT suggests the presence of a one-way relationship. However, several scholars argue that the relationship runs both ways and that each factor reinforces the other, but not necessarily on the same timescale (Webster et al., 1988; Hall, 1991). The tendency of households to locate in low-density areas is encouraged by increased mobility, simultaneously this induces more automobile travel (Altshuler, 1979). The effect of density on VMT is direct and short-term, while changes in urban travel may for the long-run induce changes in density and land use patterns. Large scale land use and transportation interaction models are better equipped to capture differences in timescale than small, one-shot models (Webster et al., 1988; Kain and Fauth, 1977).

As discussed, the interactive relationship between transportation and land use are broad and complex due, inpart, to the uncontrolled effects of other factors. The next section will address such complexity when examining the underlying influences of other factors on density and automobile dependence. 
Other Contributors to the Simultaneous Relationship

The strong simultaneous relationship between density and VMT is not the only influence over them. The relationship is also explained and reinforced by other important factors identified in the land use and transportation literature. These factors may affect density and VMT simultaneously or independently.

In fact, existing research in density and automobile dependence has identified numerous important contributors. Some of these factors are immeasurable and intangible, while others are measurable and well-defined in the existing literature. The former are based on subjective assessments that are not easily supported by empirical investigations. The list includes culture, mentality, prestige, and preferences (Pucher, 1988). In fact, the automobile has become a status symbol for desired lifestyle (Cullinane, 1992). In the U.S. and Australia, the automobile represents a preference for lifestyle that favors low-density living and automobile driving (Gordon and Richardson, 1989; Cervero, 1991). It becomes a symbol for advancement for the working class (Interrante, 1983). In mass consumption societies, the automobile has become an essential component of a new 'cultural urbanization' that expanded the mobility choices of individuals to both employment and amenities (Townroe, 1974).

The culture, mentality, and preference factors vary 
across countries and sometimes across cities within the same country. They persist over time in as much as they may result from long-term dynamic processes. This makes them hard to alter or reverse as they may run deep in the social fabric of cities. Devising measures for their effects on density and automobile dependence is not an easy task. Further, modelling and interpreting the results may prove to be difficult and misleading.

Meanwhile, some contributors to density and automobile travel patterns are measurable but uncontrollable. Topography of an area, especially hilly terrains, restrains development and makes it hard for other modes of travel to compete with the automobile. Similarly, climate may affect the level of automobile use. Excessive cold or heat would make the automobile a better option, given its comfort and convenience advantages. In Sweden, cold climate has contributed to high levels of automobile ownership. and use (McShane, Koshi, and Lundin, 1984). The two factors may encourage or retard the intensification of development and automobile travel in urban areas.

Other contributors to density and automobile dependence are hard to define and control. They are imposed from national levels and cities have minimal or no control over them. Public policy at the national level may have contributed to the increasing dominance of automobile travel and low density patterns in North America (Altshuler, 1979; 
Stover and Koepke, 1989). National policies in automobile taxation, interstate highway program, inefficient transit subsidies, land use controls, and housing programs have contributed to the decentralization of urban development, the decline in transit patronage, and the increase in automobile use during the postwar era (Huttman, 1977; Pucher, 1988, 1990). In Europe, on the other hand, high taxes on automobiles and low highway construction, coupled with strict land use controls, have contributed to the maintenance of some of the pre-war urban development patterns and continued transit viability (Pucher, 1988; Webster et al., 1986). Other public policy variables include the gross national product (GNP) and the frequency of oil shortages (Gately, 1990). Over these factors, which are national in scale, cities have little or no control. Finally, the rest of important contributors are measurable and can be used for comparisons. These factors are numerous but somewhat related. They can be grouped into four major categories: land use, economic, demographic, and transportation provision. Next is a brief examination and review of each category as found in the existing literature.

Land Use Factors. Land use factors are important contributors to density and automobile dependence (Newman and Kenworthy, 1989a, 1989b, 1992; Meyer and Gomez-Ibanez, 1981; Altshuler, 1979). Directly or indirectly, they play an important role in encouraging or retarding low density 
development and automobile travel. Such a role would affect the potentiality for other modes of travel to compete with the automobile (Warren, 1988; Mahamassani, Baaj, and Tong, $1988)$

These factors are multiple, with varying impacts on density and driving habits. The first is related to city structure. In terms of employment concentration, centralized cities encourage public transit commuting and retard automobile use due to congestion and parking limitations (Newman and Kenworthy, 1989a; Klaassen et al., 1981; Warren, 1988; Hendrickson, 1986). Meanwhile, decentralized urban structure encourages more driving, lengthens trips, and reduces public transit patronage (Byrne and Rich, 1985). The exodus of the service industry that followed population decentralization to fringe areas has increased their employment densities and transformed the structure of cities (Webster et al., 1986).

Second, job-housing and shopping-housing balance measures the degree of development mix in the city. Severe job-housing imbalance increases automobile use for workrelated travel, while shopping-housing balance affects automobile use for non-work travel (Ostro and Naroff, 1980). Mixed-use developments tend to cluster around high- rather than low-density areas, thus affecting trip rates. Meanwhile, the number of work trips and their lengths would increase in the case of job-housing imbalance or mismatch 
(Cervero, 1989; O'Connor and Maher, 1979; Burright, 1984). Therefore, the degree of development $\operatorname{mix}$ would be an important contributor to automobile usage in the city (Klaassen et al., 1981; Lowe, 1990).

Third, the city size may reflect the density level and determine the amount of automobile travel within the city. Smaller metropolitan areas are less dense and have shorter, less frequent trips at the city and zonal level than larger metropolitan areas (Keyes, 1982). Walking trips are more frequent in small cities. However, large metropolitan areas would make mass transit more feasible for most city parts compared to smaller ones. Therefore, city size is an important determinant of urban density and tripmaking. Finally, scholars of urban transportation and land use planning argue that variations in density and automobile use across world cities are closely related to the timing of development in these cities (Kain, 1985; Gomez-Ibanez, 1991; Lansing et al., 1964). City age, especially of the central city, affects its density patterns and the adaptation process to the automobile revolution (Ostro and Naroff, 1980). U.S., Canadian, and Australian cities were transformed to low-density regions by the automobile revolution due to their newness. Much of their growth has occurred in an era of high income and automobile ownership. In Europe, old, established cities were built prior to the automobile making their development adjustments slow and 
painful (Kain, 1985; Owen, 1972).

These four factors--city structure, degree of development mix, city size, and timing of development-collectively and/or independently affect density and automobile dependence in cities. Some of these factors are interdependent at both the city and the neighborhood levels. Further, some are closely related to other non-land use factors such as income, automobile ownership, and household characteristics (Kain, 1985; Webster et al., 1986).

Economic Factors. Economic factors are the second major contributors to density and automobile dependence in cities. Income and automobile ownership rate, gasoline prices, and automobile travel costs are closely related to the urban form and the number and lengths of automobile trips (Wachs, 1981; Pucher, 1988; Newman and Kenworthy, 1989a). These factors may affect locational and travel choices of urban residents.

of importance is the interrelated income and automobile ownership factors. High-income people prefer low-density living and own more automobiles than other income groups. In the U.S., Canada, and Australia, high per capita income and low automobile costs have resulted in massive suburbanization and high automobile ownership rates that are reaching saturation (Pisarski, 1987; Pucher, 1988; Newman and Kenworthy, 1989a). Meanwhile, in Europe, Asia, and developing countries, low per capita income and high 
automobile costs have retarded high percentage of urbanites from owning automobiles (Pucher, 1988). These variations in automobile ownership have affected urban densities and the levels of automobile use worldwide. High income and automobile ownership encourage driving and infrequent transit use, opposite to other measures of high gasoline prices and automobile restraints (Pucher, 1988; Hensher and Smith, 1990; Newman and Kenworthy, 1989b; Lansing et al., $1964)$.

Gasoline price is also an important determinant of density and automobile use. It varies across nations and even within the same country. Variations in gasoline prices and average vehicle efficiency worldwide may have contributed to the variations in density, modal share, and automobile travel (Byrne and Rich, 1985; Newman and Kenworthy, 1989a; Pucher, 1988; Chan, 1985). However, this effect may not be uniform throughout the city. Suburban residents, due to income considerations, are not as sensitive to price changes as central city residents (Ostro and Naroff, 1980). Further, as Altshuler (1979) suggests, high gasoline prices may affect travel behavior in the short run but would encourage only locational adjustments in the long run. The degree of price effect on density and automobile use is uncertain; nonetheless, it exists (Wachs, 1981; Chan, 1985; Kain, 1985; Train, 1986).

Finally, pricing automobile travel to reflect its true 
social costs is argued to be the most efficient strategy for controlling urban development and travel behavior (Klaassen et al., 1981; Wachs, 1981; Gordon and Richardson, 1989). These costs include automobile ownership costs, congestion costs, and social costs such as pollution, noise, and neighborhood disturbance. Congestion pricing is the most popular mechanism, but it is still practically difficult (Heilburn, 1987) - Only Singapore has successfully implemented congestion pricing (World Bank, 1986). Increasing the cost per travel mile to reflect true cost will reduce automobile travel within cities (Wachs, 1981; Gordon and Richardson, 1989).

These factors may prove to be the most important determinants of variations in density and automobile dependence across world cities. Strong association may exist between these factors as they may work together in explaining density and automobile dependence. Income and automobile ownership and income and gasoline price are prime examples. Independently or combined, they are important in understanding travel and development patterns in cities.

Demographic (Household) Factors. Accompanying economic factors, demographic factors are important contributors to density and automobile dependence at the household level. These factors include household size, income, and car ownership, number of workers in the household, and household lifecycle. First, household size affects automobile 
ownership and density of development, which in turn affect automobile use (Webster et al., 1986; Lansing et al., 1964). Coupled with this is the effect of household income and purchasing power upon automobile ownership and use (Chan, 1985). Similarly, the number of workers in a household affects its income and travel patterns. More income means more household automobiles, and more workers means additional work-related trips (Webster et al., 1986). Similarly, high-income households are attracted to lowdensity areas, especially for those with high automobile ownership (Simpson, 1992).

Finally, density and automobile dependence may be explained by the stage of a household lifecycle. Stage of lifecycle can be represented by the age of household head or the number and ages of children (Kitamura and Kostyniuk, 1986; Train, 1986; Catanese, 1972). Household Iifecycle affects its locational decisions and activity engagement and in turn its trip rates (Kitamura and Kostyniuk, 1986; Simpson, 1992).

These factors should be included in examining the important contributors to the simultaneous relationship between density and automobile dependence. They are best examined at the household or neighborhood level because of the potential distortion of this relationship if examined at an aggregate level such as the city. Averaging demographic factors at the city level will mask the inherent differences 
of density and automobile travel across households and city parts.

Transportation Provision Factors. Transportation technology is the last important category. Its factors can be essential components of our understanding of density and automobile dependence. Encouraging or retarding automobile travel could result from the provision level of transportation infrastructure within the city. The level of automobile restraints, in the form of road lengths, congestion level, and parking provisions, is important in explaining automobile use (Newman and Kenworthy, 1988, 1989b; Klaassen et al., 1981; Pucher, 1988, 1990). In fact, extensive road networks, relatively low traffic congestion, and abundant, subsidized parking spaces drove automobile use in the U.S., Australia, and some European cities to unprecedented levels (Newman and Kenworthy, 1988; Pucher, 1988; Altshuler, 1979). Conversely, European, Asian, and developing nations' cities are imposing high levels of automobile restraints that are retarding the growth of automobile use (Pucher, 1988; Hanson, 1989; World Bank, 1986; McShane, Koshi, and Lundia, 1984; Spencer and Madhavan, 1989).

The provision level of public transit also affects the modal share of travel modes and is affected by density patterns. Reliable and frequent transit services would increase transit patronage and may discourage automobile use 
(Chan, 1985; Ostro and Naroff, 1980; Pucher, 1988).

similarly, transit patronage is higher in high-density areas compared to low-density (Chan, 1985). In fact, the Subway line in Toronto and the Portland Transit Mall are prime examples of the effects of changes in transit provision on land use patterns (Pushkarev and Zupan, 1977; Dueker, Pendelton, and Rao, 1985). Transit service levels can be measured by passenger trips, vehicle miles, frequency of service, speed, seat miles, and per capita ridership (Weisman, 1981; Chan, 1985; Newman and Kenworthy, 1989a; Burright, 1984).

The two factors are interdependent. For instance, high automobile restraints would discourage automobile use and shift travel habits and public investments to other modes of travel such as walking and transit. Meanwhile, poor transit services would lure people to automobile driving leading to further deterioration to transit services. Automobile dependency would better be explained in accordance with those two measures.

In summary, the factors in the four categories that would contribute to density and automobile dependence are complex and interdependent. Analysis of density and automobile dependence should incorporate them independently or simultaneously (Gomez-Ibanez, 1991). These factors, while they vary in importance, are nonetheless essential for our understanding of this relationship. The next section 
will examine some empirical research on the effects of these factors on density and automobile dependence in cities.

\section{EMPIRICAL STUDIES OF DENSITY AND AUTOMOBILE DEPENDENCE}

For several decades, density and automobile travel have been an important area of research. The growing dominance of the automobile has been accompanied by a steady decline in urban densities worldwide, and this has prompted scholars to investigate the underlying causes of these trends. Land use and transportation scholars were alike in blaming several, but conflicting, factors for these changes in travel and development patterns. Most of their studies were concerned with the uni-directional effect of either density or VMT on the other. Others have acknowledged the presence of a complex relationship that involves density, VMT, and other socioeconomic and demographic factors (see Newman and Kenworthy, 1989b; Webster et al., 1986). This section addresses some of these studies from a historical perspective.

One of the earliest studies of the effect of density on automobile use in cities was conducted by Lansing, Mueller, and Barth (1964). In a survey of households, building structure, and urban mobility, the authors concluded that demographic factors, such as family income, age of household head, and automobile ownership, and land use factors, such as density and city age, are important determinants of 
vehicle trips per family. This study was based on a simple statistical analysis in which each factor was examined independently.

Following this study and during the energy crisis of the early eighties, three new studies were completed concerning travel demand and energy consumption. Ostro and Naroff (1980), Keyes (1982), and Chan (1985) examined the relationship between vehicle miles of travel (VMT) and gasoline consumption. They concluded that several land use, economic, and transportation infrastructure variables were important determinants of VMT. Population and employment densities, city age, gasoline prices, and availability of mass transit were the most important.

Other scholars were concerned with the effect of land use factors on automobile use and VMT in particular. Nolan and Stewart (1990) argue that intensifying population concentration in the CBD will reduce the city VMT and transportation infrastructure requirements. Similarly, Klaassen and others (1981) argue that land use factors such as city structure, job-housing balance, and spatial redistribution policies for decentralized employment centers strongly affect the city VMT. Finally, Kain and Fauth (1977) found that, in addition to other household sociodemographic factors, locational choices have significant impact on travel behavior.

Hensher (1986) and Hensher and Smith (1990) introduced 
a new approach to the analysis. In the first study, Hensher argues that the level of automobile utilization is a product of a broader household decision process. Later, Hensher and Smith (1990), using panel data, concluded that household characteristics are important determinants of household automobile travel. Similar to Fauth and Gomez-Ibanez (1977) conclusions, Hensher and Smith (1990) argue that per capita income is perhaps the single most important. These studies emphasize the importance of household characteristics in understanding travel behavior within cities.

on the density side of the relationship, several studies have recognized the importance of automobile ownership and use effects on density. For instance, Harrison $(1978,1979)$ in a comparative study of 50 U.S. metropolitan areas has concluded that vehicle ownership, highway and transit miles, per capita income, and CBD manufacturing employment influence several density measures. The study found a simultaneous effect between incremental density and automobile ownership. Another study by Webster and others (1988) has identified transport costs as an important determinant of land use patterns.

Webster and others (1986) examined several aspects of urban development and travel patterns in Europe. They concluded that level of affluence and automobile ownership, population age structure, employment level, quality and availability of different travel modes, and land use 
distribution affect trip rates. On the other hand, urban density was found to be affected by the availability of urban transport, household characteristics such as income and household size, and the built form in European cities.

Pucher published two studies that compare travel behavior between developed countries. In the first study (1988), Pucher argues that variations in travel behavior between Western Europe and North America are attributed to public policies. Policies toward automobile taxation, transit subsidies, land use controls, and housing programs have significantly influenced travel choices. Other influential transportation factors include parking and road subsidies and heavy taxation on gasoline prices and automobile ownership. The second study (1990) included Eastern Europe and the Soviet Union for comparison. Pucher argues that, controlling for income and resources, variations in travel choices are due to public policies. These policies favor the mode that coincides with the government's political ideology. Social governments favor public transit, while market-oriented governments support private transportation, especially the automobile.

Finally, Newman and Kenworthy published a book (1989b) and several articles (1988, 1989a, 1992) that examine automobile dependence in cities. Their study was the most important contribution, but also the most controversial. Their analysis and recommendations have drawn much 
criticism. They examined variations in automobile dependence between selected world cities from North America, Western Europe, Australia, and Asia.

Newman and Kenworthy analyzed the causes of variations in automobile dependence. They acknowledge the existence of a complex relationship between VMT and transport, land use, and economic factors. After comparing land use, economic, and transportation technology factors, they concluded that low population density is the prime cause of automobile dependence. They suggested that increasing density to reach 30 to 40 (12 to 16) persons per hectare (acre) would decrease automobile use significantly. They proposed several physical planning policies that would reduce automobile dependence and in turn gasoline consumption. These policies include reurbanization of current cities and reorientation of transportation priorities. Both policies would encourage transit use while discouraging automobile travel within cities.

Critics of the Newman and Kenworthy study charge that its methodology is weak and one-sided. For instance, GomezIbanez (1991) argues that the problem is complex and requires sophisticated modelling, that energy consumption is not an appropriate measure for automobile dependence, that density of new areas are comparable worldwide, and that the recommendations are too costly to implement. Similarly, Gordon and Richardson (1989) leveled harsh criticism at the 
study. They questioned the validity of international comparisons in fuel consumption, embraced the decentralization of employment and population as efficient, and criticized the authors' emphasis on rail transit, which they suggest has proven to be inefficient. Nonetheless, the Newman and Kenworthy studies are still the most comprehensive with respect to the automobile dependency phenomenon.

\section{CONCLUDING REMARKS}

Most of these studies suffer from several weaknesses which may undermine their examination of the densityautomobile dependence relationship. In addition to their lack of consideration of the interactive relationship of density and automobile dependence, most of these studies are one-sided in that they consider only some of the important factors and use simple statistical analyses. Lansing and others (1964), Nolan and Stewart (1990), Klaassen and others (1981), Hensher (1986), and Hensher and Smith (1990) used only one category to examine the contributing factors to automobile dependence. Other studies were aggregate in nature, using national data for world comparisons (Pucher, 1988, 1990). This approach is too general and cannot capture intra-country variations in automobile travel. In fact, intra-country and intra-city variations do exist and should not be overshadowed by aggregation and general approaches. 
Newman and Kenworthy's study (1989b) is the most comprehensive, but it still suffers from several weaknesses. These weaknesses include measurement problem of the study variables, the use of simple statistical analysis for modelling, and the failure to consider demographic factors in their analysis. Their study emphasizes the importance of only land use and economic factors as major determinants of density and automobile dependence.

This research is an attempt to mitigate these drawbacks and extend the analysis to include additional contributors to density and automobile dependence. It emphasizes the importance of the simultaneous relationship between density and VMT and the contributing factors to this relationship. The study intends to use a complex statistical modelling and consider variations between and within cities at three levels of analysis. The next chapter will address these issues as it introduces the research methodology. 
CHAPTER III

RESEARCH METHODOLOGY

This chapter presents the methodology framework for the study. It examines the different approaches and statistical techniques that could be used for the study analysis. The second section, "Research Design," covers problem definition, study scope, research hypotheses and models, and data sources. Each part is briefly analyzed and examined.

APPROACHES EXAMINING DENSITY AND AUTOMOBILE DEPENDENCE

The relationship between density and automobile dependence represents a broad concept that encompasses several perspectives. These perspectives relate land use patterns within the city to urban travel. With respect to urban travel, the city can be represented by several interrelated systems. It can be represented as a physical system where planners use transportation system and networks to increase the mobility choices of urban residents (Newman and Kenworthy, 1989b). The city also can be represented as an economic system where labor movement and economic vitality are important urban goals (Gordon and Richardson, 1989; Gordon, Kumar, and Richardson, 1989a). Further, the city can be portrayed as a social and a demographic unit. 
People interact and communicate through enhanced transportation systems that provide multiple mobility choices (Owen, 1972, 1976; Lynch, 1984). Finally, the city would represent a political system where public policy would affect urbanites' travel behavior (Pucher, 1988, 1990). These perspectives are important, compatible, and interrelated but cannot be represented or combined into one approach.

This research does not intend to accommodate all of these perspectives. Such an attempt would require extensive research resources and complex modelling techniques that are beyond the scope of this research. The study does not intend to adopt one perspective over another. Rather, it uses a general framework that goes beyond these perspectives while touching upon several aspects of them. It treats urban travel in the city as a product as well as an outcome which is affected by the city structure and socioeconomic characteristics of its residents and influenced by public policy. To accomplish this, the research utilizes two major approaches to the examination of density-automobile dependence relationship: an aggregate and a disaggregate approach .

\section{Aggregate Approach}

An aggregate analysis is defined as data constructed at the level of several individuals or groups through demographic, geographic, or time groupings. Groups may 
include several individuals or households, geographical areas, or time periods. This research is concerned with examining development and travel patterns within geographical areas. These areas may include traffic zones, cities or suburbs, and urban regions. Transportation data are usually compiled at one or more of these levels.

Most potential determinants of density and automobile dependency exist at these levels of analysis. Variations in national transportation policies would be exemplified within most of these determinants. However, they may or may not vary across cities within the same country. For instance, policies toward public transit services and land use controls do vary across cities within the same country. Conversely, other policies concerning automobile taxation and automobile restraints do not vary (Pucher, 1988). The main task is to select the suitable unit of analysis for the conduct of this research.

The choice of the geographical area size would be determined by the study purpose, the relevance to the problem, and the existence of relevant data. The main thrust of this research is to examine variations in density and automobile dependence across international cities. The extensive data collected and analyzed by Newnan and Kenworthy (1989b) provide a good base for the analysis. virtually all of their data are at the urban region level. Further, data about cities and suburbs for comparison and 
analysis may not exist or may be hard to collect or compile given the limited research resources.

However, given the potential intra-regional variations in travel patterns, a less aggregated level of analysis is needed. This approach is important to guard against the averaging problem of aggregate data. Further, it helps to incorporate additional variables that are either not available or not applicable at the city level. Less aggregated data analysis would help to avoid the potential ecological fallacy problem that may result from high levels of data aggregation. This type of data is used extensively by city planners for land use and transportation forecasting. Traffic analysis zones are appropriate for this task. Therefore, two levels of spatial aggregation are used in this research: urban region (or city) and Traffic Analysis Zone (TAZ). The first one is called the regional level, while the TAZ level is denoted as the zonal level.

\section{Disaggregate (Household) Approach}

Disaggregate analysis means that data are constructed at the individual or household level. Household data are used to predict its travel and locational patterns within cities. However, household travel and locational data are not easy to compile due to cost limitations. Most cities conduct these surveys in intervals of five or more years. Small scale surveys exist in a yearly basis, but they are mainly constructed for specific purpose(s) - Household data 
are indeed very valuable since they truly reflect household travel behavior without the problem of aggregation or generalization.

National Personal Transportation Study (NPTS) data of U.S. cities are one example of household data. These surveys have been conducted every seven years since 1969. The surveys' data have been used extensively by U.S. scholars to examine travel patterns of U.S. households (see Pisarski, 1987; Gordon, Kumar, and Richardson, 1989a, 1989b; Lave, 1991). NPTS of 1990 have included, for the first time, household locational attributes in addition to the travel and socio-demographic attributes found in previous surveys. This makes them very valuable for this dissertation. Household data of several U.S. cities, comparable to cities in the regional and zonal models, have been selected to examine some of the research questions. This should improve our understanding of the research problem by introducing household attributes at a disaggregated level of analysis.

\section{STATISTICAL TECHNIQUES FOR EXAMINING DENSITY AND AUTOMOBILE DEPENDENCE RELATIONSHIP}

The examination of the relationship between density and automobile dependence and the contributing effects of other factors requires the utilization of a system of simultaneous equations. Density and automobile dependence measures are endogenous variables because of their simultaneous 
relationship, while the rest of factors are treated as exogenous variables. To accomplish this, there are several statistical techniques that can be used in this research. These techniques are classified into two parts: single equation and system equation methods. The following is a brief review of some of these techniques.

\section{Single Equation Systems}

This method estimates each equation of the simultaneous relationship separately. Examples of this method include correlation analysis, ordinary least squares (OLS), and twostage least squares (2SLS).

Correlation analysis is used to assess the degree of association between a dependent variable (DV) and one independent or a set of independent variables (IVs). It assesses the relative contribution of each of the IVs towards predicting the DV (Tabachnick and Fidell, 1989). Correlation analysis is not used to explain or predict accurately the contributing effects of IVs, collectively or independently, on the DV or to control for the intercorrelation between IVs; it only measures the degree of association between these variables. These drawbacks are better treated in the OLS analysis.

OLS is a statistical technique that assesses the relationship between one DV and one or more IVs. It is used to explain or predict such relationship. The technique has a large number of desirable properties, thus making it very 
popular (Kennedy, 1992). However, it is not a good estimator of simultaneous equations due to the presence of simultaneous bias. Similarly, oLS estimator can be inconsistent because its parameters may change considerably with changes in IVs specifications, especially in small sample estimation.

Finally, the 2SLS technique is an improvement over OLS in examining simultaneous equations. This technique utilizes instrumental variable(s) to account for the simultaneous effect of other endogenous variables. This may lead to a consistent estimator that is robust (i.e., not sensitive to estimation problems such as multicolinearity and specification errors) (Kennedy, 1992). However, due to the separate estimation of the simultaneous equations, this will reduce its efficiency compared to system equation techniques (Judge et al., 1985).

\section{System Equation Methods}

The system equation method estimates all the identified structural equations in a system simultaneously. These techniques incorporate all of the available information into the system, thus lowering the variance estimates that result from estimating simultaneous equations separately. This makes them more efficient than 2SIS, which constitutes their major advantage (Judge et al., 1985). Their only drawback is that all structural parameters are vulnerable to misspecifications rather than, as in the case of single- 
equation techniques, the parameters of one equation (Judge et al., 1985). Examples of these techniques include threestage least squares (3SLS) and full information maximum likelihood (FI/ML).

The three-stage least squares (3SLS) method is an improvement over ordinary least squares (OLS) and two-stage least squares (2SLS) in terms of consistency and lack of bias, and efficiency, respectively (Intriligator, 1978; Judge et al, 1985). This technique examines jointly the effect of exogenous variables on selected endogenous variables (e.g., density and VMT). This process is completed in one step, wherein two or more equations are analyzed simultaneously with respect to each other and to the exogenous variables in the system. This research of simultaneous relationship utilizes 3SLS for its asymptotical properties and advantages over other single equation techniques.

\section{RESEARCH DESIGN}

\section{Statement of the Problem}

Over the last several decades, low-density development and increasing levels of automobile dependence have become two of the major problems facing many urban areas around the world. This is true not only for cities of the developed world but also in some developing nations. Whereas these development and travel patterns have significantly improved 
urbanites' mobility, freedom, and social contacts (in addition to their indisputable role in expanding the ranges of economic activities within and outside urban areas), they have also brought numerous problems and externalities. These negative impacts are growing with each increase in travel congestion and urban sprawl. Controlling negative externalities necessitates the examination of the relationship between density and automobile dependence and their contributing factors.

This research attempts to examine the simultaneous relationship between density and automobile dependence and the important factors that underlie their relationship within cities. The problem is complex, and the contributing factors are numerous. Some of these factors are measurable and tangible, while others are subjective and intangible. This research examines the contribution level of quantifiable factors to density and automobile dependence in selected world cities at different levels of analysis.

\section{Study scope and Sample}

The examination of density and automobile dependence in cities is divided into three complementary parts: a regional, a zonal, and a household level. The three levels of analysis utilize similar and complementary data structures.

The first part, a regional level, includes 31 world cities from four continents: North America, 11 cases; 
Western Europe, 12 cases; Asia, 3 cases; and Australia, 5 cases. Cities from developing countries will not be included in this study due to differences in historical development, lifestyles, income levels, urbanization patterns, and the lack of comparable data (Podoski, 1982; Newman and Kenworthy, 1989b).

The analysis includes three major contributors to density and automobile dependence within cities: land use factors, economic factors, and transportation technology factors. The study is based on pooled time series data that cover three different periods: 1960, 1970, 1980. These periods are snapshots of development and transportation patterns in these cities.

The second part, a zonal level, utilizes two case studies: Portland, Oregon, and Ar-Riyadh, Saudi Arabia. The selection of the two cities for further analysis was based on two main reasons. First, data collection is feasible in terms of availability and resources. Portland and Ar-Riyadh have good transportation and urban development data compared to many other cities, and they have similar land use controls (e.g., urban growth boundaries) (Al-Mosaind, 1988). Second, Portland is considered one of the most aggressive U.S. cities in promoting public transit and other modes of travel while discouraging automobile use through strict land use and transportation regulations (e.g., statewide land use planning) - Resistance to highway 
building, parking limitations in the $\mathrm{CBD}$, promotion of transit improvements, and the new Rule 12 of VMT reduction characterize Metropolitan Portland. The city resembles two contradicting phenomena: an automobile-oriented city, especially in the suburban areas, and a transit-oriented city, especially in the CBD and the central city. This diversity of transport orientation should enrich the study, especially when comparing city zones.

On the other hand, Ar-Riyadh is an automobile-dominated city with little or no efforts made to promote the use of other modes of travel. In 1988, automobile modal share was nearly 95 percent. The city is newly developed in an era of high-income and low-cost automobile ownership. Newer areas of the city are automobile-dominated in sharp contrast to older areas that are dense and non-automobile oriented. Therefore, Portland and Ar-Riyadh would provide a valuable diversity to the analysis, given the difficulty of adding other cities that are transit-dominated.

Cross-sectional zonal data that cover the years 1988 for Portland and 1986 for Ar-Riyadh are utilized for the study. Each case study is examined separately to examine density-automobile dependence relationship and identify the main factors that underlie such relationship. The analysis incorporates, in addition to the three major categories, some demographic factors.

The final part is the household level. This part 
utilizes household data compiled from 1990 U.S. National Personal Transportation Study (NPTS). Household data were clustered into three major spatial groupings: New York Metropolitan region, Snowbelt cities, and Sunbelt cities.

The selection of the spatial groupings is based on data availability and compatibility and the inherent similarities of transportation and land use patterns in these cities. New York data were selected and classified independently because of the city uniqueness with respect to U.S. cities and the large size of its data. Snowbelt cities are characterized as old, dense urban areas with strong centers that were developed prior to the automobile era. They include Chicago, Boston, and Detroit. On the other hand, Sunbelt cities are mainly newly developed, low density areas with weak centers that were shaped by the automobile. The list of Sunbelt cities includes Los Angeles, San Francisco, Houston, Denver, and Portland. These cities constitute a good representative of Snowbelt and Sunbelt cities' characteristics. These cities were selected to match the Newman and Kenworthy selection of U.S. cities in addition to matching Portland at the zonal level.

\section{Research Hypotheses}

The analysis examines several hypotheses and subhypotheses concerning density-automobile dependence relationship and the factors that underlie it within cities. These hypotheses are as follows: 
1. Population density affects the level of automobile dependence measured by vehicle miles travelled by city residents.

2. Automobile dependence level affects population density and the locational choices of urban residents.

3. Population density and automobile dependence simultaneously affect and reinforce each other.

4. Land use and urban structure attributes are major contributors to density and automobile dependence levels in urban areas. They include:

a- City structure;

b- Degree of development mix;

C- Timing of development.

5. Economic elements within the city affect its population density and automobile dependence level. They include:

a- Income level;

b- Automobile ownership;

c- Gasoline prices.

6. Transportation services and facilities in urban areas influence the level of population density and automobile dependence. They include:

a- Level of transit services;

b- Restraint on automobile use;

c- Congestion level in cities.

7. Taken together, land use, economic factors, and 
transportation factors are important determinants of density and automobile dependence.

\section{Research Models}

The dependent variables in this study measure the levels of population density and automobile dependence in cities. Density is measured by the gross or net population density within the city, the zone, or the zip code, while per capita VMT is an appropriate measure of automobile dependence. VMT measures the intensity of automobile utilization within the city or the zone by its perspective residents. This notion considers the amount of automobile travel in terms of number of trips taken in that area and their lengths. These elements are important determinants of urbanites' reliance on the automobile. Further, given the different city and TAZ sizes, this measure controls for the variations in size by using per capita VMT rather than crude VMT. Therefore, per capita VMT would measure the level of automobile dependence in the city.

In fact, several measures of automobile dependence and use were suggested in the literature. For instance, Newman and Kenworthy (1989b) used per capita gasoline consumption in their study. However, it is a poor measure of automobile dependence because it ignores the use of other fuels for transport, differs in terms of vehicle efficiency and travel speeds (Gomez-Ibanez, 1991), and is impossible to assign or allocate for the different city parts. A second measure was 
suggested by Keyes (1982), who used total VMT for each city, but it is a crude measure that ignores the city and/or zone size in terms of population or area.

Other potential measures of automobile dependence include: vehicle hours of travel (VHT), but this ignores the congestion effect; number of vehicle trips, but this does not consider the trip length; cost of a one mile trip by the different modes, but these words are hard to quantify; ratio of automobile VMT to transit VMT, but this does not consider the different city and zone sizes; and ratio of automobile trips to person trips, but this would not consider trip lengths. These measures have merits and could be partially related to automobile dependence, but they ignore important parameters that would measure the extent of automobile dependence.

Because of the existence of a simultaneous relationship between density and VMT, a system of two equation in the 3SLS technique is used. This technique requires the specification of two equations for the two endogenous variables, density and VMT. The relationship between the two endogenous variables is nonlinear, which necessitates the inclusion of a square variable for each variable. Graphically, this means that there will be a point of inflexion where the sign of the relationship changes. At this point, the value of the each variable will be at its lowest or highest depending upon the nature of the 
relationship. If the relationship between the two variables is significant, this study will attempt to calculate and identify this point, especially with respect to density. In the density curve, this is called the optimal density.

Further, these equations would include, in addition to the endogenous variables, several exogenous variables identified in the literature review. Due to the use of three levels of analysis with different right hand specifications, this research uses three different specifications. These systems of equations are constructed for the regional, zonal, and household levels. The first model is a regional model for a pooled sample of the years 1960, 1970, and 1980. It is specified as follows (see Table I for definitions and measurements of variables):

$$
\begin{aligned}
& \operatorname{VMT}_{i}: f\left(D_{i}, L U_{i}, E_{i}, T_{i}\right) \\
& D_{i}: f\left(\operatorname{VMT}_{i}, L U_{i}, E_{i}, T_{i}\right)
\end{aligned}
$$

Where:

$\mathbf{V M T}_{\mathbf{i}}$ is an endogenous variable that represents automobile dependence;

$\mathbf{D}_{\mathbf{i}}$ is an endogenous variable that represents net population density;

$\mathbf{L U}_{\mathbf{i}}$ is a land use factor;

$\mathbf{E}_{\mathbf{i}}$ is an economic factor;

$\mathbf{T}_{\mathbf{i}}$ is a transportation provision factor; and

$i$ is for a region that covers 60 cases of a pooled sample of 1960, 1970, and 1980 (only 27 cases in 1980 model).

The second model is at the zonal level for each of the two 
cities. It is specified as follows (see Tables II and III for variables' definitions and measurements):

$$
\begin{aligned}
& V M T_{i}: f\left(D_{i}, L U_{i}, E_{i}, T_{i}, H H_{i}\right) \\
& D_{i}: f\left(V M T_{i}, L U_{i}, E_{i}, T_{i}, H H_{i}\right)
\end{aligned}
$$

Where:

VMT $_{\mathbf{i}}$ is an endogenous variable that represents automobile dependence;

$D_{i}$ is an endogenous variable that represents gross or net population density;

${ }^{L} U_{i}$ is a land use factor;

$\mathbf{E}_{\mathbf{i}}$ is an economic factor;

$\mathbf{T}_{\mathbf{i}}$ is a transportation provision factor;

$\mathbf{H H}_{\mathbf{i}}$ is a demographic factor; and

$i$ is for a zone (404 zones for Portland in 1988 and 130 zones for Ar-Riyadh in 1986).

The third model is a 1990 household model for different spatial groupings of U.S. cities that include New York, Snowbelt cities, and sunbelt cities. These models are specified as follows (see Table IV for definitions and measurements) :

$V M T_{i}: f\left(D_{i}, L U_{i}, E_{i}, T_{i}, H_{i}\right)$

$D_{i}: \mathbf{f}\left(V M T_{i}, L U_{i}, E_{i}, T_{i}, H_{i}\right)$

Where:

VMT $_{\mathbf{i}}$ is an endogenous variable that represents automobile dependence;

$D_{i}$ is an endogenous variable that represents gross population density of the household zip code;

$\mathbf{L U}_{\mathbf{i}}$ is a land use factor; 
$\mathbf{E}_{\mathbf{i}}$ is an economic factor;

$\mathbf{T}_{\boldsymbol{i}}$ is a transportation provision factor;

$\mathrm{HH}_{\mathbf{i}}$ is a demographic factor; and

$i$ is for a household which includes 1868, 931, and 1531 cases for New York, Snowbelt cities, and Sunbelt cities.

\section{Data Sources}

This research is executed using secondary data. For the first part, data compiled and published by Newman and Kenworthy in their book Cities and Automobile Dependence: A Sourcebook are used in this research. This book was published in 1989 after an extensive data collection work. It includes data about 31 cities incorporated in this research in addition to the City of Moscow. Moscow was excluded from this research due to missing data and its unique political system.

For the second part, data about Portland and Ar-Riyadh were compiled from the regional governments of the two cities. Metro of Portland collects and manages land use, transportation, and socioeconomic data for the metropolitan area in order to devise regional policies. Similarly, Ar-Riyadh Development Authority (ADA) is responsible for regional policies and programs. Most of the data required for this research have been obtained from those two agencies. The rest was gathered from other public and private agencies and through published reports. 
TABLE I

DEFINITIONS AND MEASUREMENTS OF REGIONAL MODELS VARIABLES

\section{Endogenous Variables}

VMT Annual vehicle miles of travel per capita

Density Net population density (persons per acre of urbanized land)

Exogenous Variables

Land Use.

Emp. Density Fringe area employment density (jobs per acre of urbanized land)

Economic Variables

Income

Per capita income (in U.S. dollars)

Vehicle

Vehicle ownership per 1000 people

Gasoline

Gasoline price (U.S. cents per gallon)

(1980 model)

Transportation Provision Variables

Road Road length per capita (yard per person)

Parking Parking spaces in the CBD per $1000 \mathrm{CBD}$ workers

Congestion Total vehicles per mile of road

Transit Miles Miles of public transit service per person

D-1980 Dummy equals 1 for 1980 data

(pooled model only) 
TABLE II

DEFINITIONS AND MEASUREMENTS OF PORTLAND MODEL VARIABLES

Endogenous Variables

VMT

Annual vehicle miles of travel per capita

Density

Gross population density of the zone (persons per acre of gross area)

Exogenous Variables

Land Use

Emp. Density Zone employment density (jobs per gross zone area)

Dev. Timing Percentage of new buildings (built between 1960 and 1990)

Dev. Mix Ratio of number of jobs to number of households

Economic

Hilncome Percentage of high income people in the zone

Demographic

$\mathrm{HH}$ Size Average household size

HH Lifecycle Percentage of people of ages 25 to 54 years 
TABLE III

DEFINITIONS AND MEASUREMENTS OF AR-RIYADH MODEL VARIABIES

\section{Endogenous Variables}

VMT

Annual vehicle miles of travel per capita

Density

Net population density of the zone (persons per acre of developed area)

Exogenous Variables

Iand Use

Dev. Timing Development age of the zone in years

Comm Area

Area of commercial uses in acres

Govt Area

Area of governmental uses in acres

Dev. Mix

Degree of development mix (percent of singlefamily residential use to other uses)

Economic

HiIncome Dummy equals 1 for high income zones

Demographics

HiSaudi

Dummy equals 1 for zones dominated by Saudi residents

HiNon-saudi Dummy equals 1 for zones dominated by nonSaudi residents

HH Size

Average household size

Transportation

Freeway

Dummy equals 1 if the zone is located on a freeway 
TABLE IV

DEFINITIONS AND MEASUREMENTS OF HOUSEHOLD MODELS VARIABLES

Endogenous Variables

VMT

Annual vehicle miles of travel per household

Density

Gross population density of a household's zip code (persons per acre of gross area)

Exogenous Variables

Land Use

City

Dummy variable equals 1 if the household is located in the central City

Household

Vehicles Vehicles owned by the household

Workers Number of workers in the household

HH size Number of household members

HH lifecycle Dummy equals 1 for households with children

Age

Age of household head

Education

Education of household head

Transportation

D-Transit Dummy equals 1 for household located within 1 to 6 blocks from a public transit station 
The final part, household data, is compiled from the U.S. National Personal Transportation Study (NPTS) of 1990. The survey was conducted by the Research Triangle Institute with the sponsorship of several U.S. federal agencies. The survey is a unique source of personal travel data that provides information on household location and household trips, their purposes, and their modes of travel (U.S. DOT, 1992a). Household data of this research include locational (land use), economic, demographic, and transportation attributes. Most of the data were standardized to fit the research framework. 
CHAPTER IV

\section{COMPARATIVE ANALYSIS}

Automobile dependence and density have been long recognized as interdependent. Most empirical analysis of this relationship has utilized comparative analysis. Availability of data and research resources have limited most of these studies to simple statistical techniques.

This chapter attempts to reiterate most of these analyses using the available data for this research. It works as introductory to a more rigorous examination of the density-automobile dependence relationship presented in the next chapter. This chapter examines variations in urban development and travel patterns in the selected world cities. It compares variations in densities, vehicle ownership, and VMT between international cities. It concludes with a sumnary of the comparative analysis of density and automobile dependence variations.

INTERNATIONAL (INTERCITY) COMPARISONS: LAND USE AND TRAVEL PATTERNS

Land use and travel patterns vary among major world cities. Figure 2 shows that density, income, vehicle ownership, and VMT vary considerably between cities of the developed world (see Appendix A for individual cities' 
statistics). Low density and high income are associated with high levels of automobile ownership and VMT. These variations are attributed to variations in several underlying economical, social, and political factors (Pucher, 1990). Some of these factors are interdependent between themselves and with other land use and travel behavior measures. This part attempts to identify some of the important factors which affect density and automobile dependence.

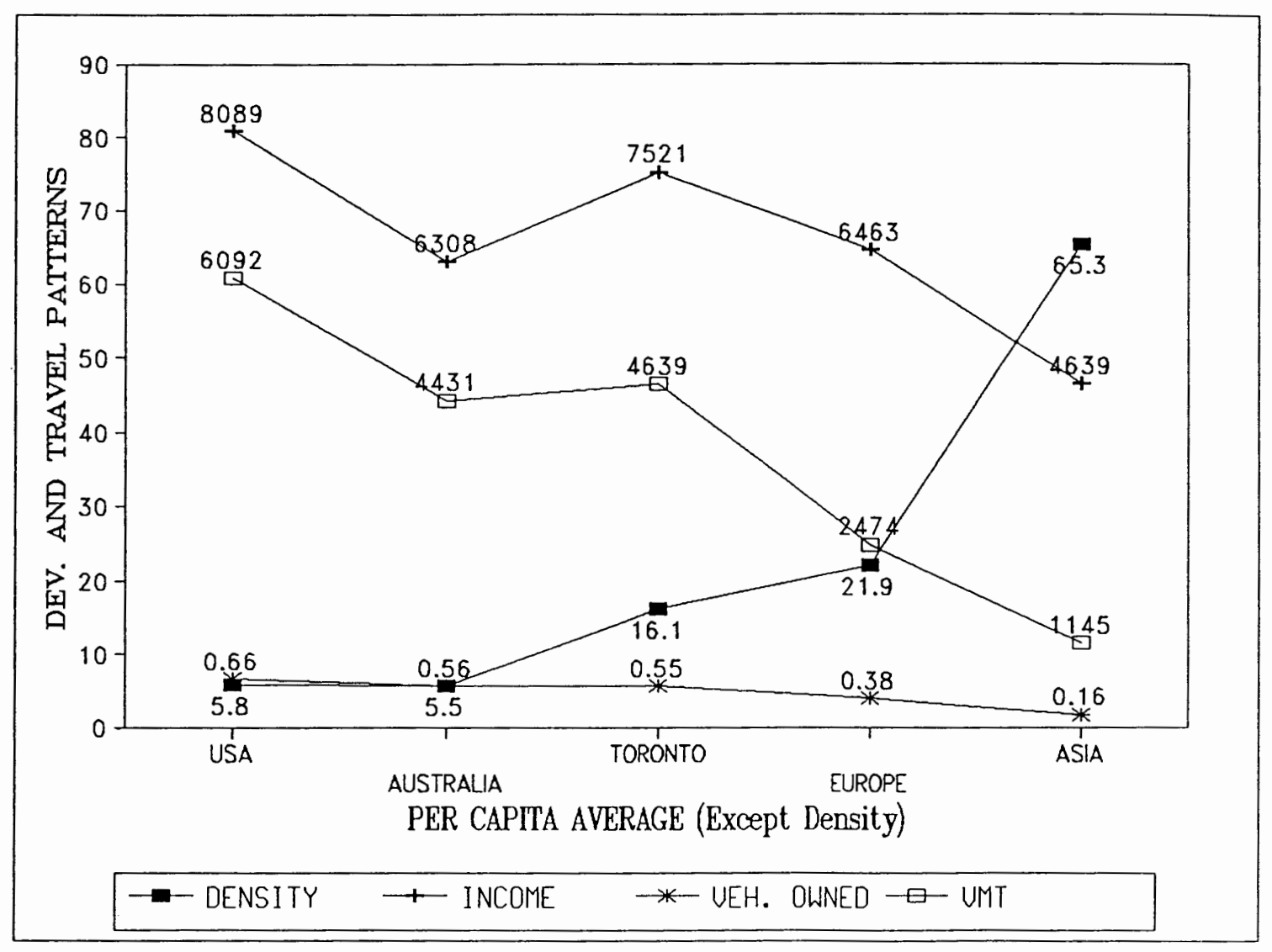

Figure 2. Variations in Development and Travel Patterns. Source: adjusted from Newman and Kenworthy, 1989b. 
Variations in Urban Development Patterns

In most world cities, urban densities are falling. For instance, most of the selected world cities have experienced a decline in population density between 1960 and 1980 . Table $\mathrm{V}$ shows that in average population density in U.S., Australian, European, and Asian cities have fallen from 13 to 45 percent. Only densities of Los Angeles, Hong Kong, and Toronto have risen from 1960 to 1980 . In other Canadian cities, gross population densities have fallen in amounts from one percent in Montreal to 250 percent in Edmonton between 1966 and 1986 (Patterson, 1993) - Similarly, densities of cities like Brisbane, Australia, and Amsterdam, Netherlands, have fallen to nearby half of the 1960 level. These density variations are attributed in part to changes in development patterns in newly developed areas. Table V shows that outer (fringe) areas, areas developed in an era of high income and automobile ownership levels, are not as dense as old, central areas (Gomez-Ibanez, 1991). In 1980, inner city areas on average are two to four times denser than outer areas. Further, outer area densities are on average 8 to 37 percent lower than those of 1960 . Australian and European cities are among the highest. These changes in densities have reduced the gap between U.S. and Australian cities on one side, and European and Asian cities on the other side. Nonetheless, the latter are still 4 to 12 times denser than U.S. and Australian cities. 
TABLE V

VARIATIONS IN URBAN DEVELOPMENT PATTERNS 1980

\begin{tabular}{|llllll|}
\hline $\begin{array}{l}\text { AVERAGE } \\
\text { CITY }\end{array}$ & $\begin{array}{l}\text { POP. } \\
\text { DENSITY }\end{array}$ & $\begin{array}{l}\text { DENSITY } \\
\text { 8CHANGE } \\
1960-80\end{array}$ & $\begin{array}{l}\text { INNER } \\
\text { DENSITY }\end{array}$ & $\begin{array}{l}\text { OUTER } \\
\text { DENSITY }\end{array}$ & $\begin{array}{l}\text { OUT.DEN } \\
\text { 8CHANGE } \\
1960-80\end{array}$ \\
\hline USA & 5.8 & -25.8 & 18.3 & 4.6 & -7.7 \\
AUSTRALIA & 5.5 & -45.1 & 10.0 & 5.1 & -36.6 \\
TORONTO & 16.1 & 7.1 & 23.3 & 13.8 & 32.9 \\
EUROPE & 21.9 & -37.8 & 37.7 & 17.5 & -24.6 \\
ASIA & 65.3 & -12.8 & 190.9 & 46.9 & 2.2 \\
\hline
\end{tabular}

Source: Calculated by the author from Newman and Kenworthy, 1989b.

Further, the decentralization of employment activities to fringe areas has intensified population decentralization (Meyer and Gomez-Ibanez, 1981). This has fostered population decentralization and in turn led to the decline in overall city density. Table VI shows that employment densities of outer city areas have increased on average from 9 to 136 percent between 1960 and 1980. Phoenix, Perth, Toronto, Brussels, and Tokyo are among the highest.

These variations in urban development patterns have contributed to the variations in density and automobile travel among major world cities. The tendency towards low-

1 overall metropolitan density.

2 Inner area is defined as the pre-World war II city boundary or the central city in most U.S. cities. area.

3 outer area is the rest of metropolitan region excluding inner 
density living is apparent in most of these cities. This has contributed to increased levels of automobile dependence within these cities, which in turn may have reinforced these patterns.

TABLE VI

VARIATIONS IN POPULATION AND EMPLOYMENT DENSITIES

1980

\begin{tabular}{|llll|}
\hline AVERAGE CITY & $\begin{array}{l}\text { POPULATION } \\
\text { DENSITY }\end{array}$ & $\begin{array}{l}\text { OUTER } \\
\text { EMPLOYMENT } \\
\text { DENSITY }\end{array}$ & $\begin{array}{l}\text { OUT. EMP. } \\
\text { 8CHANGE } \\
1960-80\end{array}$ \\
\hline USA & 5.8 & 2.2 & 16.8 \\
AUSTRALIA & 5.5 & 1.5 & 9.4 \\
TORONTO & 16.1 & 5.6 & 136.2 \\
EUROPE & 21.9 & 6.8 & 4.8 \\
ASIA & 65.3 & 17.6 & -- \\
\hline
\end{tabular}

Source: Calculated by the author from Newman and Kenworthy, 1989b.

Variations in Transportation Systems and Travel Patterns

Coupled with continuous decline of urban densities in most world cities, automobile ownership and travel have increased rapidly. Table VII shows that automobile ownership per capita has increased on average from 36 to 74 percent between 1960 and 1980. Rapid increases of ownership levels are observed in both European and Asian cities. The rest of world cities may have reached the saturation level, especially U.S. cities.

4 outer employment density in terms of number of employees per acre of outer area. 
Similarly, in terms of automobile travel, most world cities have experienced comparable increases in per capita VMT between 1960 and 1980. VMT in these cities on average have increased to near half of the 1960 level. On the other hand, between 1960 and 1980, per capita transit trips on average have decreased in U.S. and Australian cities and increased in the rest. This increased the gap between those two groups. For instance, in 1980, transit trips per capita in Tokyo is 52 times the level in Phoenix, U.S.A. Only New York and Chicago, U.S.A., and Sydney, Australia, have a transit use that is two to three times less than the European and Asian average.

TABIE VII

VARIATIONS IN TRAVEL PATTERNS 1980

\begin{tabular}{|c|c|c|c|c|c|c|}
\hline $\begin{array}{l}\text { AVERAGE } \\
\text { CITY }\end{array}$ & $\begin{array}{l}\text { VEHICLE } \\
\text { OWNED }^{5}\end{array}$ & $\begin{array}{l}\text { 8CHANGE } \\
1960-80\end{array}$ & $\begin{array}{l}\text { VMT PER } \\
\text { CAPITA }\end{array}$ & $\begin{array}{l}8 \text { CHANGE } \\
1960-80\end{array}$ & $\begin{array}{l}\text { TRANSIT } \\
\text { TRIPS }^{6}\end{array}$ & $\begin{array}{l}\text { 8CHANGE } \\
1960-80\end{array}$ \\
\hline USA & 0.656 & 35.7 & 6092 & 46.6 & 65.8 & -19.0 \\
\hline AUSTRAIIA & 0.559 & 49.0 & 4431 & 47.8 & 94.1 & -51.3 \\
\hline TORONTO & 0.554 & 37.8 & 4639 & -- & 177.6 & 13.0 \\
\hline EUROPE & 0.375 & 58.2 & 2474 & 51.4 & 299.2 & 14.6 \\
\hline ASIA & 0.163 & 73.7 & 1145 & 47.0 & 430.4 & 28.1 \\
\hline
\end{tabular}

Source: Calculated by the author from Newman and Kenworthy, 1989b.

\footnotetext{
5 Vehicle ownership per capita.

6 Total transit (bus, rail, ferry) trips per capita.
} 
Another indicator of the increasing dependence on the automobile is presented in Table VIII and Figure 3. With the exception of Asian and major European cities, in 1980 the automobile share of work-related trips is the highest compared to other modes. Only one-third of work trips in Toronto and an average European city were taken by public transit. Similarly, walking and bicycling trips are substantial in Asian and European cities but negligible in North American and Australian cities. On average, walk and bicycle work trips are 1.5 times greater than automobile trips in Asian cities, while automobile trips are 10 to 15 times greater than walking and bicycling trips in Australia and North America. These contrasting figures indicate the dominance of automobile travel in North American and Australian cities as compared to European and Asian cities. These variations in modal split and automobile dependence are attributed to variations in several factors. They include variations in density, income, and public provision of transportation facilities. First, urban densities are considerably higher in Asian and European cities than those of North American and Australian cities. However, in terms of per capita income, the European average is comparable to the Australian average. This suggests that other important factors may be responsible for these variations in density and automobile travel. 
TABLE VIII

VARIATIONS IN MODAL SPLIT 1980

\begin{tabular}{|c|c|c|c|c|c|}
\hline CITY & $\begin{array}{l}\text { POP. } \\
\text { DENSITY } \\
\end{array}$ & $\begin{array}{l}\text { INCOME PER } \\
\text { CAPITA }\end{array}$ & $\begin{array}{r}8 \\
\text { PRIVATE } \\
\end{array}$ & $\begin{array}{l}\text { ODAL SPLIT } \\
\text { TRANSIT }\end{array}$ & 7 \\
\hline BOSTON & 4.9 & 7709 & 74.1 & 16.1 & 9.8 \\
\hline CHICAGO & 7.1 & 8336 & 75.5 & 18.3 & 6.2 \\
\hline DENVER & 4.8 & 8013 & 88.1 & 6.5 & 5.3 \\
\hline DETROIT & 5.7 & 8430 & 93.1 & 4.1 & 2.8 \\
\hline HOUSTON & 3.6 & 8391 & 93.9 & 3.3 & 2.8 \\
\hline LOS ANGELES & 8.1 & 7560 & 88.0 & 7.7 & 4.2 \\
\hline NEW YORK & 8.1 & 7403 & 63.6 & 28.3 & 8.1 \\
\hline PHOENIX & 3.5 & 7047 & 94.6 & 2.2 & 3.2 \\
\hline SAN FRANCISCO & 6.3 & 8438 & 77.5 & 17.0 & 5.5 \\
\hline WASHINGTON & 5.4 & 9565 & 80.7 & 14.1 & 5.2 \\
\hline ADELAIDE & 5.3 & 5948 & 77.7 & 16.5 & 5.8 \\
\hline BRISBANE & 4.2 & 5900 & 78.1 & 16.6 & 5.3 \\
\hline MELBOURNE & 6.7 & 6800 & 73.7 & 20.6 & 5.7 \\
\hline PERTH & 4.4 & 6109 & 84.0 & 12.0 & 4.0 \\
\hline SYDNEY & 7.2 & 6784 & 65.1 & 29.5 & 5.4 \\
\hline CALGARY & 4.6 & -- & 72.1 & 19.6 & 8.3 \\
\hline EDMONTON & 3.8 & -- & 72.7 & 18.4 & 8.9 \\
\hline MONTREAL & 11.5 & -- & 63.9 & 27 & 9.1 \\
\hline OTTAWA-HULI & 6.3 & -- & 60.8 & 28.3 & 10.8 \\
\hline TORONTO & 11.7 & 7521 & 63.0 & 31.2 & 5.8 \\
\hline VANCOUVER & 7 & - & 75.5 & 18.1 & 6.4 \\
\hline AMESTRDAM & 20.7 & 5856 & 58.0 & 14.0 & 28.0 \\
\hline BRUSSELS & 27.4 & 6293 & 57.7 & 26.7 & 15.6 \\
\hline COPENHAGEN & 12.4 & 6746 & 36.8 & 31.0 & 32.2 \\
\hline FRANKFURT & 22.0 & 6967 & 54.0 & 19.0 & 27.0 \\
\hline HAMBURG & 17.0 & 6967 & 43.9 & 41.0 & 15.3 \\
\hline IONDON & 22.9 & 4990 & 38.0 & 39.0 & 23.0 \\
\hline MUNICH & 23.2 & 6967 & 38.0 & 42.0 & 20.0 \\
\hline PARIS & 19.7 & 6678 & 36.4 & 39.8 & 23.8 \\
\hline VIENNA & 29.4 & 6052 & 40.4 & 44.9 & 14.7 \\
\hline
\end{tabular}

7 Percentage modal split of work trips.

8 Gross (Canadian cities) and net (otherwise). 
TABLE VIII

\section{VARIATIONS IN MODAL SPLIT 1980 \\ (continued)}

\begin{tabular}{||llllll||}
\hline \multirow{2}{*}{ CITY } & POP. & INCOME PER & \multicolumn{3}{c|}{ \& } \\
& DEDAL SPLIT \\
& DENSITY & CAPITA & PRIVATE & TRANSIT & FT./BICYCLE \\
\hline WEST BERLIN & 25.9 & 6967 & 48.0 & 37.0 & 15.0 \\
ZURICH & 21.9 & 6610 & 45.0 & 34.0 & 21.0 \\
\hline HONG KONG & 119.4 & 3973 & 3.3 & 62.2 & 34.5 \\
SINGAPORE & 33.9 & 3948 & 24.6 & 59.6 & 15.8 \\
TOKYO & 42.6 & 5996 & 16.1 & 59.0 & 24.9 \\
\hline
\end{tabular}

Source: Newman and Kenworthy, 1989b; Patterson, 1993; Parker, 1993.

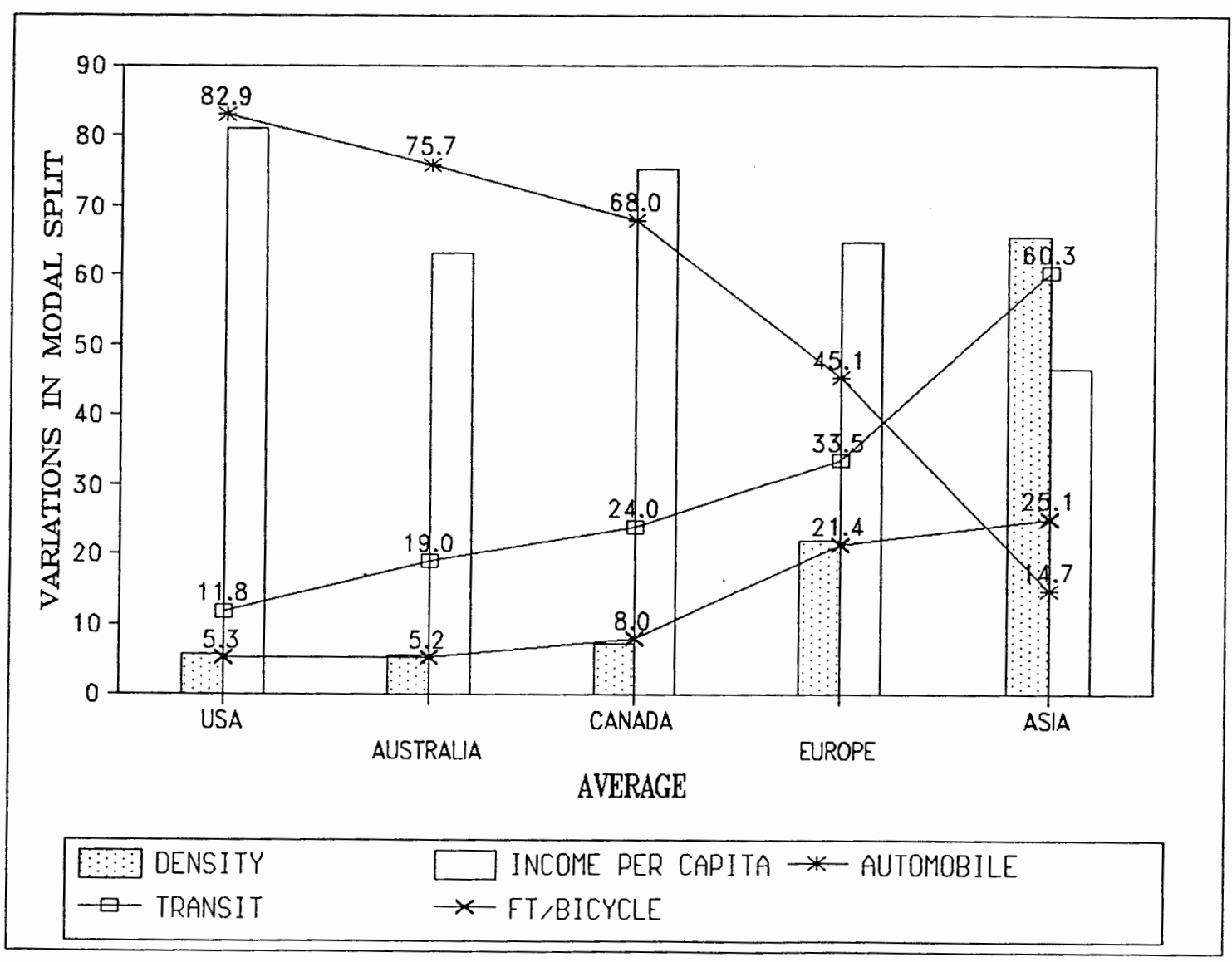

Figure 3. Variations in Modal Split. Source:

Newman and Kenworthy, 1989b; Parker, 1993. 
Finally, variations in density and automobile dependence may be attributed to variations in public provision of transportation facilities. Pucher (1988) and other scholars argue that these variations are attributed to public policies in land use and transportation factors. Table IX shows that public provision of roads and public transit facilities do vary considerably among world cities. On average, road lengths in the U.S. and Australia are much higher than the Asian and European average. Conversely, in terms of vehicle service miles, transit services in Asia are nearly two to three times the U.S. and Australian average. This may explain some of the variations in automobile and transit use between world cities.

\section{TABLE IX}

VARIATIONS IN TRANSPORTATION PROVISION 1980

\begin{tabular}{|c|c|c|c|c|}
\hline CITY & $\begin{array}{l}\text { ROAD } \\
\text { LENGTH }^{9}\end{array}$ & $\begin{array}{l}\text { 8CHANGE } \\
1960-80 \\
\end{array}$ & $\begin{array}{l}\text { TRANSIT } \\
\text { MILES } 10\end{array}$ & $\begin{array}{l}\text { \&CHANGE } \\
1960-80 \\
\end{array}$ \\
\hline USA & 7.2 & -0.6 & 18.8 & 5.3 \\
\hline AUSTRALIA & 9.5 & 13.8 & 35.2 & $-28 \cdot 9$ \\
\hline TORONTO & 3.0 & 58.8 & 50.4 & 66.9 \\
\hline EUROPE & 2.3 & 64.5 & 49.4 & 14.2 \\
\hline ASIA & 1.1 & -- & 64.2 & -- \\
\hline
\end{tabular}

Source: Calculated by the author from Newman and Kenworthy, $1989 \mathrm{~b}$.

\footnotetext{
9 Total road lengths (yard per capita)

10 Miles of transit services (e.g. bus, rail, ferry)
} 
Summary

These comparative analyses show that several important factors may be responsible for the variations in density and automobile dependence among world cities. Both density and automobile dependence vary with respect to each other and to changes in other important factors. They include mainly urban densities, income, automobile ownership, and public provisions of roads and public transit.

However, this type of analysis identifies only levels of association between factors. It does not control for indirect effects, nor does it isolate the effects of several factors simultaneously. When examining complex relationships such as density and automobile dependence, other effects may confound the interpretation of the results. This in turn results in inaccurate policy implications. These relationships require more sophisticated analyses to account for confounding effects. The next chapter is an attempt to accomplish that by using the 3SLS technique. 
CHAPTER V

ANALYTICAL ANALYSIS

A discussion of the results of the analytical analysis is presented in this chapter. The seven research hypotheses are analyzed here. They are examined at the three levels of analysis: regions, zones, and households. This chapter is divided into four sections. The first section includes an outline of the empirical analysis design and the statistical technique used to complete this research. The second section examines the simultaneous relationship between density and VMT and the contributing factors to this relationship at three levels of analysis. Within these levels of analysis, sub-models of several spatial and temporal groupings are analyzed. The third section examines the optimal city and zone densities of the research case studies as derived from their models' results. Finally, a brief conclusion of the research analytical analysis is included.

\section{THE DESIGN OF EMPIRICAL ANALYSIS}

The empirical analysis of the simultaneous relationship between density and automobile dependence is measured by two distinct measures: population density (gross or net) and 
vehicle miles of travel (VMT). The other contributing factors to this relationship include land use, economic factors, demographics, and transportation system. Land use factors include employment density, degree of development mix, timing of development (building age). Economic factors include mainly measures of income, automobile ownership, and cost of travel in terms of gasoline prices. Household characteristics, in terms of size, number of workers, lifecycle, and age and education level of household head, are included. Finally, transportation provision factors include auto-related facilities such as road length, CBD parking, and congestion level, transit miles, and proximity to a freeway and transit-oriented facilities. The objective of this research is to examine the simultaneous effect of density and VMT controlling for the effects of other factors.

The analysis uses two endogenous variables, density and VMT, for two system equations. The exogenous variables were selected from the three or four major categories: land use, economic, demographic, and transportation provision. The study general model is designed as follows:

$$
\begin{aligned}
& V M T_{i}: f\left(D_{i}, L U_{i}, E_{i}, T_{i}, H H_{i}\right) \\
& D_{i}: f\left(V M T_{i}, L U_{i}, E_{i}, T_{i}, H H_{i}\right)
\end{aligned}
$$

Where:

VMT $_{\mathbf{i}}$ is an endogenous variable that represents automobile dependence; 
$D_{i}$ is an endogenous variable that represents population density;

$\mathbf{L U}_{\boldsymbol{i}}$ is land use factors;

$\mathbf{E}_{\boldsymbol{i}}$ is economic factors;

$\mathbf{T}_{\mathbf{i}}$ is transportation provision factors;

$\mathbf{H H}_{\mathbf{i}}$ is demographic factors (not included in the regional model); and

$i$ is for the unit of analysis.

The two equations are estimated jointly for each of the three levels of analysis. Each level of analysis is specified with different sets of exogenous variables (see Chapter III for models' specifications). The 3SLS technique is used in this research. The technique examines simultaneously the effect of each endogenous variable on the other and the effects of exogenous variables on the two endogenous variables (i.e., density and VMT).

The analysis is divided into two parts. First, it examines the simultaneous effect of density and VMT. The estimated $t$-scores of the two equations are examined to determine its statistical significant. The first equation examines the hypothesis that density affects VMT, while the second equation examines the hypothesis that VMT affects density. If the estimated t-scores of density and VMT are statistically significant in both equations, this result suggests that density and VMT have a bi-directional relationship. In other words, density affects VMT, negatively or positively, and VMT affects density. However, 
if the estimated $t$-scores are not statistically significant in both equations this result suggests that density has no relationship to VMT.

Second, this analysis examines the effects of other factors on both density and VMT. The last four hypotheses contend that several variables individually or collectively affect density and VMT simultaneously. The estimated tscore is used as a measure of the statistical significance of these exogenous variables' effects. Variables with a predictable direction of influence on the endogenous variables will be tested using a one-tailed t-test, while other variables are tested using two-tailed t-tests. The explanatory power of the system of equation in the 3SLS and the individual equations are also examined.

Some of study data at the three levels of analysis were missing or miscoded. Only cases with missing values for VMT and/or density were excluded from the analysis. Missing values for other exogenous variables were treated using regression analysis. Exogenous variables were regressed with each other to estimate the value of missing data cells. The empirical analysis of this dissertation consists of two components. The first is investigation of the simultaneous relationship between density and VMT. The second is examination of the contribution effects of other factors on density and VMT. This analysis proceeds for different levels of analysis: the urban region (regional), 
the traffic analysis zone (zonal), and then the household.

\section{Specification Strategies}

Because 3SLS technique is very sensitive to changes in model specifications for the two equations, the model should be constructed carefully to avoid problems of misspecification. Most of the exogenous variables used in the analysis do affect both density and VMT either directly or indirectly.

The selection of each equation's variables was subject to multiple criteria. Ranked based on importance, they include specification consistency across models, higher explanatory powers for each equation and the system at large, higher t-scores for endogenous and then exogenous variables, and lower standard error of estimates. All potential model specifications were subjected to the above criteria. The specification that fulfilled these criteria was selected for each model and sub-model in the three levels of analysis. The next section presents the results of these models.

THE RELATIONSHIP BETWEEN DENSITY AND VMT AND THE EFFECTS OF OTHER FACTORS AT THE REGIONAL LEVEL

At this aggregate level of analysis, the relationship between density and VMT and the effects of other contributors on the two variables are examined. The 3SLS technique uses two endogenous variables, density and VMT, 
with two system equations. The exogenous variables were selected from three major categories: land use, economic, and transportation provision. The variables used in the analysis are defined in Table I, Chapter III. See Appendix B for summary statistics on these variables.

The two equations were estimated jointly for density and VMT. The results for both equations are presented in Table $X$. The estimated $t$-scores for both variables and their squared terms are statistically significant at the 0.01 level of the two-tailed t-tests. This suggests that a negative, nonlinear, and bi-directional relationship exists between density and VMT.

When examining the results of the two simultaneous equations, this bi-directional effect is not the only notable. For instance, economic factors such as vehicle ownership and per capita income are important determinants of VMT and density, respectively. Both variables are significant at the 0.05 level of the two-tailed t-tests. In the VMT model, vehicle ownership rate within the city affects positively the total miles driven in that city. Alternatively, in the density model, income level within the city negatively affects the overall population density.

Other land use and transportation variables also significantly affect VMT and density. In the VMT model, decentralized city structure, in terms of fringe employment density, positively affects VMT but in a nonlinear form. 
Similarly, transportation factors, such as the total number of transit miles within the city, negatively affects VMT. The ratio of $C B D$ parking to $C B D$ jobs is statistically not significant in explaining VMT in the city, even though it has the right sign.

In the density model, other transportation variables do not strongly affect density. Road length within the city negatively affects density, as expected, but with an insignificant coefficient. Congestion level within the city increases with high-density living; however, its coefficient is weakly significant.

The dummy variable included in the VMT model that represents data for 1980 is positively significant. It indicates an increase in VMT in the selected case studies during 1980 compared to 1960 and 1970. For that reason, as well as the existence of 1980 gasoline price data, another model of simultaneous equations is examined. See Table XI for 1980 model results. The results reinforce the original model results but with slight differences. For instance, income coefficient has become insignificant even though it has the right sign. In the VMT and density models, congestion level and transit miles variables, respectively, have the expected sign but they are statistically not significant. Of importance is the effect of gasoline prices on VMT. The model results indicate that VMT significantly decrease as gasoline prices increase. 
TABLE X

RESULTS OF THE POOLED REGIONAL MODEL

\begin{tabular}{|c|c|c|c|c|}
\hline \multirow[b]{2}{*}{ Variable } & \multicolumn{2}{|c|}{ VMT Model } & \multicolumn{2}{|c|}{ Density Model } \\
\hline & Coefficient & T-Score & Coefficient & T-score \\
\hline VMT & & & -0.01 & $-4 \cdot 6^{+t}$ \\
\hline VMT square & & & $8 E-07$ & $3.0^{++}$ \\
\hline Density & $-249 \cdot 3$ & $-3.7^{++}$ & & \\
\hline Density square & 3.7 & $3.7^{++}$ & & \\
\hline Land Use & & & & \\
\hline Employment Density & 923.3 & $3.2^{++}$ & & \\
\hline Emp. Dens. Square & -67 & $-3 \cdot 4^{++}$ & & \\
\hline Economic & & & & \\
\hline Income & & & -0.003 & $-2.0^{+}$ \\
\hline Vehicle Ownership & 5.8 & $6.5^{++}$ & & \\
\hline Transport & & & & \\
\hline Road Length & & & -0.01 & -0.05 \\
\hline CBD Parking & 0.1 & 0.3 & & \\
\hline Congestion & & & 0.08 & $1.5^{\star}$ \\
\hline Transit Miles & -13.7 & $-3.0^{+t}$ & & \\
\hline$D-1980$ & 410.9 & $1.9^{+}$ & & \\
\hline Constant & 1499 & $3.6^{t+}$ & 57 & $5.6^{++}$ \\
\hline Model $\mathrm{R}^{2}$ & & 0.93 & & 0.54 \\
\hline S.E. Estimate & & 455.6 & & 86.6 \\
\hline Sample size & & 60 & & 60 \\
\hline system $R^{2}$ & & & & \\
\hline
\end{tabular}

* Significant at 0.05 level (one-tailed)

+ significant at the 0.05 level (two-tailed)

++ significant at the 0.01 level (two-tailed) 
TABLE XI

RESULTS OF THE 1980 REGIONAI MODEL

\begin{tabular}{|c|c|c|c|c|}
\hline \multirow[b]{2}{*}{ Variable } & \multicolumn{2}{|c|}{ VMT Model } & \multicolumn{2}{|c|}{ Density Model } \\
\hline & Coefficient & $\mathrm{T}$-score & Coefficient & $\mathrm{T}$-score \\
\hline VMT & & & -0.05 & $-5 \cdot 8^{t+}$ \\
\hline VMT square & & & $5 E-06$ & $6.4^{t+}$ \\
\hline Density & -285.9 & $-2 \cdot 8^{t+}$ & & \\
\hline Density square & 4.5 & $3.0^{t+}$ & & \\
\hline Land Use & & & & \\
\hline Employment Density & 1083 & $2.7^{++}$ & & \\
\hline $\begin{array}{l}\text { Emp. Dens. Square } \\
\text { Economic }\end{array}$ & -84.3 & $-2 \cdot 9^{+t}$ & & \\
\hline Income & & & -0.002 & -0.5 \\
\hline Vehicle own & 5.2 & $3.9^{t+}$ & & \\
\hline $\begin{array}{l}\text { Gasoline Price } \\
\text { Transport }\end{array}$ & -4.8 & $-2 \cdot 1^{+}$ & & \\
\hline Road length & & & 0.05 & 0.13 \\
\hline CBD Parking & 0.4 & 0.8 & & \\
\hline Congestion & 2.6 & 0.9 & & \\
\hline Transit Miles & & & 0.2 & $1 \cdot 1^{\star}$ \\
\hline constant & 2284 & $2.4^{+}$ & 114 & $5.5^{+t}$ \\
\hline Model $\mathrm{R}^{2}$ & & 0.94 & & 0.75 \\
\hline S.E. Est. & & 449.9 & & 11.2 \\
\hline Sample size & & 27 & & 27 \\
\hline system $R^{2}$ & & & & \\
\hline
\end{tabular}

* Significant at 0.05 level (one-tailed)

+ significant at the 0.05 level (two-tailed)

++ significant at the 0.01 level (two-tailed) 
Coefficients of elasticity were estimated to examine the sensitivity of the two endogenous variables to the percentage changes in the exogenous variables. Table XII summarizes the elasticity at the means for the two models. VMT appears to be most sensitive to changes in population and fringe employment densities and least sensitive to changes in $C B D$ parking and transit miles. Meanwhile, density appears to be more responsive to changes in vehicle miles than changes in congestion and income level. Controlling for other factors, this indicates the importance of the mutual effect of density and VMT.

Further, the two models, pooled and 1980, are comparable and behave similarly. With the exception of VMT effect on density, all of the significant variables have comparable elasticities. This indicates the persistence of these effects over time. In general, the elasticities of the exogenous variables in the 1980 model are lower than their counterparts in the pooled model. This suggests either a weakening effect of these factors on density and automobile dependence, the importance of gasoline price effect on VMT, or both. OnIY VMT has a stronger effect on density in the 1980 model than the pooled model due to increases in urban mobility. These increases in VMT may have exerted strong influence on density patterns. Other than that, the pooled and 1980 models show similar effects of density, VMT, and other contributing factors. 
TABLE XII

ELASTICITIES OF REGIONAI MODELS

\begin{tabular}{||l|lc|cc|}
\hline \multirow{2}{*}{ Variable } & \multicolumn{2}{|c|}{ VMT Model } & \multicolumn{2}{c|}{ Density Model } \\
\cline { 2 - 5 } & Pooled & 1980 & Pooled & 1980 \\
\hline $\begin{array}{l}\text { VMT } \\
\text { Lensity } \\
\text { Land Use }\end{array}$ & -0.4 & -0.3 & -2.0 & -4.8 \\
$\begin{array}{l}\text { Econor Emp. density } \\
\text { Income Per Capita } \\
\text { Vehicle Ownership }\end{array}$ & 0.4 & 0.2 & & \\
$\begin{array}{l}\text { Gasoline Price } \\
\text { Transport } \\
\text { Road Length } \\
\text { CBD Parking }\end{array}$ & 0.7 & 0.6 & -0.9 & $-0.6^{*}$ \\
Congestion & $0.01^{*}$ & $0.03^{*}$ & $-0.02^{*}$ & $0.04^{*}$ \\
Transit Miles & -0.1 & $0.06^{*}$ & 0.4 & \\
\hline
\end{tabular}

* Not significant

The system of equations in the pooled model explains much of the variability in VMT and density jointly and individually, as indicated by the high scores of system $\mathrm{R}^{2}$ and their respective $R^{2}$. System $R^{2}$ is 0.95 . This means that the two equations used in the system together explain 95 percent of the variability in the two endogenous variables, VMT and density, taken jointly ${ }^{11} \cdot R^{2}$ for VMT

11 System $R^{2}$ measures the degree of fit of all of the system equations. It is a broad concept that changes extensively with minor changes in specification. Instead, $\mathrm{R}^{2}$ for each equation and $t$-scores for the coefficients are sufficient for model evaluation. 
model is very high, 0.93 , while $R^{2}$ for density model is reasonably high, 0.54. The two equations are statistically significant at the one percent level of the two-tailed test. Much of the unexplained variability in the two models, especially in the density model, is probably due to variations in local conditions and lifestyles in the selected sample of cities. On the other hand, R-square in the VMT model may have been inflated due to the sample size (only 60 cases) used in the analysis, even though multicolinearity between exogenous variables are not seriously present. These results should be cautiously interpreted to avoid exaggeration. Nonetheless, it should not affect our interpretation of the models' coefficients. Most of the coefficients in the analysis have the expected sign, and many are statistically significant. of importance, the analysis confirms the strongly acknowledged, simultaneous relationship between density and VMT.

\section{THE RELATIONSHIP BETWEEN DENSITY AND VMT AND THE EFFECTS OF OTHER FACTORS AT THE ZONAI LEVEL}

At a lower level of aggregation, the relationship between density and VMT and the effects of other contributors on the two variables are examined. The problem of city averaging, the need to include development timing variable in the model, and the desire for models' comparisons were primary reasons for including zonal level 
analysis. Two case studies are used in this level of analysis: Portland and Ar-Riyadh. The 3SLS technique is also used for the two endogenous variables, density and VMT. The exogenous variables used were selected from four major categories: land use, economic, demographic, and transportation provision. The two models' variables are defined in Tables II and III, Chapter III. See Appendix B for summary statistics on these variables. Next is a presentation of the Portland and Ar-Riyadh models' results.

\section{Results of the Portland Model}

Density and VMT equations were estimated jointly. The results for both equations are presented in Table XIII. The estimated $t$-scores for both variables and the square term of VMT are statistically significant at the 0.01 level of the two-tailed t-tests. Density squared variable is statistically significant at the 0.05 level of the onetailed t-test. This indicates the existence of a negative, nonlinear, and simultaneous relationship between gross population density and per capita VMT. This relationship is much stronger in the direction where VMT affects density. Controlling for their effects on each other, density and VMT are affected by other important variables. In the VMT model, land use variables such as employment density and degree of development mix are statistically significant. Employment density reduces vehicle miles traveled in the zone, while the degree of development mix, in terms of the 
ratio of jobs to households, unexpectedly increases vehicle miles. This may be due to its correlation with employment density, which would result in biased estimates. In addition, household size is negative and statistically significant. The larger the household size, the lower the vehicle miles per capita in the zone.

Results for density model show the importance of demographic factors in explaining density patterns of portland zones. High income and family lifecycle variables have negative, statistically significant coefficients. As confirmed by the model, high income people and people in the family formation lifecycle tend to prefer low-density over high-density areas. Further, timing of development variable is negatively related to density. High percentage of new buildings are found in low-density zones. Development timing variable is statistically significant at the 0.05 level of the one-tailed $t$-test.

Analysis of the models' elasticity at the means provides a good base for comparing the importance of the model variables. In the VMT model, VMT variable is highly responsive to changes in all of the model variables, particularly density and degree of development mix. Similarly, VMT and income variables are much more effective in altering density patterns then development timing and household lifestyle. The sensitivity analysis affirms the strength of the simultaneous relationship. 
TABLE XIII

RESULTS OF PORTLAND ZONES MODEL

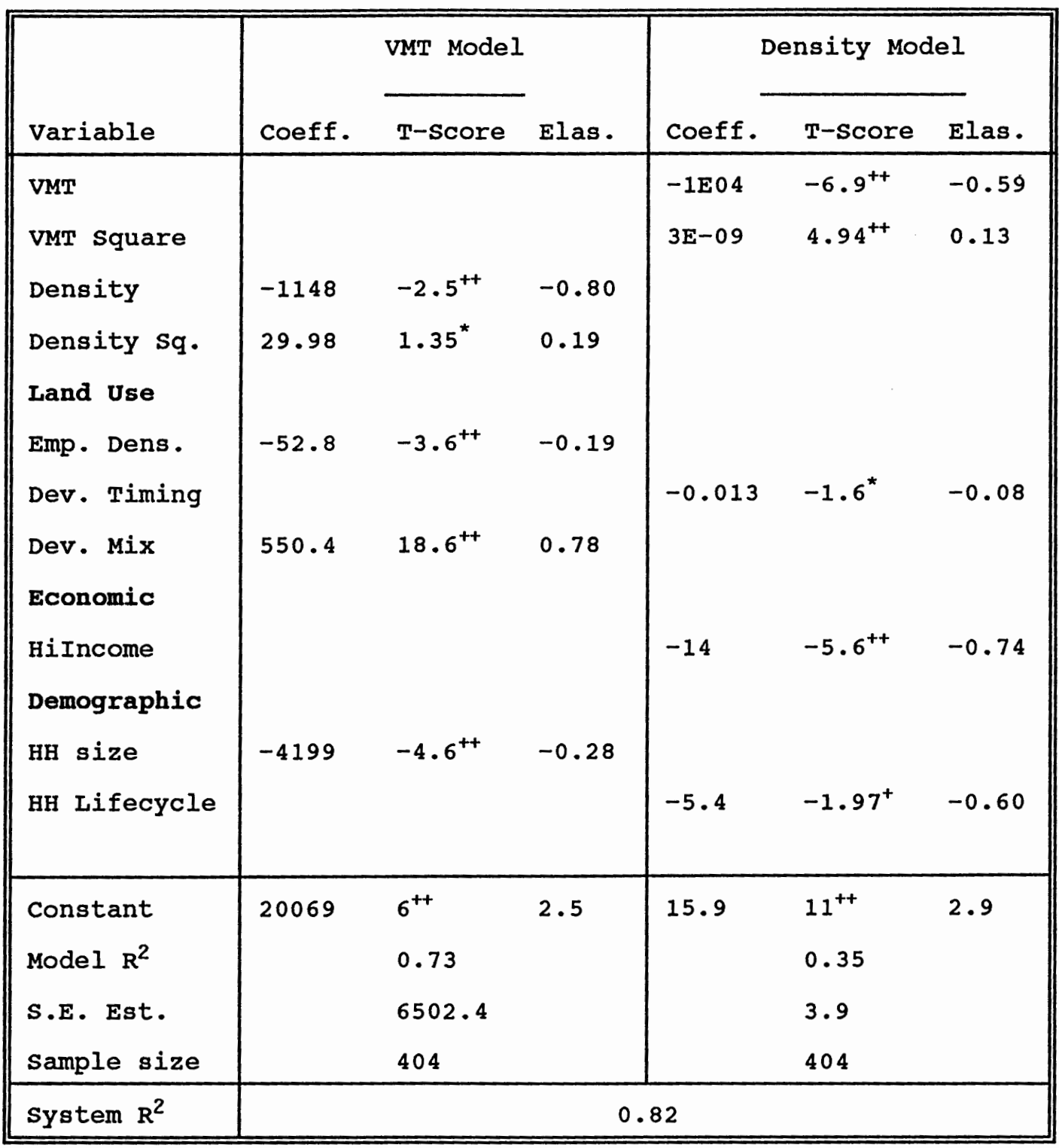

* significant at 0.05 level (one-tailed)

+ significant at the 0.05 level (two-tailed)

++ significant at the 0.01 level (two-tailed) 
The overall simultaneous system of equations is statistically significant at the 0.01 level of the twotailed test. System $R^{2}$ is 0.82 . The two equations in the system together explain 82 percent of the variability in the two dependent variables, VMT and density, taken jointly. $\mathrm{R}^{2}$ for VMT model is quite high, 0.73 , compared to $R^{2}$ for density model, 0.35. The variables used in the VMT model apparently explain more of the variations in VMT compared to density in the density model.

What is important here is that VMT and density affect each other simultaneously. This confirms the results found in the regional models and emphasizes the expected nature of this relationship. Further, timing of development may have played an important role in explaining variations between zones with respect to density and VMT and in turn reducing the simultaneous effect of density and VMT. Finally, the models' results have shown the importance of economic and demographic factors in affecting both density and VMT simultaneously.

Results of the Ar-Riyadh Model

Density and VMT equations for Ar-Riyadh zones were estimated jointly. The model results are presented in Table XIV. The estimated $t$-scores for density and its squared term in the VMT model are statistically significant at the 0.05 level of the two-tailed t-tests and the one-tailed $t-$ 
test, respectively. VMT and VMT square in the density model are not statistically significant and have the wrong signs. This result suggests that there is a negative, nonlinear, and uni-directional relationship between net population density and per capita VMT in the direction where density affects VMT. Density patterns in the city are apparently explained by factors other than VMT.

In addition, a variety of land use, transportation and demographic variables affect both VMT and density simultaneously. In the VMT model, the degree of development mix, measured as the percentage of single-family homes, is positively related to VMT. It is statistically significant. This means that the higher the percentage of single-family homes in a zone, the higher the VMT. Further, zones that are located on a freeway are positively related to VMT. This dummy variable is statistically significant. Finally, VMT variable is affected by other demographic factors such as the percentage of Saudi and non-Saudi residents in the zone. The two variables are statistically significant at the 0.05 level of the one-tailed $t$-test. It indicates that Saudi residents drive more than non-Saudis. In the density model, land use factors such as total area of commercial and governmental activities are positively related to density. The two variables are statistically significant. Of importance is the positive effect of building age on density. The results show that 
TABLE XIV

RESULTS OF AR-RIYADH ZONES MODEL

\begin{tabular}{|c|c|c|c|c|c|c|}
\hline \multirow[b]{2}{*}{ Variable } & \multirow[b]{2}{*}{ coeff. } & \multirow{2}{*}{$\frac{\text { VMT Model }}{\text { T-Score }}$} & \multirow{2}{*}{ Elas. } & \multirow[b]{2}{*}{ coeff. } & \multicolumn{2}{|c|}{ Density Model } \\
\hline & & & & & T-Score & Elas. \\
\hline VMT & & & & 0.01 & 0.99 & 2.41 \\
\hline VMT square & & & & $-6 E-07$ & -1.0 & -0.95 \\
\hline Density & -119.9 & $-2 \cdot 2^{+}$ & -0.53 & & & \\
\hline $\begin{array}{l}\text { Density Sq. } \\
\text { Land Use }\end{array}$ & 0.77 & $1.07^{\star}$ & 0.24 & & & \\
\hline Dev. Timing & & & & 3.6 & $1.5^{\star}$ & 1.0 \\
\hline Comm Area & & & & 30.3 & $2.1^{+}$ & 0.18 \\
\hline Govt Area & & & & 44.2 & $4.1^{++}$ & 0.34 \\
\hline $\begin{array}{l}\text { Dev. Mix } \\
\text { Economic }\end{array}$ & 68 & $5.2^{++}$ & 0.53 & & & \\
\hline $\begin{array}{l}\text { HiIncome } \\
\text { Demographic }\end{array}$ & & & & -20.1 & $-1.72^{\star}$ & -0.12 \\
\hline $\mathrm{HH}$ size & & & & -2.74 & -0.6 & -0.69 \\
\hline Hisaudi & 504.3 & $2.44^{+}$ & 0.06 & & & \\
\hline $\begin{array}{l}\text { Hinon-Saudi } \\
\text { Transport }\end{array}$ & -1092 & $-1.56^{\star}$ & -0.05 & & & \\
\hline Freeway & 1540 & $2.9^{++}$ & 0.17 & & & \\
\hline Constant & 1506 & $4.7^{++}$ & 0.59 & -13.3 & -0.9 & 1.17 \\
\hline Model $\mathrm{R}^{2}$ & & 0.34 & & & 0.22 & \\
\hline s.E. Est. & & 1682.7 & & & 11.38 & \\
\hline Sample size & & 130 & & & 130 & \\
\hline system $R^{2}$ & & & & & & \\
\hline
\end{tabular}

* Significant at 0.05 level (one-tailed)

+ significant at the 0.05 level (two-tailed)

++ significant at the 0.01 level (two-tailed) 
age of development positively affects zonal density. This relationship is statistically significant at the 0.05 level of the one-tailed t-test. Older zones of the city are more dense than newer zones. Finally, the dummy variable that represents high-income zones is negative and statistically significant at the 0.05 level of the one-tailed $t$-test. The elasticity at the means of the study variables provides a comparative analysis of the effects of the study variables on density and VMT. In the VMT model, VMT variable is highly responsive to changes in density, development mix, and the presence of saudi residents in the zone. This result shows the continuous domination of density effect on VMT, similar to all of the previous models. On the other hand, density is only responsive to changes in land use, income, and household size variables. Land use factors include development timing and the total acreage of commercial and governmental facilities. Changes in VMT do not strongly affect density. The sensitivity analysis shows the strength of the density effect on VMT, while density is affected by other important land use and demographic variables.

The system of simultaneous equations is statistically significant at the 0.01 level of the two-tailed test. System $\mathrm{R}^{2}$ is 0.48 . This means that the model equations together explain 48 percent of the variability in the two dependent variables, VMT and density, taken jointly. $\mathrm{R}^{2}$ for 
VMT model is quite low, 0.34 , while $R^{2}$ in density model, 0.22 , is very low, even though the model has some significant variables. This is due, in part, to the exclusion of some important variables from the analysis because of data limitations.

The major findings of this analysis are not consistent with the findings of the two previous analyses in which density and VMT are simultaneously related. The model shows that only density affects VMT. Similar to the Portland model, development timing may have played an important role in explaining variations between zones with respect to density and VMT. The analysis suggests that other land use and demographic variables would explain density and VMT better than the simultaneous relationship between them.

THE RELATIONSHIP BETWEEN DENSITY AND VMT AND THE EFFECTS OF OTHER FACTORS AT THE HOUSEHOLD LEVEL

At this level of disaggregation, the relationship between density and VMT and the effects of other contributors are examined. The household level analysis includes three models, New York, Snowbelt, and Sunbelt. The last two models incorporate several sub-models for individual cities. The 3SLS technique is also used for this analysis. The exogenous variables were selected from the four major categories: land use, economic, demographic, and transportation provision. The variables used in these 
models are defined in Table IV, Chapter III. See Appendix B for summary statistics on these variables. The next three sections present the results of the three major household models: New York, Snowbelt cities, and Sunbelt cities.

\section{Results For New York Model}

Density and VMT equations were estimated jointly. The results of these equations are presented in Table XV. The estimated T-scores for density and VMT coefficients are statistically significant at the 0.01 level of the twotailed t-tests, except VMT square. VMT square variable is statistically significant at the 0.05 level of the onetailed t-test. The results show that density and VMT mutually affect each other at the household level, controlling for other explanatory factors. Gross population density of the household zip code area and the household vehicle miles have a negative, nonlinear, and bi-directional relationship. This relationship is slightly stronger in the direction where VMT affects density.

Further, some of the variables included in the system of equations are statistically significant and contribute to the density-VMT simultaneous relationship. In the VMT model, household vehicle ownership, household lifecycle, and proximity of household residence to a transit station were important determinants of household VMT. Vehicle ownership at the household level positively affects household travel behavior and trip-making. Further, the results show 
TABLE XV

RESULTS OF THE HOUSEHOLD MODEL FOR METROPOLITAN NEW YORK

\begin{tabular}{|c|c|c|c|c|}
\hline \multirow[b]{2}{*}{ Variable } & \multicolumn{2}{|c|}{ VMT Model } & \multicolumn{2}{|c|}{ Density Model } \\
\hline & \multicolumn{2}{|l|}{ Coefficient } & Coefficient & T-score \\
\hline VMT & & & $-9 E-05$ & $-4 \cdot 1^{++}$ \\
\hline VMT square & & & $4 \mathrm{E}-10$ & $1.45^{*}$ \\
\hline Density & -10787 & $-16 \cdot 6^{+t}$ & & \\
\hline Density square & 86.9 & $12.5^{++}$ & & \\
\hline Land Use & & & & \\
\hline city & 1262 & 0.9 & & \\
\hline Household & & & . & \\
\hline Vehicles & 4609 & $13 \cdot 3^{++}$ & & \\
\hline Workers & & & -0.05 & -0.5 \\
\hline HH size & & & -0.06 & $-2 \cdot 5^{+t}$ \\
\hline $\mathrm{HH}$ Lifecycle & -2385 & $-3.0^{++}$ & & \\
\hline Age & & & & \\
\hline Education & & & -0.01 & -0.8 \\
\hline Transport & & & & \\
\hline & -3432 & $-3 \cdot 2^{++}$ & & \\
\hline Constant & 34490 & $20^{++}$ & 4.5 & $69^{t+}$ \\
\hline Model $\mathrm{R}^{2}$ & & 0.40 & & 0.26 \\
\hline S.E. Est. & & 12740 & & 2.06 \\
\hline Sample size & & 1868 & & 1868 \\
\hline system $R^{2}$ & & & & \\
\hline
\end{tabular}

* Significant at 0.05 level (one-tailed)

+ significant at the 0.05 level (two-tailed)

++ significant at the 0.01 level (two-tailed) 
that households that have children drive less than childless households. Finally, proximity to a transit station affects household VMT, while household location with respect to the central city does not significantly affect VMT.

In the density model, only household size is statistically significant in explaining density. Household size is negatively related to density. Other factors such as the number of workers in the household and the educational level of household head are not statistically significant.

Analysis of the models' elasticity at the means provides a good base for comparison (see Table XX). In the VMT model, VMT variable is highly responsive to changes in density and vehicle ownership variables. Changes in the rest of variables do not strongly affect VMT. Similarly, VMT variables are much more effective in altering density patterns than other variables of household characteristics. The system of simultaneous equations is statistically significant at the 0.01 percent level of the two-tailed test. System $\mathrm{R}^{2}$ is quite high, 0.69, while $\mathrm{R}^{2}$ for VMT and density models are 0.40 and 0.26 , respectively. The explanatory power of the two models is low. These results suggests that demographic variables are not sufficient to explain most of the variations in density and VMT at the household level.

The utilization of household data for Metropolitan New 
York provides a valuable contribution to the research objectives. The results of the model confirm the strength of the simultaneous relationship between density and VMT. Previous regional and zonal models have reached similar conclusions. Further, other household characteristics were important determinants of density and VMT. These variables may only be appropriate at this level of analysis due to aggregation problems.

\section{Results For Snowbelt Cities Model}

At this disaggregate level, density and VMT equations were estimated jointly. The results are presented in Table XVI. The t-scores for all density and VMT coefficients are statistically significant at the 0.01 level of the twotailed t-tests. Gross population density of the household zip code area and household VMT have a negative, nonlinear, and bi-directional relationship. This indicates that density and VMT have a mutual effect at the household level.

Most of the exogenous variables included in the model are statistically significant contributors to the densityVMT simultaneous relationship. In the VMT model, household vehicle ownership, age of household head, and proximity of household residence to a transit station were important determinants of household VMT. Age of household head is negatively related to household VMT. Households with children drive more than childless households, but the relationship is not statistically significant. In addition, 
TABLE XVI

RESULTS OF THE HOUSEHOLD MODEL FOR SNOWBELT CITIES

\begin{tabular}{|c|c|c|c|c|}
\hline \multirow[b]{2}{*}{ Variable } & \multicolumn{2}{|c|}{ VMT Model } & \multicolumn{2}{|c|}{ Density Model } \\
\hline & Coefficient & T-Score & Coefficient & T-Score \\
\hline VMT & & & $-8 E-05$ & $-10^{++}$ \\
\hline VMT square & & & $6 E-10$ & $7.5^{++}$ \\
\hline Density & -39218 & $-8 \cdot 2^{++}$ & & \\
\hline Density square & 528.1 & $6.9^{++}$ & 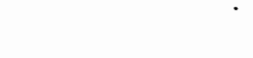 & \\
\hline Land Use & & & & \\
\hline city & -1508 & $-1.16^{*}$ & & \\
\hline Household & & & & \\
\hline Vehicles & 4599 & $6.3^{++}$ & & \\
\hline Workers & & & 0.08 & $1.5^{\star}$ \\
\hline HH size & & & -0.02 & -0.64 \\
\hline HH Lifecycle & 574.8 & 0.5 & & \\
\hline Age & -236.6 & $-5.4^{++}$ & & \\
\hline Education & & & 0.001 & 0.17 \\
\hline Transport & & & & \\
\hline D-Transit & -4123 & $-2.85^{+t}$ & & \\
\hline D-BOSTON & & & 0.59 & $3.1^{++}$ \\
\hline D-CHICAGO & & & 1.14 & $8.4^{++}$ \\
\hline Congtant & 90202 & $9.3^{++}$ & 2.9 & $25^{++}$ \\
\hline Model $\mathrm{R}^{2}$ & & 0.30 & & 0.26 \\
\hline S.E. Est. & & 33570 & & 1.74 \\
\hline Sample size & & 931 & & 931 \\
\hline system $\mathrm{R}^{2}$ & & & & \\
\hline
\end{tabular}

* Significant at 0.05 level (one-tailed)

+ Significant at the 0.05 level (two-tailed)

++ significant at the 0.01 level (two-tailed) 
households that live in central cities drive less than their suburban counterparts. This variable is statistically significant at the 0.05 level of the one-tailed t-tests. In the density model, only the two dummies that represent Chicago and Boston and the number of workers in the household are statistically significant. The three variables are positively related to density. For the two cities, gross densities are higher than gross density in Detroit. Other factors, such as household size and the educational level of household head, are not statistically significant.

Then, two sub-models were constructed for Chicago and Boston to check for variations from the original model. The results are presented in Appendix C. Chicago model results show that density and VMT mutually affect each other, controlling for other exogenous variables. The relationship is statistically significant as in the combined model of Snowbelt cities. The rest of exogenous variables behave similarly with respect to VMT and density except household size. Household size is negatively related to density and significant at the 0.05 level of the one-tailed t-test.

Similarly, the Boston model results show that density and VMT are simultaneously related, but their square variables are weakly significant. The rest of variables' effects are similar to the Chicago model, except for the education variable. The educational level of household head 
is negatively related to density. It is statistically significant. Both models confirm the results of the combined Snowbelt cities model.

The analysis of elasticity at the means for the Snowbelt model strongly confirms the conclusions of the New York model (see Table XVII). In the VMT model, VMT continue to show a strong response to changes in density variables followed by vehicle ownership variable. Changes in the other variables are not strong enough to alter VMT significantly. Similarly, VMT variables are much more effective in altering density patterns than other variables of household characteristics.

Further comparisons between the snowbelt cities model and the two models of Chicago and Boston are presented in Table XVII. It shows that, in the three models, significant variables behave similarly. These variables maintained similar directions of influence but with variable strengths. For instance, the simultaneous relationship is the strongest in the Snowbelt cities model, while vehicle ownership is stronger in the individual city models than the combined model. Weakly significant or insignificant variables did not change across models. These observations suggest the strong influence of these factors in Chicago and Boston over the combined snowbelt model.

The system of simultaneous equations of the Snowbelt model is statistically significant at the 0.01 percent level 
of the two-tailed t-test. System $R^{2}$ is quite high, 0.62 , while $\mathrm{R}^{2}$ for the VMT model, 0.30 , and the density model, 0.26 , are relatively low. Given the variability of cases used in this model in terms of spatial location and data limitations, the explanatory power of the two models could be improved considerably with more diverse data covering a wide range of attributes.

TABLE XVII

ELASTICITIES OF THE HOUSEHOLD MODELS FOR SNOWBELT CITIES

\begin{tabular}{|c|c|c|c|c|c|c|}
\hline \multirow[b]{2}{*}{ variable } & \multicolumn{3}{|c|}{ VMT Model } & \multicolumn{3}{|c|}{ Density Model } \\
\hline & $\begin{array}{l}\text { snowbelt } \\
\text { cities }\end{array}$ & Chicago & Boston & $\begin{array}{l}\text { snowbelt } \\
\text { cities }\end{array}$ & Chicago & Boston \\
\hline VMT & & & & -0.9 & -0.66 & -0.37 \\
\hline $\begin{array}{l}\text { Density } \\
\text { Land Use }\end{array}$ & -1.6 & -1.3 & -0.60 & & & \\
\hline city & -0.02 & -0.05 & $0.01^{*}$ & & & \\
\hline Household & & & & & & \\
\hline Vehicles & 0.35 & 0.41 & 0.76 & & & \\
\hline Workers & & & & 0.07 & $-0.07^{\star}$ & $0.01^{\star}$ \\
\hline нн size & & & & $-0.03^{\star}$ & -0.10 & $-0.06^{\star}$ \\
\hline $\begin{array}{l}\mathrm{HH} \\
\text { Lifecycle }\end{array}$ & $0.01^{*}$ & $0.04^{*}$ & $-0.04^{\star}$ & & & \\
\hline Age & -0.37 & -0.20 & -0.53 & & & \\
\hline $\begin{array}{l}\text { Education } \\
\text { Transport }\end{array}$ & & & & $0.01^{*}$ & $-0.02^{\star}$ & -0.24 \\
\hline D-Transit & -0.12 & -0.09 & -0.11 & & & \\
\hline
\end{tabular}

* Not significant 
The Snowbelt model provides more in-depth analysis and comparison of variations in density and VMT at the household level. The results of this analysis confirm the strength of the simultaneous relationship between density and VMT. Previous regional, zonal, and household models have reached similar conclusions. Further, these results show that other household characteristics, such as vehicle ownership and household demographics, are also important in explaining VMT and density.

\section{Results For Sunbelt Cities Model}

At this disaggregate level, density and VMT equations were estimated jointly. The results of these equations are presented in Table XVIII. The estimated t-scores for density and VMT coefficients are statistically significant at the 0.01 level of the two-tailed t-tests. Gross population density of the household zip code area and household VMT have a negative, nonlinear, and bi-directional relationship. This indicates that density and VMT have a strong mutual effect at the household level.

Further, most of the exogenous variables in the model are statistically significant contributors to the densityVMT relationship. In the VMT model, household vehicle ownership, age of household head, and proximity of household residence to a transit station were important determinants of household VMT. As in the New York model, households with children drive less than childless households, but the 
TABLE XVIII

RESULTS OF THE HOUSEHOLD MODEL FOR SUNBELT CITIES

\begin{tabular}{|c|c|c|c|c|}
\hline \multirow[b]{2}{*}{ Variable } & \multicolumn{2}{|c|}{ VMT Model } & \multicolumn{2}{|c|}{ Density Model } \\
\hline & coefficient & T-Score & coefficient & T-Score \\
\hline VMT & & & $-3 E-05$ & $-4.97^{++}$ \\
\hline VMT square & & & $3 E-11$ & $3 \cdot 3^{+t}$ \\
\hline Density & -17098 & $-4.1^{++}$ & & \\
\hline Density square & 196.5 & $2.8^{++}$ & & \\
\hline Land Use & & & & \\
\hline city & -1008 & $-1.35^{\star}$ & & \\
\hline Household & & & & \\
\hline Vehicles & 9207 & $19.2^{++}$ & & \\
\hline Workers & & & 0.02 & 0.64 \\
\hline HH size & & & -0.06 & $-4.4^{++}$ \\
\hline HH Iifecycle & -1133 & -1.4 & & \\
\hline Age & -148 & $-4 \cdot 7^{++}$ & & \\
\hline Education & & & -0.02 & $-6.0^{++}$ \\
\hline Transport & & & & \\
\hline D-Transit & -1500 & $-3 \cdot 3^{++}$ & & \\
\hline D-HOUSTON & & & -0.26 & $-2.1^{+}$ \\
\hline D-LOS ANGELES & & & 0.60 & $7.7^{++}$ \\
\hline Constant & 38651 & $5.1^{t+}$ & 2.7 & $34^{++}$ \\
\hline Model $\mathrm{R}^{2}$ & & 0.50 & & 0.39 \\
\hline S.E. Est. & & 34784 & & 1.37 \\
\hline Sample size & & 1531 & & 1531 \\
\hline system $R^{2}$ & & & & \\
\hline
\end{tabular}

* Significant at 0.05 level (one-tailed)

+ significant at the 0.05 level (two-tailed)

++ Significant at the 0.01 level (two-tailed) 
relationship is not statistically significant. In addition, households that live in central cities drive less than their suburban counterparts. This variable is statistically significant at the 0.05 level of the one-tailed t-test.

In the density model, most of the exogenous variables are statistically significant. Household size and education of household head are negatively related to density. City comparisons show that gross density in Houston is lower, while gross density in Los Angeles is higher than those of reference cities. The reference cities include San Francisco, Denver, and Portland. The number of workers variable continues to show a positive sign, but it is not statistically significant.

The two models for Los Angeles and Houston were constructed like those for snowbelt cities. The results are presented in Appendix C. The Los Angeles model results show that density and VMT mutually affect each other, controlling for other exogenous variables. The relationship is statistically significant in the direction where VMT affects density. The other direction of the relationship is statistically weak, even though it has the expected signs. Similar results are found in the Houston model. Density may not be a strong determinant of household VMT. Other factors such as vehicle ownership and age of household head better explain VMT. In the density model, household size and education level of household head continue to be the second 
important determinants of density. The rest of the exogenous variables behave similarly with respect to VMT and density, but they are not statistically significant. With respect to density effect on VMT, both models do not confirm the results of the selected sunbelt cities model.

The analysis of elasticity at the means of Sunbelt cities strongly confirms the conclusions of the other household models (see Table XIX). In the VMT model, VMT continue to show a strong response to changes in density variables, followed by vehicle ownership variable and then age of household head. Changes in the other variables are not strong enough to alter VMT significantly. Similarly, VMT variables are much more effective in altering density patterns than other variables of household characteristics. Further examination of the differences in elasticities between the Sunbelt cities, Los Angeles, and Houston models is presented in Table XIX. The table shows that VMT is. better explained in the combined sumbelt model than the two individual city models. The simultaneous relationship is strong in the combined sunbelt cities model compared to the individual city models. Generally, the three models are comparable in showing the importance of vehicle ownership effect on VMT and of VMT and household head education on density. Meanwhile, the Los Angeles model is more comparable to the combined model than to the Houston model. This may have resulted from the size and influence of Los 
TABLE XIX

ELASTICITIES OF THE HOUSEHOLD MODELS FOR SUNBELT CITIES

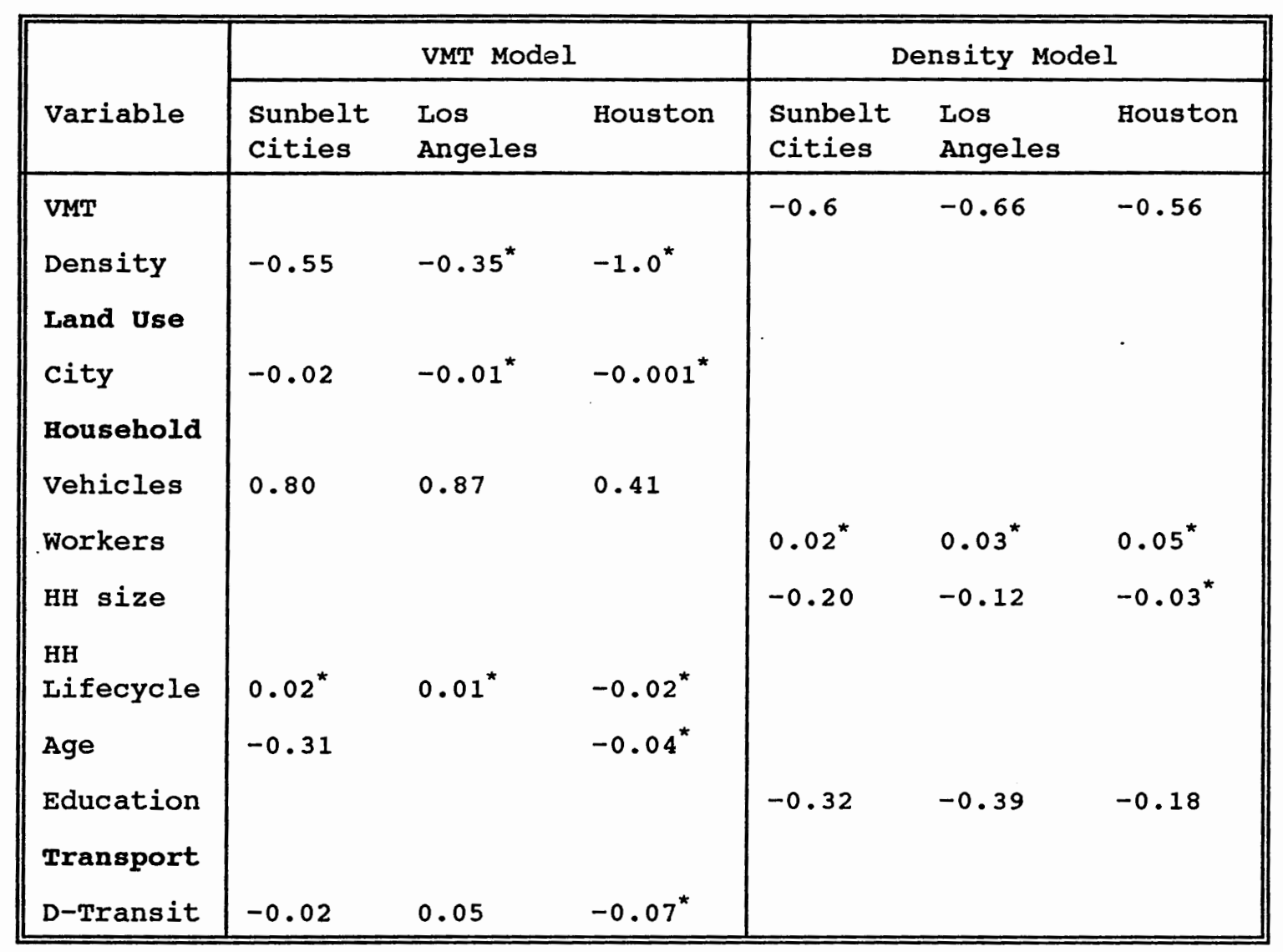

* Not significant

Angeles cases. Los Angeles is a large city with nearly half of the Sunbelt model case studies.

The system of simultaneous equations in the combined Sunbelt model is statistically significant at the 0.01 percent level of the two-tailed test. System $R^{2}$ is quite high, 0.73, while $\mathrm{R}^{2}$ for VMT and density models are reasonably high, 0.50 and 0.39 respectively. The explanatory power of this model in much better than the previous household models. The exogenous variables, 
especially demographic variables, are good determinants of density and VMT compared to other models.

The results of the selected sunbelt cities confirm the strength of the simultaneous relationship between density and VMT. This is consistent with the results of the previous household models. Further, other household characteristics such as vehicle ownership and household demographics were also important in explaining VMT and density.

Portland Zonal and Household Models

A model for Portland households is constructed for the purpose of comparison with the zonal model. The model results are presented in Appendix $C$. The results show a strong, simultaneous relationship between density and VMT, much stronger than the results of the zonal model. In the household model, household demographics such as vehicle ownership, household head age and education, and household size and lifecycle are statistically significant determinants of density and VMT. Other important variables for VMT include household location and proximity to a transit station. With respect to household size, and lifestyle, these results partially confirm the zonal level results.

The zonal and household models are comparable in that they show a strong, simultaneous relationship between density and VMT. Further, the two Metropolitan Portland 
models complement each other. The zonal model emphasis on land use factors is matched by the emphasis of the household model on household demographics. Both factors are important determinants of variations in density and VMT. The two levels of analysis suggest that land use, economic, and demographic factors are important contributors to the simultaneous relationship between density and VMT.

\section{Summary}

The three household models and their sub-models are mainly consistent in their findings. Table XX shows the importance of the simultaneous relationship between gross density and household VMT. A negative, nonlinear relationship exists between the two variables. This relationship is much stronger in explaining variations in density and VMT than other exogenous variables. The simultaneous relationship is the strongest in the snowbelt model and weakest in the sunbelt model. The weak effect of density on VMT is apparent in the automobile-dominated cities of the Sunbelt such as Los Angeles and Houston. Household VMT is apparently driven by important factors other than population density. Meanwhile, VMT show a strong influence on density in the snowbelt and sunbelt cities. This suggests profound impacts of automobile travel and increased mobility on development patterns in these cities.

The three models also incorporate some significant household characteristics that help explain changes in VMT 
TABLE XX

ELASTICITIES OF THE THREE HOUSEHOLD MODELS

\begin{tabular}{|c|c|c|c|c|c|c|}
\hline \multirow[b]{2}{*}{ Variable } & \multicolumn{3}{|c|}{ VMT Model } & \multicolumn{3}{|c|}{ Density Model } \\
\hline & $\begin{array}{l}\text { New } \\
\text { York }\end{array}$ & $\begin{array}{l}\text { snowbelt } \\
\text { cities }\end{array}$ & $\begin{array}{l}\text { Sunbelt } \\
\text { Cities }\end{array}$ & $\begin{array}{l}\text { New } \\
\text { York }\end{array}$ & $\begin{array}{l}\text { snowbelt } \\
\text { cities }\end{array}$ & $\begin{array}{l}\text { Sunbelt } \\
\text { cities }\end{array}$ \\
\hline VMT & & & & -0.3 & -0.9 & -0.6 \\
\hline $\begin{array}{l}\text { Density } \\
\text { Land Use }\end{array}$ & -2.2 & -1.6 & -0.55 & & & \\
\hline $\begin{array}{l}\text { city } \\
\text { Household }\end{array}$ & $0.01^{\star}$ & -0.02 & -0.02 & & & \\
\hline Vehicles & 0.4 & 0.35 & 0.80 & & & \\
\hline Workers & & & & $-0.01^{\star}$ & 0.07 & $0.02^{\star}$ \\
\hline нН size & & & & -0.04 & $-0.03^{\star}$ & -0.20 \\
\hline $\begin{array}{l}\text { HH } \\
\text { Lifecycle }\end{array}$ & -0.04 & $0.01^{*}$ & $0.02^{*}$ & & & \\
\hline Age & & -0.37 & -0.31 & & & \\
\hline $\begin{array}{l}\text { Education } \\
\text { Transport }\end{array}$ & & & & $-0.03^{\star}$ & $0.01^{\star}$ & -0.32 \\
\hline D-Transit & -0.07 & -0.12 & -0.02 & & & \\
\hline
\end{tabular}

* Not Significant

and density. Household vehicle ownership positively affects VMT. On the other hand, household location within the central city and in close proximity to a transit station negatively affects household VMT. Households are more inclined to use transit and reduce their VMT if they are located close to the transit stations that are mainly available in central cities. Other household factors modestly affect density and VMT with no general agreement between the three models. Of significance, age of household 
head and household size tend to negatively affect VMT and density, respectively. The rest of household characteristics are not significantly present in these models.

These elasticities confirm the conclusions of the regional and zonal models. They show the strength and importance of the density-automobile dependence simultaneous relationship. Further, household models show that household characteristics should not be overshadowed by other land use and economic factors. They are essential determinants of variations in density and automobile dependence.

\section{OPTIMAI DENSITY ANALYSIS}

The strong relationship between density and VMT in the previous models induces further investigation of the question of optimal population density. With respect to VMT, optimal density of a city means that per capita VMT would be the least if the city reaches that density level. For a given mobility level of city residents, the optimal density can be calculated using the below formula:

$\mathrm{VMT}=-\mathrm{B}_{1} \mathrm{D}+\mathrm{B}_{2} \mathrm{D}^{2}$

$\partial \mathrm{VMT} / \mathrm{D}=-\mathrm{B}_{1}+2 \mathrm{~B}_{2} \mathrm{~d}=0$

Optimal Density $(d)=B_{1} / 2 * B_{2}$

Where:

d is optimal population density, gross or net;

$\mathbf{B}_{\mathbf{1}}$ is density variable coefficient; and 
$\mathbf{B}_{2}$ is density square variable coefficient.

Results of optimal density estimations of all of the study models are presented in Table XXI. In the regional model, the optimal net population density is estimated to be 33.7 persons per acre. Its mean net density equals 16.4 persons per acre, nearly one half of the estimated optimal density. Newman and Kenworthy find that automobile use declines swiftly where densities exceed 12 to 16 persons per acre, far less than the optimal density estimated in this study. This study emphasizes the optimal density where VMT would be the least, compared to the Newman and Kenworthy scale of efficient density. For 1980 data, optimal density is estimated to be 31.8 persons per acre, near the estimated level of the pooled regional model. The average density for 1980 is 17.2 persons per acre, about two-thirds the estimated optimal density for 1980 data. With respect to time, this may suggest a tendency for urban densities to rise and become closer to the estimated optimal density. Further, the optimal gross density for Metropolitan Portland zones is found to be 19.1 persons per acre. The mean gross density equals 5.5 persons per acre, far short of the optimal level. Considering the differences in density measurement, this estimate is near the regional model estimates. Density in the regional model is measured in terms of net density rather than gross density. However, optimal gross density for Portland zones may not be as 
TABLE XXI

ESTIMATIONS OF OPTIMAL DENSITIES FOR THE STUDY MODELS

\begin{tabular}{|c|c|c|c|}
\hline Level of Analysis & Case study & $\begin{array}{l}\text { Optimal } \\
\text { Density }\end{array}$ & $\begin{array}{l}\text { Mean } \\
\text { Density }\end{array}$ \\
\hline Urban Region & $\begin{array}{l}\text { Overall (Net) } \\
1980 \text { (Net) }\end{array}$ & $\begin{array}{l}33.7 \\
31.8\end{array}$ & $\begin{array}{l}16.4 \\
17.2\end{array}$ \\
\hline Zonal & $\begin{array}{l}\text { Portland (Gross) } \\
\text { Ar-Riyadh (Net) }\end{array}$ & $\begin{array}{l}19.1 \\
77.9\end{array}$ & $\begin{array}{l}5.5 \\
23.5\end{array}$ \\
\hline Household Zip Code & $\begin{array}{l}\text { New York (Gross) } \\
\text { Snowbelt (Gross) } \\
\text { Chicago (Gross) } \\
\text { Sunbelt (Gross) } \\
\text { Los Angeles } \\
\text { (Gross) }\end{array}$ & $\begin{array}{l}62.1 \\
37.1 \\
37.1 \\
43.5 \\
60.1^{\star}\end{array}$ & $\begin{array}{l}16.5 \\
7.8 \\
11.9 \\
5.1 \\
8.3\end{array}$ \\
\hline
\end{tabular}

* Not significant

1 Mean density of research case studies

source: author's calculations

consistent as the regional estimates due to the statistical weakness of the density variable.

In Ar-Riyadh model, the optimal density is estimated to equal 77.9 persons per acre. The mean net density equals 23.5 persons per acre, less than one third the optimal level. When compared with regional data estimation, the optimal net density for Ar-Riyadh zones is higher than the 33.7 figure estimated in the regional analysis. However, caution should be used when comparing the two models, due to statistical and practical differences. The relationship 
between density and VMT in the Ar-Riyadh model is not as strong as in the regional model. Further, a variety of cultural and social differences between Ar-Riyadh and the selected sample of cities do exist, and these may make comparison inappropriate.

Given the significant relationship between density and VMT in all of the major household models, it would be meaningful to calculate their optimal gross density. For Metropolitan New York, the optimal gross density is estimated to be 62.1 persons per acre, while the mean gross density of zip code areas is 16.5 persons per acre. In the Snowbelt model, the results show that optimal gross density equals 37.1 persons per acre, far lower than the New York figure. The mean gross density for snowbelt cities equals 7.8 persons per acre, nearly five times less than the optimal level. Finally, the optimal gross density for Sunbelt cities equals 43.5 persons per acre, which is lower than the New York figure but higher than the snowbelt cities figure. The mean gross density for sunbelt cities is 5.1 persons per acre. Household VMT would be the least if the gross density of sunbelt cities increases by eight times the existing level.

When compared with optimal density estimates at the regional and zonal levels, the optimal densities for household models are much higher. These disparities may be in part due to differences in variables' definitions. 
Density and VMT are defined differently in the household and other regional and zonal models. Therefore, a comparison between household models' results of optimal density and other models' results may not be valid or valuable.

The optimal density analysis reveals a tendency of existing average densities of case studies to be far less than their estimated optimal densities. These estimates fall well beyond the significance range of the research data. However, some cities or zones within the study have densities that are near the optimal level. For these cases, VMT would be the least and increases in density would result in increases in VMT. Beyond or below these levels, VMT would be higher than the optimal level. This type of analysis is important for policy implications, but it should be interpreted cautiously.

\section{CONCLUSIONS}

The results of the models at the three levels of analysis confirm most of the study hypotheses. With respect to the strength and direction of the relationship between density and automobile dependence measured in VMT, most of the models constructed affirm the existence of a simultaneous relationship between density and VMT. These models show that, controlling for other extraneous variables, density and VMT have a negative, nonlinear relationship. This is true for all levels of analysis, 
except the Ar-Riyadh model. The density-VMT relationship is stronger in the regional and the household models than the zonal models. This may have resulted from the inclusion of development timing variables in the zonal models. Timing of development could affect both travel behavior and density patterns. Further, the analysis of the study models shows that the simultaneous effect is the most important in explaining both density and VMT.

Another conclusion is that other land use, economic, demographic or household, and transportation variables are also important determinants of density and VMT. The diversity of model construction in terms of levels of analysis has enriched the study and allowed for the inclusion of several important variables that are unique or most efficient at a certain level. For instance, density and VMT are strongly affected by land use factors at the aggregate (regional and zonal) level and demographic factors at the disaggregate (household) level. Economic and transportation factors are also important determinants of density and VMT at the three levels of analysis.

Finally, the complex relationship between density and VMT examined in this study warrants the use of rigorous analysis. Previous analyses of this relationship have employed simple statistical techniques such as correlation and regression analyses that may not reflect the true nature of this relationship. Three-stage least square models are 
more efficient in accounting for this relationship compared with other techniques. This model acknowledges the simultaneous relationship between density and VMT, while controlling for the effect of other variables simultaneously. 
CHAPTER VI

RESEARCH FINDINGS

Described in the previous chapter, the analytical analysis has examined the simultaneous relationship between density and automobile dependence and how other important factors have contributed to our understanding of these two particular factors. This chapter reviews the major research findings. It discusses the results of the models in the area of the simultaneous relationship and then the effects of other factors on density and automobile dependence. The chapter concludes with a summary of the principal findings of the research.

DENSITY AND AUTOMOBIIE DEPENDENCE RELATIONSHIP

The empirical findings of this research at the different levels of analysis are consistent. With the exception of Ar-Riyadh, these results substantiate the existence of a simultaneous relationship between density and automobile dependence. The statistical analysis supports the well-acknowledged notion that density and VMT negatively affect each other.

However, the magnitude of the density-VMT simultaneous effect varies across models. The elasticities tables (presented in Chapter $V$ ) show variable effects of density on 
VMT and vice versa. First, with respect to their effects on VMT, density variables have different elasticities at the means ranging between -0.3 and -2.2 . Net density models, regional and Ar-Riyadh, have elasticities of -0.4 and -0.3 , respectively. This means doubling the existing zone and city densities would reduce the zone and city VMT per capita by 30 to 40 percent. This is near Holtzclaw's suggested estimate of 25 to 30 percent reduction in VMT as a result of doubling density (Nadis and MacKenzie, 1993). The estimated optimal city density in the regional model is nearly double the case studies average. This means that increasing the average density to the optimal level would reduce VMT per capita by 40 percent. This significant reduction in VMT exemplifies the importance of density effect at both the zonal and the city level.

Further, gross density models, Portland and the three household models, have elasticities for density variables between -0.6 and average of -1.2 . In Portland and the other U.S. sample of cities, increasing the zonal gross density by 10 percent would reduce per capita and household VMT by 6 and 12 percent, respectively. Strong density effect on VMT is apparent in New York and other Snowbelt cities.

Second, VMT have strong impact on density, both net and gross. At the regional level, the point elasticity of density variable is -2.0 . This means a 10 percent reduction in VMT per capita in the city would increase net density by 
20 percent. This is comparable to the estimated 4 percent reduction in VMT that would result from increasing an average density by 10 percent. Other models of gross zonal density show smaller elasticities than the rest. They range from -0.3 to -0.9 . This means densities of these cases would be reduced by 3 to 9 percent if VMT increases by 10 percent.

What these models have shown is that a sizable increase in either density or VMT would certainly have a strong impact on the other. This strong mutual impact is attributed to several important causes. First, low-density development encourages more automobile driving due to the separation of land uses in low-density areas. The residents of such an area would make more trips for longer trip lengths to reach their work, shopping, and recreational activities as compared to residents of mixed-use development. Exclusive zoning for incompatible uses has contributed to these land use separations. Second, the congestion level in low-density areas is low, thus making automobile driving attractive. In terms of travel time and comfort, other modes of travel would lose much of their attractiveness. Finally, sufficient public transit and nonmotorized travel may not be feasible in low-density areas due to potentially low ridership and longer trip lengths. This in turn would make automobile travel the only available option for these areas residents. 
Meanwhile, increased auto-mobility has been a major force in population and employment decentralization. This process has led to the development of low-density areas outside the urban core. Inaccessible locations were made accessible by the automobile, thus encouraging the development of urban pockets outside the urban edge. These processes are long term and usually take decades to be fully observed. Short term effects of changes in urban mobility are reflected in minor locational and travel behavior adjustments.

This research did not attempt to capture time differences in the effects of density and automobile dependence. It relied on cross-sectional and pooled data that reflect snapshots of development patterns. Dynamic and time series analysis are better equipped to capture these temporal variations.

In summary, the interactive relationship between density and automobile dependence is clearly present in this research. This strong relationship is also supported by other important factors from different urban outlooks. The next section presents the major research findings of the effects of these factors on density and automobile dependence. 
OTHER FACTORS AFFECTING DENSITY AND AUTOMOBILE DEPENDENCE

\section{Land Use Factors}

Land use factors are one of the most important determinants of density and automobile dependence. In terms of employment location and development mix, urban form and development patterns affect the city VMT. The decentralization of employment has increased the city miles of automobile travel. This may have been the result of an imbalance between the number and type of jobs offered and the characteristics of nearby residents. Job-housing imbalance would result in complex commuting patterns that are dominated by a suburban-to-suburban commute. These travel patterns lead to rapid increases in VMT, especially of single occupancy vehicles (Cervero, 1990).

At the zonal level, central city zones with high employment densities have lower VMT than do suburban zones. Residents of central cities and high employment density zones drive less than residents of other zones due to increased congestion, proximity to employment activities and transit services, and parking shortages. On the other hand, zones that have a high percentage of single family homes have higher per capita VMT. These zones tend to be Iow in density with a low degree of development mix of land uses. In these zones, residents need to drive more, in terms of number and length of trips, than mixed-use zones. In zones with high degree of development mix and employment 
concentration, VMT will be considerably lower than VMT in other zones.

Meanwhile, density of the zone is positively related to the age of building stock. Zones with high percentage of new buildings are less dense than old city zones. These inter-zonal variations in density patterns are attributed to several factors that shaped development patterns over time. These factors include increases in automobile use, increases in per capita income, and changes in lifestyles and preferences (Meyer and Gomez-Ibanez, 1981).

\section{Economic Factors}

Several economic factors have strong effects on density and automobile dependence. High auto ownership induces extra trips that may not be made in the case of low level of ownership, especially nonwork-related trips. This study suggests that increasing the existing automobile ownership level in the city by 10 percent would increase VMT per capita by 7 percent. At the household level, this effect would increase household VMT by 3.5 to 8 percent. The latter represents potential increases in Sunbelt cities. This effect is considerably high, especially for those cities with low automobile ownership level(e.g. European and Asian cities). U.S. and Canadian cities are near the saturation level in terms the ratio of vehicles to drivers. Nonetheless, with continuous increases in automobile ownership, considerable increases in VMT will be observed in 
these cities.

On the other hand, increases in gasoline prices have had a negative impact on VMT. Increasing gasoline prices to double the existing level would result in 20 percent reduction in VMT per capita. Because high gasoline prices increase per mile cost of travel, some drivers may change their travel behavior by cutting unnecessary trips, mainly nonwork-related, in the short run, while encouraging locational adjustments in the long run. This has important implications for those who advocate increasing gasoline and automobile ownership taxes to reduce VMT.

Similarly, per capita income is negatively related to density. This study shows that increases in per capita income would lead to a decline in urban densities. Similarly, high income zones tend to be less densely populated than low income zones. Increases in per capita income would make single family.homes in mainly suburban locations affordable. In most developed nations, increases in disposable income encourage low density development on the city fringes, a preference that is fueled by the desire for privacy, spacious living, and a better environment.

\section{Demographic Factors}

Density and VMT are also affected by other important demographic factors such as household size and lifestyle. Household size is negatively related to VMT and density. At the zonal level, a 10 percent increase in household size 
would reduce VMT per capita by 3 percent and zonal density by 7 percent. At the household level, smaller declines in density could result from increasing household size. In general, large households prefer low-density living and drive less than smaller households. VMT per capita decreases with increases in household size due to trip efficiencies in terms of trips made for multiple purposes.

In addition, household lifecycle has an important impact on locational decisions and trip making. This study shows that households in the family formation stage prefer low-density areas and those with children drive less than childless households. For instance, in the New York household model, the difference is nearly 2400 miles of annual household VMT. Similarly, the age of household head affects negatively household VMT. This has important implications for U.S. cities. If current travel trends continue in the future, significant reduction in VMT could be observed as the baby boom generation of the Second World War ages.

Finally, a household's locational decisions are also affected by the educational level and the number of workers in the household. Highly educated people prefer low-density living, while dual (or more) workers in the household prefer central, high-density locations for employment proximity.

\section{Transportation Provision Factors}

The last group of factors that significantly affects 
density and automobile dependence is related to transportation provision. This includes transit and highway provision and proximity to these facilities. First, transit provision in the city affects negatively per capita VMT. This effect is not very significant. For each additional one mile of transit service, a reduction of 0.1 mile of per capita VMT will be observed. This means increasing transit service to reduce VMT may not be the optimal solution since it would result in small reductions in VMT.

Second, the provision of highways and the congestion level in the city is closely related to urban density. Congestion is clearly present in high density areas, while extensive road network would decrease density. This study shows that a 10 percent increase in existing city density would increase its congestion level by 4 percent. This means many urban areas may not be able to drastically increase their density levels unless other measures are taken to control traffic congestion.

Finally, proximity to transportation facilities affects locational decisions and travel behavior. Proximity to a transit station reduces household VMT as household members are inclined to use public transit, especially in congested cities. This could amount to a reduction of 1500 to 4100 miles of annual household VMT. Sunbelt cities would endure the least impact of transit proximity. Meanwhile, accessibility to a freeway would encourage more automobile 
driving and would increase VMT per capita in the zone by nearly 1500 miles annually . This has several implications for automobile travel and the siting of transportation facilities such as freeways and transit stations.

\section{CONCLUSIONS}

The primary objective of this study has been to analyze the simultaneous effect of density and automobile dependence. Other research questions were aimed at determining the effects of other factors on density and automobile dependence. In addition to its treatment of the complexity of the research relationships, this research is unique in terms of its inclusion of three levels of analysis. No previous work in the land use and transportation field has attempted to do this. Each level of analysis findings is comparable with previous work in that level.

The principal findings of this research include the following:

1. Density and automobile dependence effects on each other are present in all levels of analysis: regional, zonal, and household.

2. The simultaneous relationship between density and automobile dependence is generally the most important determinant of each factor.

3. Second in importance, density and automobile 
dependence are affected by other land use factors such as city structure, development timing, and degree of development mix.

4. Variations in income, automobile ownership, and other demographic factors are strongly related to variations in density and automobile dependence.

5. At various levels of analysis, some factors become more important than others in explaining density and automobile dependence.

6. The analysis of optimal densities for aggregate models, regional and zonal, shows comparable estimations. They tend to be more than double the existing average density of the study cases.

The empirical findings of this research at the different levels of analysis are consistent with previous empirical work (Newman and kenworthy, 1989b; Keyes, 1982; Pucher, 1988; Webster et al., 1986.). This research has highlighted the complexity of this simultaneous relationship, and recognizes the existence of interactive effects between density and automobile dependence. The strong relationship between density and VMT is also supported by other important factors from different urban outlooks. 


\section{CHAPTER VII}

\section{DISCUSSIONS AND RESEARCH IMPLICATIONS}

This study of the simultaneous relationship between density and automobile dependence and their underlying factors aids our understanding of the interactive nature of such relationships. Existing literature in land use and transportation has acknowledged but never systematically examined these relationships. The findings of this study and of comparable future research in this area will help to fill this gap.

The study approach and analysis has also provided new directions for future research in the land use and transportation interaction field. This study highlights the complexity and the importance of urban development and transportation relationship. This research supports the argument of other research that this relationship is of significant importance in explaining existing and future urban development and travel patterns.

This chapter discusses the generalizability and limitations of this study, goes on to explore some of the relevant theoretical and policy implications of the research findings, and ends with recommendations for further research. 
GENERALIZABILITY OF THE STUDY

As noted in the previous chapter, the study case studies in this research are confined to cities in the developed world. The city of Ar-Riyadh, Saudi Arabia, is only the exception--not for its urban development and economic patterns, but for its cultural and social differences from the rest of the case studies. All of the cases used at the three levels of analysis have highly developed urban development and transportation systems. Therefore, it is safe to say that these results can be transferred to other cities of similar size from the study cases in the developed world, albeit with some modifications. These modifications are necessary to adjust for local differences. These results may not be applicable for the developing world due to the inherent differences between developed and developing countries. However, due to the precedence of developed countries in experiencing the pros and cons of low-density living and increased automobile dependence, developing countries may use these results to guide their future plans in accommodating or restraining automobile use.

\section{RESEARCH LIMITATIONS}

This study was an attempt to overcome some of the research shortcomings of previous work. To examine the density-automobile dependence relationship, the study has 
relied on quantitative analysis and has incorporated different levels of analysis using an advanced statistical technique. The latter constitutes its major strength, while the former results in its major weakness. Locational choices and travel behavior are affected by important social, cultural, and behavioral factors. Variations in culture, lifestyles, and consumer preferences cannot be accounted for using quantitative analysis. More advanced qualitative analysis is needed for future research.

Also, data availability and accuracy can be a concern, given the research reliance on secondary data. They have limited most of the study models to cross-sectional analysis rather than more desirable time-series analysis. Further, some of the cost-related variables were not included in the analysis. Congestion pricing, taxes on automobile ownership, and other taxes related to automobile operating costs are important determinants of variations in modal. split and locational choices.

In terms of data analysis, most statistical techniques, including the 3SLS, cannot isolate causes from effects. Scholars have pinpointed the difficulty of isolating cause from effect, or a consequence as opposed to a byproduct, in the density-automobile dependence relationship (GomezIbanez, 1991; Gordon and Richardson, 1989). Similarly, the changes which density and automobile dependence have on each other may require different timescales in order to be 
reflected in changes in urban development and travel patterns. Cross-sectional data do not show these variations in timescale since they represent only a snapshot of existing conditions. Future advancements in statistical analysis could overcome that.

Finally, the results of the international case studies should be interpreted with caution. International comparison studies are sometimes known to have unwarranted generalizations. This research has partially attempted to avoid that by introducing additional models for comparison at different levels of analysis.

\section{THEORETICAL IMPLICATIONS}

The simultaneous relationship between density and travel patterns has never been clearly examined in small scale, empirical analysis. Most of the existing studies of this relationship have been conducted using one level of analysis for one leg of this relationship. At the city or regional level, in addition to the Newman and Kenworthy study of automobile dependence (1989b), the Pushkarev and Zupan study (1977) compares variations in development patterns in several U.S. cities. The study tests the feasibility of different public transit modes for selected city corridors based on criteria such as downtown size and corridor density.

Meanwhile, at the household level, several small scale 
studies are available mostly to compare variations in household travel behavior (Hensher, 1985; Hensher and Smith, 1990; Strathman and Dueker, 1991; Webster et al., 1986). These studies rely on survey data with no formal modelling of the relationship between urban development and travel behavior. Therefore, no comparable study exists for comparison with this dissertation approach.

The research findings provide a strong support for the interactive theory of density and automobile dependence. At different analysis scales, the research findings have confirmed what many scholars have postulated but never examined. The Newman and Kenworthy (1989a, 1989b, 1992), Keyes (1980), Burright (1985), Gomez-Ibanez (1975), and Harrison (1975) studies of automobile travel have only examined one leg of the simultaneous relationship between urban densities and automobile travel. Some of these studies have reached similar conclusions with respect to density effects on automobile travel; however they did not consider the feedback effect of changes in travel behavior on densities and locational choices. This research fills this theoretical gap in the land use and transportation interaction literature.

Further, in addition to its examination of the simultaneous relationship, this research introduces several measures that would affect the relationship. It includes several land use, economic, demographic, and transportation 
factors. This process proves to be essential since these factors show strong effects on density and automobile dependence.

To guard against generalizations of international comparisons, this study has utilized three levels of analysis; regional, zonal, and household. The first two levels would capture inter- and intra-city variations in development and travel patterns, while the household level deals with variations between individual units. Summing up these individual patterns to represent cities or zones would mask any inherent differences at the disaggregate level. similarly, dealing solely with the individual unit to examine development and travel patterns and devise appropriate policies may be misleading. Aggregate level, city or national, effects are also important determinants of variations between cities or countries. The research findings show the importance of both aggregate and disaggregate effects.

This research reveals both similarities and differences between the three models findings. The models are similar in showing the importance of the density-automobile simultaneous relationship but differ as to the importance of other contributors to variations in urban developments and travel patterns. This indicates the importance of multilevel analysis in complex relationships. Therefore, this research approach and its conclusions would certainly be a 
valuable contribution to the land use and transportation field.

\section{PLANNING AND POLICY IMPLICATIONS}

The finding of a simultaneity effect of density and automobile dependence has significant planning and policy implications. State and local officials and land use and transportation planners are increasingly aware of the importance of these relationships in affecting land use and traffic conditions in the city. Concerns over the immobility of some of segments of the society, the quality of urban life, and the escalating problems associated with automobile dependence, development patterns, and infrastructure costs have induced further examinations of these outcomes. Land use and transportation interaction is certainly an important contributor to these outcomes.

In addition, other contributing factors to changes in density and automobile dependence are also important for planners and policy makers. Whereas some of these factors are not controllable nor affected by public policies, most of them result from a collection of public and private agencies' actions and policies (Pucher, 1988; Newman and Kenworthy, 1989b). These policies include growth and development controls, gasoline prices, capital and operating costs of the automobile, and public provision of transportation facilities. Planners and policy makers could 
have an impact on these policies and in turn affect urban development and travel patterns.

Several scholars have argued for the effectiveness of several policies that deal with transportation and land use problems. One of the most acknowledged policies were suggested by Newman and Kenworthy $(1989 a, 1989 b)$. They argue that physical planning strategies can be a more efficient mean for dealing with the problem of excessive automobile use than economic policies, such as taxing gasoline and vehicles. Specifically, Newman and Kenworthy (1989a: 33) identify several policies to control automobile dependence:

* Increase urban density;

* Strengthen the city center;

* Extend the proportion of the city that has inner-area land use;

* Provide a good transit option; and

* Restrain the provision of automobile infrastructure.

However, Gordon and Richardson (1989) criticized the Newman and Kenworthy policies as being inappropriate and infeasible. They argue that variations in automobile dependence are due to variations in lifestyles and travel behavior, that government intervention would be the problem, and that congestion pricing and market adjustment are more efficient than the Newnan and Kenworthy policies.

The two strategies suggested by those distinguished scholars ignore an important outcome of these policies that relates to urban mobility. They claim these policies would improve urban mobility by restricting automobile use through 
urban design and/or economic pricing. Either strategy implies a drastic change to preferences and lifestyles that is contrary to current trends.

This study suggests a combined strategy consisting of physical planning as well as several economic and transportation policies are needed to address complex land use and transportation problems. This requires devising and implementing a comprehensive set of land use and transportation policies, including physical planning strategies. This approach is essential to deal with the various elements related to land use and urban transportation. Relying solely on physical planning solutions to solve existing land use and transportation problems is too simplistic and can be misleading. Physical planning is a weak process for shaping urban development patterns (Hanson, 1992). The findings of this research findings show that physical planning can be an important strategy if supported by and coordinated with several economic and transportation factors.

Meanwhile, relying on the market to mitigate the negative externalities of urban sprawl and excessive automobile use may be too costly. Decisions about the use of land are made by private owners, developers, and real estate agents who aim to maximize their profits without paying for the costs they impose on the society. Without both physical intervention and price correction, cities will 
continue to become more intolerable.

What this research suggests is that combining several polices should help in reducing the negative externalities of low-density development and automobile dependence. It supports some of the policies suggested by Newman and Kenworthy that relate to increasing population density. However, this density increase should target small and major urban centers rather than areawide increase in density. Areawide density increase would result in hardships to residents and industries by increasing traffic congestion, to local governments by increasing the costs of providing additional infrastructure to the existing stock, and to society by imposing lifestyles that may not be acceptable to the majority of residents (Cervero, 1990). In terms of rapid shifts toward service industry and smaller household size, current economical and demographic trends would make increasing density in selected locations feasible (Van der Ryn and Calthorope, 1986). Variable residential densities could be developed around urban centers to provide multiple residential choices. Further, these centers and sub-centers could be designed to achieve a sizable share of mixeddevelopment in terms of job-housing and shop-housing balance. This would reduce the number of motorized trips generated in the area, shorten trip lengths, and increase ridesharing (Cervero, 1990).

Coupled with physical planning policies, this research 
confirms the importance of other economic policies. Increasing the costs of automobile ownership and travel would have a strong impact on trip making. This could be achieved by imposing taxes on automobile ownership and gasoline prices as suggested by virtue of their significance. However, these policies should incorporate mechanisms to compensate the urban poor without inducing additional travel. Similarly, eliminating public subsidy of low-density development by charging residents their full social costs would encourage compact development (Altshuler, 1979; Pucher, 1988; Downs, 1992). These charges can be levied through property taxes, impact fees, and fuel and congestion fees (Cervero, 1990).

Finally, this research did not show strong effects of transportation infrastructure on automobile dependence. The provision of roads and public transit have marginal impacts on density and automobile dependence. Other transportation polices that have a direct impact on transportation supply and demand may be more effective (Downs, 1992; Hall, 1991). Transportation supply management, transportation demand management, and provisions for paratransit services are gaining popularity as incremental solutions to existing transportation problems (Altshuler, 1979; Hall, 1991; Deaken, 1987; Gordon, 1991).

In fact, land use and transportation policies and strategies should be well coordinated. Scholars of the 
field argue that land use and transportation are inseparable (Deaken, 1987; Cervero, 1988; Meyer and Gomez-Ibanez, 1981). City planners and public officials should be aware of the importance of this relationship not only at the regional level but even at a smaller planning unit, (i.e. the neighborhood).

To be implemented, most of the recommended policies require strong regional and local governments. Regional governments are better equipped to achieve policies that are regional in nature. Sufficient resources, and sometimes power in the case of U.S. cities, should be granted to these governments. Meanwhile, the local role in this process is indeed essential. Local governments are to be encouraged to coordinate and integrate their land use and transportation policies. Most of the potential policies and actions suggested in this research would take place at the local level. This makes the local involvement in implementing these policies indispensable. Therefore, an increased role for regional and local governments is necessary to coordinate and integrate land use and transportation policies.

The question of urban mobility also has important implications. It affects the locational choices of urban residents and the private sector. In highly mobile societies, speed, reliability, and comfort are needed for efficient mobility (Ohta, 1989). During the last several 
decades, increasing urban mobility in terms of increasing VMT was viewed as a goal and most transportation improvements and policies have targeted that (Gamble, 1976). Reversing this goal without careful considerations of its consequences would not be socially desirable. In fact, minority groups were the major beneficiaries of increased mobility in the last several decades. Iimitations imposed on urban mobility (i.e. VMT reduction) would certainly fall on them first. What land use and transportation planners ought to consider is how to enhance urban mobility for these groups without enduring severe social consequences.

In fact, the question of VMT reduction and its effect on density continues to be an interesting area of research. Recently, several U.S. cities including Portland, Oregon, (i.e., Rule 12) have introduced policies that target future VMT reductions in the city. Whereas the rationale behind these policies is understandable, due to the increased problems of automobile travel and congestion, reducing VMT per se may not an efficient nor a desirable strategy (Bae, 1993). This should not be viewed as a goal by itself; rather it is one part in a series of multiple goals that include land use and growth management, environmental improvement, enhanced mobility, and economic vitality. 
SUGGESTIONS FOR FURTHER RESEARCH

This research has disclosed several prospects for further research in the field of land use and transportation. First, a comprehensive study of the relationship between urban development patterns and travel behavior in the developing world is needed. In this part of the world, very few studies were conducted using comparative analysis. The growing trends of emulating the developed world in its urban development and travel patterns warrant more advanced analytical studies to guide their future developments.

Second, this research incorporates only medium and large size cities. Over the past decades, smaller cities in the developed world have developed distinct development patterns shaped by the automobile revolution. In the U.S., the rapid influx of large city residents to these towns may have fostered changes in development and travel patterns. Further, the transit role in these cities' urban development is still not clearly understood. There is still a great need for examining development and travel patterns in small size cities.

Third, the rich household data published for U.S. and other world cities can be used for further analysis using different time frames. Household comparisons are of great value to land use and transportation scholars since they deal with the behavior of the individual unit without the 
problem of aggregation. Further, household travel behavior data may be combined with qualitative measures of household preferences and lifestyles to complement this type of research. This research has utilized a small portion of the NPTS data where a greater need for further investigation is needed.

Fourth, this research incorporates two major dimensions of the urban system that relate to transportation and urban development. A third dimension that deals with the welfare of the people, the system users, has not been included. In fact, variations in development and travel patterns over time are partially explained by variations in development timing. This timing aspect may reflect changes in preferences and lifestyles of urbanites over time. The people's preference for locational and travel choices was modelled using some surrogate measures of their well-being, such as income and automobile ownership. This is not adequate and further research in these relationships is certainly needed in the form of a third equation to capture the simultaneity of the welfare dimension.

Fifth, the question of optimal density with respect to multiple societal goals warrants further investigation. There still would be a need to examine how future urban development patterns should be tailored to fulfil not a single but multiple, interrelated societal goals. Land use and transportation goals should be balanced with other 
social, economic, and environmental goals that affect the lifestyles and well-being of urban residents.

Finally, future advancement in computer technologies and data availability would allow for an enhanced examination of complex relationships. The research limitations section has identified several limitations of the research statistical technique in which future advancement in computer technology could help in solving that. There would remain a need for dynamic models that can account for the continuous effects of density and automobile dependence at different levels of analysis. In addition, these models may incorporate some qualitative values to the immeasurable effects on density and automobile dependence. Complex, large scale analysis is also needed to incorporate additional factors to those used in this research. This research can be a step ahead in this direction, but there is still a further need for more analysis. Future analysis should account for the complex, interactive relationships between several land use, economic, and transportation factors. 
Al-Mosaind, M. 1988. The Physical Boundaries of the Saudi Cities. Unpublished Thesis. Atlanta: Georgia Institute of Technology.

Al-Mosaind, M., K. J. Dueker, and J. G. Strathman. 1993. Light Rail Transit Stations and Property Values: A Hedonic Price Approach. Center for Urban Studies. Portland: Portland State University.

Alonso, W. 1960. A theory of the urban land market. Papers and Proceedings of the Regional Science Association 6: 149-157.

Alonso, W. 1964. Location and Land Use. Cambridge: Harvard University Press.

Altshuler, A. with J. Womack and J. Pucher. 1979. The Urban Transportation System: Politics and Policy Innovation. Cambridge: MI Press.

Altshuler, A., M. Anderson, D. Jones, D. Roos, and J. Womack. 1986. The Future of the Automobile. Cambridge: MI Press.

Anas, A. 1981. The Estimation of Multinomial Logit Models of Joint Location and Travel Mode Choice From Aggregate Data. Journal of Regional Science. 21, 2, 223-242.

Ar-Riyadh Development Authority (ADA). 1986. Demographic, Transportation, Land Use, and Economic Studies For the City of Ar-Riyadh, Stage 2.4, Economic Studies, Task C, Technical Report. December 14.

Ar-Riyadh Development Authority. 1987. Demographic, Transportation, Land Use, and Economic Studies For the City of Ar-Riyadh, Stage 2.2, Task 2.2.3, Residential Survey Summary Report. July 7.

Ar-Riyadh Development Authority. 1987. Demographic, Transportation, Land Use, and Economic Studies For the City of Ar-Riyadh, Technical Report. September.

Attoe, W. 1988. Transit, Land Use \& Urban Form. Center for the Study of American Architecture, University of Texas at Austin. 
Bae, C. H. C. 1993. Air quality and Travel Behavior: Untying the Knot. Journal of the American Planning Association. $59,1: 65-74$.

Baum, P. 1971. Issues in Optimal Density. Los Angeles: University of California.

Bly, P. H. and F. V. Webster. 1985. Comparison of Interactive Land Use and Transport Models. Transportation Research Record 1125. 29-38. Washington, D.C.: Transportation Research Board.

Bourne, L. S. 1992. Self-Fulfilling Prophecies? Decentralization, Inner City decline, and the Quality of Urban Life. Journal of the American Planning Association. $58,4: 509-513$.

Brown, H. J., J. R. Ginn, F. J. James, J. F. Kain, and M. R. Straszheim. 1972. Empirical Models of Urban Land Use: Suggestions on Research objectives and Organizations. Exploratory Report 6, National Bureau of Economic Research. New York: Columbia University Press.

Burgess, E. W. 1925. The Growth of the City. In The City, ed. R.E. Park, E.W. Burgess, and R.A. McKenzie, Chicago: University of Chicago Press.

Burright, B. 1984. Cities and Travel. New York: Garland Publishing.

Byrne, J. and D. Rich. 1985. Energy and Cities: Energy Policy studies. Vol. 2. New Brunswick: Transactions Books.

Catanese, A. J. 1970 Commuting Behavior Patterns of Families. Traffic Quarterly. 439-457.

Catanese, A. J. 1972. New Perspective in Urban Transportation Research. Lexington Books.

Cervero, R. 1986a. Urban Transit in Canada: Integration and Innovation at Its Best. Transportation Quarterly. $40,3: 293-316$

Cervero, R. 1986b. Suburban Gridlock. New Brunswick: Center for Urban Policy Research.

Cervero, R. 1989. Congestion relief: The Land Use Alternative. Journal of planning Education and Research. 10, 2: 119-129. 
Cervero, R. 1991. Job-Housing Balancing and Regional Mobility. Journal of the American Planning Association. 55, 2: 136-150.

Chan, Y. 1985. Highway Travel and Fuel Consumption from 1970 to 1980. Transportation Quarterly. 39, 1: 39-57.

Christaller, w. 1966. The Central Places of Southern Germany. Translated by C. Baskin. Englewood Cliffs, N.J.: Prestice-Hall.

Clark, J. W. 1976. Directing the Evolution of Urban Land Use to Achieve Improved Transportation System

-Performance. Transportation Research Record 565, 6169. Washington, D.C.: Transportation Research Board.

Cullinane, S. 1992. Attitudes Towards the Car in the U.K.: Some Implications for Policies in Congestion and the Environment. Transportation Research-A. 26A, 4: 291301.

Daniels, P. W. and A. M. Warnes. 1980. Movement in Cities. London: Methuen \& Co. Ltd.

Deaken, E. 1989. Land Use and Transportation Planning in Response to Congestion Problems: A Review and Critique. Transportation Research Record 1237, 77-86. Washington, D.C.: Transportation Research Board.

Downs, A. 1979. The Automotive Population Explosion. Traffic Quarterly. 33, 3: 347-362.

Downs, A. 1992. Stuck in Traffic: Coping with Peak Hour Traffic. Washington, D.C.: The Brookings Institute.

Dueker, K. J., H. Pendleton, and R. L. Rao. 1983. Evaluation of Portland Transit Mall. Transportation Research Record 931. Washington, D.C.: Transportation Research Board.

Dunn, J. 1981. Miles to Go: European and American Transportation Policies. Cambridge: MIT Press.

Evans, A. 1973. The Economics of Residential Location. London: Macmillan.

Fauth, G. R. and J. A. Gomez-Ibanez. 1979. Transferring Demand Models to Predict Benefits From Central Area Auto Restraint in Boston. Discussion Paper: D78-24. Cambridge: Harvard University, Department of City and Regional Planning. 
Gakenheimer, R. 1978. The Automobile and the Environment: An International Perspective. Cambridge: MI Press.

Gamble, H. B. 1976. Transportation and Land Development: Societal Problems and Interrelations. Transportation Research Record 565, 18-52. Washington, D.C.: Transportation Research Board.

Gately, D. 1990. The U.S. Demand for Highway Travel and Motor Fuel. The Energy Journal. 11, 3: 59-73.

Giuliano, G. 1986. Iand Use Impacts of Transportation Investments: Highway and Transit. In The Geography of Urban Transportation, edited by $S$. Hanson. New York: Guilford.

Golob, T. F. 1989. The Causal Influences of Income and Car Ownership on Trip Generation by Mode. Journal of Transport Economics and Policy. May, 141-162.

Golob, T. F. 1990. The Dynamics of Household Travel Time Expenditures and Car Ownership Decisions.

Transportation Research-A. 24A, 6: 443-463.

Gomez-Ibanez, J. A. 1991. A Global View of Automobile Dependence. Journal of the American Planning Association. $57,3: 376-379$.

Gordon, D. 1991. Steering A New Course: Transportation, Energy, and The Environment. Washington, D.C.: Isalnd Press.

Gordon, P., A. Kumar, and H. W. Richardson. 1989a. Congestion, Changing Metropolitan Structure, and City Size. International Regional Science Review. 12 , 1: 45-56.

Gordon, P., A. Kumar, and H. W. Richardson. 1989b. The Influence of Metropolitan Spatial Structure on Commuting Times. Journal of Urban Economics. 26: 138149 .

Gordon, P., and H. W. Richardson. 1989. Gasoline Consumption and Cities: A Reply. Journal of the American Planning Association. $55,3: 342-345$.

Haines, V. A. 1986. Energy and Urban Form: A Human Ecological Perspective. Urban Affairs Quarterly. 21, $3: 337-353$.

Hall, P. 1988. Cities of Tomorrow. Oxford: Blackwell Publishers. 
Hall, P. 1991. The Fourth Crisis in Urban Transportation. Working Paper 536. Institute of Urban and regional Development, University of California at Berkeley.

Hamilton, B. W. 1982. Wasteful Commuting. Journal of Political Economy. 90, 5: 1035-1053.

Hansen, W. G. 1959. How Accessibility Shapes Land Use. American Institute of Planners Journal. Vol. $25, \mathrm{pp}$. 73-77.

Hanson, M. E. 1989. The Motor Vehicle Dominated City as a Non-Sustainable Urban Form: Mexico City and Jakarta. Computer, Environment, and Urban Systems. 13: 95-108.

Hanson, M. E. 1992. Automobile Subsidies and land Use: Estimates and Policy Responses. Journal of the American Planning Association. 58, 1: 60-71.

Harris, C. D. and E. L. Ullman. 1945. The Nature of Cities. The Annals of the american Academy of Political Science. 242: 7-17.

Harrison, D. 1978. Transportation and The Dynamics of Urban Land Use. Discussion Paper: D78-22. Cambridge: Harvard University, Department of City and Regional Planning.

Harrison, D. 1979. Simulating the Impacts of Transportation Policies on Urban Land Use Patterns. Discussion Paper: D78-32. Cambridge: Harvard University, Department of City and Regional Planning.

Heilbrun, J. 1987. Urban Economics and Public Policy. New York: St. Martin's.

Hendrickson, C. 1986. A Note on Trends in Transit Commuting in the United States Relating to Employment in the Central Business District. Transportation Research-A. 20A, 1: 33-37.

Hensher, D. 1977. Urban Transport Economics. Cambridge: Cambridge University Press.

Hensher, D. 1985. Empirical Vehicle Choice and Usage Models in the Household Sector: A Review. International Journal of Transport Economics. XII, 3: 231-259. 
Hensher, D. and N. Smith. 1990. Estimating Automobile Utilization with Panel Data: An Investigation of Alternative Assumptions for the Initial Conditions and Error Covariances. Transportation Research-A. 24A, 6: 417-426.

Hoover, E. and R. Vernon. 1959. Anatomy of a Metropolis; The Changing Distribution of People and Jobs within the New York Metropolitan Region. Cambridge: Harvard University Press.

Hoyt, H. 1939. The Structure and Growth of Residential Neighborhoods in American Cities. Washington, D.C.: U.S. Government Printing Office.

Huttman, J. P. 1977. Conflicts in Planning for cars. Humboldt-Journal-of-Public-Relations. 4, 2, 90-97.

Interrante, J. 1983. The Road to Autopia: The Automobile and the Spatial Transformation of American Culture. In The Automobile and American Culture, edited by D. L. Lewis and L. Goldstien. Ann Arbor: The University of Michigan Press.

Intriligator, M. 1978. Econometrics Models, Techniques, And Applications. Englewood Cliffs: Prentice-Hall.

Isard, W. 1942. Transport Development and Building Cycles. Quarterly Journal of Economics. IVII: 90-112.

Isard, W. 1956. Location and Space Economy. Cambridge: MI Press.

James, F. J. 1974. Models of Employment and Residence Iocation. Center for Urban Policy Research: Rutgers University.

Judge, G. G., R. C. Hill, W. Griffiths, H. Lutkepohl, and T. Lee. 1985. Theory and Practice of Econometrics. New York: John Wiley \& Sons.

Kain, J. F. and G. R. Fauth. 1977. The Impact of Urban Development on Auto Ownership and Transit Use. Research Report D77-18, Cambridge: Harvard University.

Kain, J. F. 1975. Essays on Urban Spatial Structure, Ballinger Publishing Company.

Kain, J. F. 1985. Urban development and Transport Patterns in Developed Countries in an Era of Expensive Energy. Research in Urban Economics, 5: 129-147. 
Kellerman, A. and S. Krakover. 1986. Multi-Sectoral Growth in Space and Time: An Empirical Approach. Regional studies. 20, 2: 117-129.

Kennedy, P. 1992, A Guide to Econometrics. Cambridge: MIT Press.

Keyes, D. L. 1982. Energy for Travel: The Influence of Urban Development Patterns. Transportation Research-A. 16A, 1: $65-70$.

Kingham, R. I. 1976. Suburban Highways and Roads as Instruments of Land Use Change. Transportation Research Record 565, 53-60. Washington, D.C.: Transportation Research Board.

Kitamura, R. and L. Kostyniuk. 1986. Maturing Motorization and Household Travel: The Case of Nuclear-Family Households. Transportation Research-A. 20A, 3: 245-260.

Klaassen, L. H., J. A. Bourdrez, and J. Volmuller. 1981. Transport and Reurbanization. Aldershot, UK: Gower.

Lansing, J., E. Mueller, and N. Barth. 1964. Residential Location and Urban Mobility. Ann Arbor: Survey Research Center, University of Michigan.

Lave, C. 1990. Things Won't Get A Lot Worse: The Future of U.S. Traffic Congestion. Irvine: University of California.

Lowe, M. 1990. Alternatives to the Automobile: Transport for Livable Cities. Washington, D.C.: Worldwatch Institute.

Mahamassani, H., M. Baaj, and C. Tong. 1988. Characterization and Evolution of Spatial Density Patterns in Urban Areas. Transportation. 15: 233-256.

McShane, M. P., M. Koshi, and O. Lundin. 1984. Public Policy Toward the Automobile: A Comparative Look at Japan and Sweden. Transportation Research-A. 18A, 2: 97-109.

Meyer, J. R. and J. A. Gomez-Ibanez. 1981. Autos, Transit and Cities. Cambridge: Harvard University Press.

Michell, R. and C. Rapkin. 1954. Urban Traffic: A Function of Land Use. New York: Columbia University Press. 
Michell, R. 1959. Metropolitan Planning for Land Use and Transportation. Washington, D.C.: The office of Public Works Planning.

Mills, E. S. 1972. Studies in the Structure of the Urban Economy. Baltimore: The Johns Hopkins University press.

Moses, I. N. and H. F. Williamson. 1967. The Location of Economic Activity in Cities. American Economic Review. 67: 211-222.

Muller, Thomas. Fiscal Impacts of Land Development. The Urban Institute: Washington, D.C. 1975.

Muth, R. 1969. Cities and Housing. Chicago: University of Chicago Press.

Nadis, S. and J. J. MacKenzie. 1993. Car Trouble. Boston: Beacon press.

Newman, P. W. 1992. The Search for the Good City. Town and Country Planning. 59, 10: 272-5.

Newman, P., J. Kenworthy, and J.R. Lyons. 1985. Transport Energy Use in the Perth Metropolitan Region: Some Urban Policy Implications. Urban Policy and Research. 3, 2 : 4-15.

Newnan, P. and J. Kenworthy. 1988. The Transport Energy Trade-Off: Fuel-Efficient Traffic Versus Fuel-Efficient Cities. Transportation Research-A. 22A, 3: 163-174.

Newman, P. and J. Kenworthy. 1989a. Cities and Automobile Dependence: A Sourcebook. Aldershot, UK: Gower Technical.

Newman, P. and J. Kenworthy. 1989b. Gasoline Consumption and Cities: A Comparison of U.S. Cities with a Global Survey. Journal of the American Planning Association. $55,1: 24-37$.

Newman, P. and J. Kenworthy. 1992. Is There a Role for Physical Planners. Journal of the American Planning Association. $58,3: 353-362$.

Nolan, D. and G. Stewart. 1991. Downtown Population Growth and Commuting Trips: Recent Experience in Toronto. Journal of the American Planning Association. 57, 2: 165-182. 
O'Connor, K. and C. Maher. 1979. Change in the Spatial Structure of a Metropolitan Region: Work-Residence Relationships in Melbourne. Regional Studies. 13: 361-380.

Ohta, K. 1989. The development of Japanese Transportation Policies in the Context of Regional Development. Transportation Research-A. 23A, 1: 91-101.

Ostro, B. D. and J. I. Naroff. 1980. Decentralization and the Demand for Gasoline. Land Economics. 56, 2: 169180 .

Owen, W. 1966. The Metropolitan Transportation Problem: Washington, D.C.: The Brookings Institute.

Owen, W. 1972. The Accessible City. Washington, D.C.: The Brookings Institute.

Owen, W. 1976. Transportation for Cities. Washington, D.C.: The Brookings Institute.

Owen, W. 1987. Transportation and World Development. Baltimore: The johns Hopkins University Press.

Parker, A. H. 1993. Land Use and Automobile Dependence: Planning for Sustainability in Urban Regions. Thesis. Vancouver, B. C.: The University of British Columbia.

Patterson, J. 1993. Urban Public Transit and Sustainable Cities. Sustainable Cities. No. 6, Spring/Summer.

Pederson, E. O. 1980. Transportation in Cities. Oxford: Pergamon Press.

Pisarski, A. E. 1987. Commuting in America. Westport, CN: Eno Foundation for Transportation, Inc.

Podoski, J. 1982. Prospects of Public Transport in African Cities. Transport Policy and Decision Making. 2 , 1 : $81-88$.

Pucher, J. 1988. Urban Travel Behavior as the Outcome of Public Policy: The Example of Modal-Split in Western Europe and North America. Journal of the American Planning Association. $54,4: 500-520$.

Pucher, J. 1990. Capitalism, Socialism, and Urban Transportation: Policies and Travel Behavior in the East and West. Journal of the American Planning Association. $56,3: 278-296$. 
Pushkarev, B. and J. Zupan 1977. Public Transportation and Land Use Policy. Bloomington: University of Indiana Press.

Putman, S. H. 1983. Integrated Urban Models: Policy Analysis of Transportation and Land Use. London: Pion.

Real Estate Research Corporation. 1974. The Costs of Sprawl, Detailed Cost Analysis. Washington, D.C.: U.S. Government Printing office.

Renner, M. 1988. Rethinking the Role of the Automobile. Washington, D.C.: Worldwatch Institute.

Robert, R. 1986. Analysis of Demographic Trends and Travel Patterns: Implications for the Future of Portland Transit Market. In Transportation Research Record 1067, 1-8. Washington, D.C.: Transportation Research Board.

Schneider, J. B. and J. R. Beck. 1972. Reducing the Travel Requirements of the American City: An Investigation of Alternative Urban Spatial Structure. Transportation Research Record 499, 12-19. Washington, D.C.: Transportation Research Board.

Sharp, R. 1982. Energy Efficiency and Equity of Various Urban Land Use Patterns. Urban Ecology. 7: 1-18.

Simpson, W. 1992. Urban Structure and the Iabor Market: Worker Mobility, Commuting, and Underemployment in Cities. Oxford: Clarendon Press.

Small, K. A. 1980. Energy Scarcity and Urban Development Patterns. International Regional Science Review. 5, 2: 997-119.

Small, K. A. 1985. Transportation and Urban Change. In The New Urban Reality, edited by P.E. Peterson. Washington, D.C.: Brookings Institute.

Smith, w. 1986. Interactions Between Transportation and High-Rise, High-Density Living. Ekistics. 320, SepOct.: $336-344$.

Spencer, A. H. and S. Madhavan. 1989. The car in Southeast Asia. Transportation Research-A. 23A, 6: 425-437.

Stover, V. and F. Koepe. 1988. Transportation and Land Development. Englewood Cliffs, N.J.: Prentice Hall. 
Strathman, J. G. and K. J. Dueker. 1991. Congestion and Travel Behavior. Center for Urban Studies. Portland: Portland State University.

Suh, S. H. 1990. Wasteful Commuting: An Alternative Approach. Journal of Urban Economics. 28, 3: 277-86.

Tabachnick, B. G. and L. S. Fidell. 1989. Using Multivariate Statistics. New York: Harper \& Row.

Thomson, J. M. 1977. Great Cities and their Traffic. London: Penguin.

Townroe, .P. M. 1974. Social and Political Consequences of the Motor Car. North Pomfret, Vermont: David \& Charles.

Train, K. 1986. Qualitative Choice Analysis: Theory, Econometrics, and an Application to Automobile Demand. Cambridge: MI Press.

U.S. Department of Transportation (DOT). 1992a. 1990 National Personal Travel Survey: Summary of Travel Trends. Washington, D.C.: Federal Highway Administration, Office of Highway Information Management.

U.S. DOT. 1992b. 1990 National Personal Travel Survey: Travel Behavior Issues in the 1990s. Washington, D.C.: Federal Highway Administration, Office of Highway Information Management.

U.S. DOT. 1992c. 1990 National Personal Travel Survey: User's Guide for the Public Use. Washington, D.C.: Federal Highway Administration, Office of Highway Information Management.

Van der Ryn, R. S. and P. Calthorpe. 1986. Sustainable Communities. San Francisco: Sierra Club.

Vuchic, V. R. 1981. Urban Public transportation Systems and technology. Englewood Cliffs, N.J.: Prentice Hall.

Vuchic, V. R. 1984. The Auto Versus Transit Controversy: Toward a Rational Synthesis for Urban Transportation Policy. Transportation Research-A. A, 2: 125-133.

Wachs, M. 1981. Pricing Urban Transportation: A Critique of Current Policy. Journal of the American Planning Association. $47,3:$ 247-251. 
Wachs, M. 1984. Autos, Transit, and the Sprawl of Los Angeles: The 1920s. Journal of the American Planning Association. 50, 3: 297-310.

Warren, W. D. 1988. Impacts of Land Use on Mass Transit Development: A Comparison of Canberra to Springfield. Transportation Quarterly. 42, 2: 223-242.

Webster, F. P., P. Bly, R. Johnson, N. Paulley, and M. Dasgupta. 1986. Changing Patterns of Urban Travel. United Kingdom: Transport and Road Research laboratory.

Webster, F. P., P. Bly, and N. Paulley. 1986. Urban LandUse and Transport Interaction: Policies and Models. Aldershot: Avebury.

Weisman, M. 1981. Variables Influencing Transit Use. Transportation Quarterly. 35, 3: 371-383.

White, M. J. 1988. Urban Commuting Journeys Are Not Wasteful. Journal of Political Economy. 96, 5: 10971110 .

Williams, P. 1989. The Influence of Residential Accessibility on Household Trip-Making. Socio-Economic Planning Science. 23, 6: 373-385.

Willson, W. W. and D. C. Shoup. 1990. Parking Subsidies and Travel Choices: Assessing the Evidence. Transportation. 17: 141-157.

Wingo, L. 1961. Transportation and Urban Land, Resources and the Future. Washington, D.C.

World Bank. 1975, 1985. Urban Transport. New York: Oxford University Press.

Wright, C. 1992. Fast Wheels, Slow Traffic: Urban Transportation Choices. Philadelphia: Temple University Press.

Yago, G. 1984. The Decline of Transit: Urban Transportation in Germany and US cities, 1900-1970. New York: Cambridge University Press. 
APPENDIX A

DEVELOPMENT AND TRAVEL PATTERNS IN WORLD CITIES 
TABLE XXII

VARIATIONS IN URBAN DEVELOPMENT PATTERNS 1980

\begin{tabular}{|c|c|c|c|c|c|c|c|}
\hline CITY & DENSITY & $\begin{array}{l}\text { \%CHANGE } \\
1960-80\end{array}$ & $\begin{array}{l}\text { INNER } \\
\text { DENSITY }\end{array}$ & $\begin{array}{l}\text { OUTER } \\
\text { DENSITY }\end{array}$ & $\begin{array}{l}\text { ¿CHANGE } \\
1960-80\end{array}$ & $\begin{array}{l}\text { OUTER EMP. } \\
\text { DENSITY }\end{array}$ & $\begin{array}{l}\text { \%CHANGE } \\
1960-80\end{array}$ \\
\hline BOSTON & 4.9 & -49.6 & 18.4 & 4.0 & -38.8 & 1.8 & 4.9 \\
\hline CHICAGO & 7.1 & -37.1 & 22.3 & 4.6 & -6.1 & 2.1 & 26.8 \\
\hline DENVER & 4.8 & -56.3 & 7.9 & 4.0 & -22.4 & 2.0 & -15.5 \\
\hline DETROIT & 5.7 & -32.6 & 19.8 & 4.3 & -6.6 & 2.0 & 37.1 \\
\hline HOUSTON & 3.6 & -14.6 & 8.5 & 3.2 & 7.7 & 1.4 & -- \\
\hline LOS ANGELES & 8.1 & 8.5 & 12.2 & 7.1 & 12.6 & 3.7 & -1.1 \\
\hline NEW YORK & 8.1 & -13.6 & 44.0 & 5.3 & -3.1 & 2.4 & 18.4 \\
\hline PHOENIX & 3.5 & -1.2 & 7.9 & 3.4 & 6.0 & 1.5 & 37.0 \\
\hline SAN FRANCISCO & 6.3 & -6.5 & 24.2 & 5.3 & 3.9 & 2.2 & 20.0 \\
\hline WASHINGTON & 5.4 & -55.3 & 18.2 & 4.4 & -30.3 & 2.4 & 23.4 \\
\hline Av. (USA) & 5.8 & -25.8 & 18.3 & 4.6 & -7.7 & 2.2 & 16.8 \\
\hline ADELAIDE & 5.3 & -30.2 & 7.7 & 5.0 & -23.4 & 1.5 & -- \\
\hline BRISBANE & 4.2 & -105.9 & 7.6 & 3.7 & -102.2 & 1.0 & -10.7 \\
\hline MELBOURNE & 6.7 & -23.8 & 12.1 & 6.4 & -19.1 & 1.8 & 0.0 \\
\hline PERTH & 4.4 & -44.4 & 6.4 & 4.0 & -25.3 & 1.1 & 28.6 \\
\hline SYDNEY & 7.2 & -21.0 & 16.1 & 6.4 & -13.3 & 2.0 & 19.5 \\
\hline Av. (AUSTR) & 5.5 & -45.1 & 10.0 & 5.1 & -36.6 & 1.5 & 9.4 \\
\hline TORONTO & 16.1 & 7.1 & 23.3 & 13.8 & 32.9 & 5.6 & 136.2 \\
\hline AMESTERDAM & 20.7 & -91.9 & 34.3 & 13.2 & -120.7 & 4.2 & -62.9 \\
\hline BRUSSELS & 27.4 & -48.8 & 41.4 & 20.3 & -69.7 & 6.4 & 132.8 \\
\hline COPENHAGEN & 12.4 & -31.9 & 24.4 & 9.6 & 4.2 & 4.6 & -53.6 \\
\hline FRANKFURT & 22.0 & -61.5 & 25.7 & 19.9 & -24.3 & 10.2 & 56.3 \\
\hline HAMBURG & 17.0 & -63.8 & 36.4 & 14.3 & -48.9 & 4.9 & -40.3 \\
\hline LONDON & 22.9 & -16.2 & 32.1 & 19.7 & -3.3 & 7.6 & -2.1 \\
\hline MUNICH & 23.2 & 0.5 & 65.5 & 19.7 & 13.2 & 8.7 & 8.7 \\
\hline PARIS & 19.7 & -42.0 & 43.8 & 10.6 & -19.2 & 3.1 & -10.6 \\
\hline STOCKHOLM & 20.9 & -27.7 & 24.0 & 18.7 & -3.9 & 6.6 & 46.8 \\
\hline VIENNA & 29.4 & -26.8 & 54.6 & 24.2 & -18.2 & 9.4 & -15.5 \\
\hline WEST BERLIN & 25.9 & -34.6 & 34.4 & 23.3 & -18.2 & 8.4 & -28.9 \\
\hline ZURICH & 21.9 & -8.6 & 36.2 & 17.0 & 14.1 & 6.9 & 26.5 \\
\hline Av. (EUR) & 21.9 & -37.8 & 37.7 & 17.5 & -24.6 & 6.8 & 4.8 \\
\hline HONG KONG & 119.4 & 12.5 & 426.9 & 91.4 & -- & 27.0 & -- \\
\hline SINGAPORE & 33.9 & -25.6 & 83.0 & 25.7 & -22.8 & -- & -- \\
\hline TOKYO & 42.6 & -25.2 & 63.0 & 23.5 & 27.2 & 8.2 & 73.7 \\
\hline Av. (ASIA) & 65.3 & -12.8 & 190.9 & 46.9 & 2.2 & 17.6 & -- \\
\hline
\end{tabular}

Source: Newman and Kenworthy, 1989b 
TABLE XXIII

VARIATIONS IN TRAVEL PATTERNS

(PER CAPITA)

1980

\begin{tabular}{|c|c|c|c|c|c|c|}
\hline CITY & $\begin{array}{l}\text { VEHICLE } \\
\text { OWNERSHIP }\end{array}$ & $\begin{array}{l}\% \text { CHANGE } \\
1960-80\end{array}$ & VMT & $\begin{array}{l}\% \text { CHANGE } \\
1960-80\end{array}$ & $\begin{array}{l}\text { TRANSIT } \\
\text { TRIPS }\end{array}$ & $\begin{array}{l}\text { \%CHANGE } \\
1960-80\end{array}$ \\
\hline BOSTON & 0.557 & 41.0 & 6148 & 53.5 & 79.9 & -24.2 \\
\hline CHICAGO & 0.518 & 37.5 & 4978 & 45.9 & 114.6 & -21.2 \\
\hline DENVER & 0.853 & 32.8 & 6204 & 35.8 & 26.9 & -37.4 \\
\hline DETROIT & 0.691 & 41.9 & 7233 & -- & 25.7 & -47.1 \\
\hline HOUSTON & 0.797 & 37.2 & 7208 & 37.7 & 14.7 & -48.6 \\
\hline LOS ANGELES & 0.667 & 23.1 & 6252 & 22.3 & 59.2 & 59.1 \\
\hline NEW YORK & 0.459 & 34.6 & 4103 & 31.2 & 121.5 & -39.9 \\
\hline PHOENIX & 0.689 & 33.1 & 6631 & 26.4 & 9.1 & -35.0 \\
\hline SAN FRANCISCO & 0.681 & 26.7 & 6501 & 39.6 & 115 & 12.0 \\
\hline WASHINGTON & 0.645 & 49.4 & 5661 & -- & 91.2 & -7.8 \\
\hline Av. (USA) & 0.656 & 35.7 & 6092 & 46.6 & 65.8 & -19.0 \\
\hline ADELAIDE & 0.568 & 48.5 & 4247 & 50.9 & 83.2 & -41.7 \\
\hline BRISBANE & 0.595 & 56.2 & 4558 & 54.2 & 79.3 & -65.8 \\
\hline MELBOURNE & 0.528 & 47.5 & 4368 & 44.7 & 94.8 & -57.4 \\
\hline PERTH & 0.614 & 47.5 & 4956 & 47.6 & 70.8 & -47.8 \\
\hline SYDNEY & 0.489 & 45.2 & 4026 & 41.7 & 142.3 & -43.8 \\
\hline Av. (AUSTR) & 0.559 & 49.0 & 4431 & 47.8 & 94.1 & -51.3 \\
\hline TORONTO & 0.554 & 37.8 & 4639 & -- & 177.6 & 13.0 \\
\hline AMESTRDAM & 0.342 & 71.4 & -- & - & 345.4 & 4.1 \\
\hline BRUSSELS & 0.408 & 53.2 & 2898 & 46.3 & 265.8 & 37.5 \\
\hline COPENHAGEN & 0.296 & 53.4 & 2604 & 62.2 & 200.9 & -- \\
\hline FRANKFURT & 0.427 & 58.6 & -- & -- & 306.3 & 61.6 \\
\hline HAMBURG & 0.382 & 66.0 & 3124 & 54.0 & 248.3 & -27.0 \\
\hline LONDON & 0.356 & 47.5 & 2090 & 46.4 & 284.4 & -34.8 \\
\hline MUNICH & 0.398 & 56.3 & 2326 & 47.2 & 306.9 & -- \\
\hline PARIS & 0.383 & 51.8 & 1981 & 44.7 & 259.1 & -12.2 \\
\hline STOCKHOLM & 0.390 & 55.6 & 3313 & 58.8 & 302.3 & 116.4 \\
\hline VIENNA & 0.374 & 56.3 & 2000 & -- & 312.9 & 1.0 \\
\hline WEST BERLIN & 0.306 & 71.1 & 1933 & -- & 394.5 & 2.8 \\
\hline ZURICH & 0.432 & 56.6 & -- & -- & 363.3 & -3.8 \\
\hline Av. (EUR) & 0.375 & 58.2 & 2474 & 51.4 & 299.2 & 14.6 \\
\hline HONG KONG & 0.066 & 82.8 & 562 & -- & 466.3 & 50.5 \\
\hline SINGAPORE & 0.155 & 62.0 & -- & -- & 353.1 & -- \\
\hline TOKYO & 0.267 & 76.4 & 1728 & 47.0 & 471.8 & 5.6 \\
\hline Av. (ASIA) & 0.163 & 73.7 & 1145 & 47.0 & 430.4 & 28.1 \\
\hline
\end{tabular}

source: Newman and Kenworthy, $1989 \mathrm{~b}$. 
TABLE XXIV

VARIATIONS IN TRANSPORTATION PROVISION 1980

\begin{tabular}{||lllll||}
\hline CITY & ROAD & \%CHANGE & TRANSIT & \%CHANGE \\
& LENGTH & $1960-80$ & MILES & $1960-80$ \\
\hline BOSTON & 5.7 & -- & 16.3 & 0.0 \\
CHICAGO & 5.5 & 4.2 & 26 & -20.2 \\
DENYER & 10.3 & 6.8 & 15.6 & 59.6 \\
DETROIT & 6.4 & 11.5 & 10.3 & -9.3 \\
HOUSTON & 11.7 & -- & 5.7 & -55.8 \\
LOS ANGELES & 4.9 & -8.2 & 16.8 & 38.1 \\
NEW YORK & 5.2 & 9.3 & 36.3 & -4.6 \\
PHOENIX & 11.4 & -32.5 & 4.5 & -25.0 \\
SAN FRANCISCO & 5.4 & 4.3 & 31.4 & 48.5 \\
WASHINGTON & 5.6 & -- & 24.9 & 22.0 \\
AV. (USA) & 7.2 & -0.6 & 18.8 & 5.3 \\
\hline ADELAIDE & 10.0 & 56.9 & 32.2 & -27.8 \\
BRISBANE & 7.6 & -11.5 & 30.2 & -38.0 \\
MELBOURNE & 8.7 & -2.5 & 32.8 & -30.3 \\
PERTH & 14.6 & -5.7 & 32.8 & -21.9 \\
SYDNEY & 6.8 & 31.9 & 48.1 & -26.6 \\
AV.(AUSTR) & 9.5 & 13.8 & 35.2 & -28.9 \\
\hline TORONTO & 3.0 & 58.8 & 50.4 & 66.9 \\
\hline AMESTRDAM & 2.3 & 50.0 & 46.4 & 48.1 \\
BRUSSELS & 1.8 & -39.3 & 39.7 & -16.3 \\
COPENHAGEN & 4.7 & 230.8 & 68.4 & 51.5 \\
FRANKFURT & 2.2 & 300.0 & 34.1 & -- \\
HAMBURG & 2.4 & 22.2 & 50.3 & 20.9 \\
LONDON & 2.1 & 26.7 & 74.9 & -1.3 \\
MUNICH & 1.8 & 13.3 & 47 & -- \\
PARIS & 1.0 & 50.0 & 29.4 & 9.8 \\
STOCKHOLM & 2.5 & 53.3 & 74.3 & 35.9 \\
VIENNA & 1.8 & 41.7 & 41.5 & -3.6 \\
WEST BERLIN & 1.7 & 25.0 & 52 & 0.7 \\
ZURICH & 2.9 & -- & 39 & -3.9 \\
AV.(EUR) & 2.3 & 64.5 & 49.4 & 14.2 \\
\hline HONG KONG & 0.3 & -- & 72.7 & -- \\
SINGAPORE & 1.1 & -- & 61.3 & -- \\
TOKYO & 2.1 & -- & 58.6 & 27.3 \\
AV. (ASIA) & 1.1 & -- & 64.2 & -- \\
\hline
\end{tabular}

Source: Newman and Kenworthy, $1989 \mathrm{~b}$. 
APPENDIX B

SUMMARY STATISTICS OF THE RESEARCH MODELS 
TABLE XXV

SUMMARY STATISTICS FOR THE POOLED REGIONAL MODEL

\begin{tabular}{|llllll||}
\hline VARIABLE & $\begin{array}{l}\text { N OF } \\
\text { CASES }\end{array}$ & MINIMUM & MAXIMUM & MEAN & $\begin{array}{l}\text { STD } \\
\text { DEV }\end{array}$ \\
\hline VMT & 60 & 292 & 7233 & 3768 & 1693 \\
DENSITY & 60 & 3.5 & 120.1 & 16.4 & 21.4 \\
EMP. DENSITY & 60 & 1.0 & 26.9 & 4.3 & 4.8 \\
INCOME & 60 & 850 & 10295 & 4934 & 2349 \\
VEH. OWNERSHIP & 60 & 41.8 & 852.5 & 444.8 & 168.1 \\
ROAD IENGTH & 60 & 0.8 & 50.5 & 17.3 & 12.0 \\
CBD PARKING & 60 & 28.9 & 1033 & 285.8 & 199.8 \\
CONGESTION & 60 & 18.8 & 264.3 & 79.2 & 49.6 \\
TRANSIT MILES & 60 & 3.3 & 74.9 & 33.3 & 19.7 \\
DUMMY 1980 & 60 & 0.0 & 1.0 & 0.45 & 0.5 \\
\hline
\end{tabular}

TABLE XXVI

SUMMARY STATISTICS FOR THE 1980 REGIONAL MODEL

\begin{tabular}{|llllll||}
\hline \hline VARIABLE & $\begin{array}{l}\text { N OF } \\
\text { CASES }\end{array}$ & MINIMUM & MAXIMUM & MEAN & $\begin{array}{l}\text { STD } \\
\text { DEV }\end{array}$ \\
\hline VMT & 27 & 561.9 & 7233 & 4158 & 1897 \\
DENSITY & 27 & 3.5 & 120.1 & 17.2 & 23 \\
EMP. DENSITY & 27 & 1.0 & 26.9 & 4.8 & 5.2 \\
INCOME & 27 & 3973 & 10295 & 7212 & 1419 \\
VEH. OWNERSHIP & 27 & 66.3 & 852.5 & 501.2 & 177.5 \\
GAS PRICES & 27 & 81.5 & 332.8 & 179.7 & 90.0 \\
ROAD LENGTH & 27 & 0.8 & 43.6 & 16.0 & 11.2 \\
CBD PARKING & 27 & 37.4 & 1033 & 288.4 & 206.2 \\
CONGESTION & 27 & 28.9 & 256.2 & 92.8 & 51.8 \\
TRANSIT MILES & 27 & 4.5 & 74.9 & 37.7 & 20.5 \\
\hline
\end{tabular}


TABLE XXVII

SUMMARY STATISTICS FOR PORTLAND ZONAL MODEL

\begin{tabular}{|llllll||}
\hline VARIABLE & $\begin{array}{l}\text { N OF } \\
\text { CASES }\end{array}$ & MINIMUM & MAXIMUM & MEAN & $\begin{array}{l}\text { STD } \\
\text { DEV. }\end{array}$ \\
\hline VMT & 404 & 167 & 46450 & 6361 & 6068 \\
DENSITY & 404 & 0.01 & 34.1 & 5.53 & 4.78 \\
EMP. DENSITY & 404 & 0.0 & 394.7 & 7.16 & 27.1 \\
DEV. MIX & 404 & 0.0 & 158.8 & 6.0 & 17.68 \\
DEV. TIMING & 404 & 0.0 & 100 & 34.5 & 28.4 \\
HIINCOME & 404 & 0.09 & 0.51 & 0.29 & 0.1 \\
HH SIZE & 404 & 0.86 & 3.88 & 2.43 & 0.44 \\
HH LIFECYCLE & 404 & 0.26 & 0.81 & 0.62 & 0.1 \\
\hline
\end{tabular}

TABLE XXVIII

SUMMARY STATISTICS FOR AR-RIYADH ZONAL MODEL

\begin{tabular}{|llllll||}
\hline VARIABLE & $\begin{array}{l}\text { N OF } \\
\text { CASES }\end{array}$ & MINIMUM & MAXIMUM & MEAN & $\begin{array}{l}\text { STD } \\
\text { DEV. }\end{array}$ \\
\hline VMT & 130 & 936 & 18322 & 5413 & 3184 \\
DENSITY & 130 & 0.01 & 196.3 & 23.48 & 39.3 \\
DEV. TIMING & 130 & 2 & 62 & 13.0 & 13.8 \\
DEV. MIX & 130 & 0.0 & 100 & 46.3 & 26.8 \\
COMM AREA & 130 & 0.0 & 146.5 & 9.7 & 16.2 \\
GOVT AREA & 130 & 0.0 & 1166 & 89.3 & 165 \\
HIINCOME & 130 & 0.0 & 1.0 & 0.21 & 0.41 \\
HH SIZE & 130 & 4.3 & 8.0 & 6.3 & 0.86 \\
HISAUDI & 130 & 0.0 & 1.0 & 0.42 & 0.50 \\
HINONSAUDI & 130 & 0.0 & 1.0 & 0.26 & 0.44 \\
FREEWAY & 130 & 0.0 & 1.0 & 0.61 & 0.49 \\
\hline
\end{tabular}


TABLE XXIX

SUMMARY STATISTICS FOR NEW YORK HOUSEHOLD MODEL

\begin{tabular}{|llllll||}
\hline VARIABLE & $\begin{array}{l}\text { N OF } \\
\text { CASES }\end{array}$ & MINIMUM & MAXIMUM & MEAN & $\begin{array}{l}\text { STD } \\
\text { DEV. }\end{array}$ \\
\hline VMT & 1868 & 0.0 & 131000 & 20544 & 16883 \\
DENSITY & 1868 & 0.0 & 93.8 & 16.5 & 22.4 \\
CITY LIMIT & 1868 & 0.0 & 1.0 & 0.34 & 0.48 \\
VEHICLES & 1868 & 0.0 & 7.0 & 1.83 & 0.92 \\
WORKERS & 1868 & 0.0 & 7.0 & 1.30 & 0.96 \\
HH SIZE & 1868 & 1.0 & 11.0 & 4.31 & 3.24 \\
HH LIFECYCLE & 1868 & 0.0 & 1.0 & 0.93 & 0.5 \\
AGE & 1868 & 17.0 & 88 & 45.3 & 15.0 \\
EDUCATION & 1868 & 1.0 & 32 & 20.0 & 7.2 \\
D-TRANSIT & 1868 & 0.0 & 1.0 & 0.62 & 0.49 \\
\hline
\end{tabular}


TABLE XXX

SUMMARY STATISTICS FOR SNOWBELT CITIES HOUSEHOLD MODEL

\begin{tabular}{|llllll||}
\hline VARIABLE & $\begin{array}{l}\text { N OF } \\
\text { CASES }\end{array}$ & MINIMUM & MAXIMUM & MEAN & $\begin{array}{l}\text { STD } \\
\text { DEV }\end{array}$ \\
\hline VMT & 931 & 3.0 & 127157 & 24809 & 19376 \\
DENSITY & 931 & 0.08 & 46.88 & 7.79 & 14.4 \\
CITY LIMIT & 931 & 0.0 & 1.0 & 0.40 & 0.49 \\
VEHICLES & 931 & 1.0 & 7.0 & 1.92 & 0.92 \\
WORKERS & 931 & 0.0 & 5.0 & 1.22 & 0.82 \\
HH SIZE & 931 & 1.0 & 10.0 & 2.91 & 1.46 \\
HH LIFECYCLE & 931 & 0.0 & 1.0 & 0.44 & 0.50 \\
AGE & 931 & 8.0 & 88.0 & 41.0 & 15.8 \\
EDUCATION & 931 & 0.0 & 32.0 & 17.1 & 11.9 \\
D-TRANSIT & 931 & 0.0 & 1.0 & 0.74 & 0.44 \\
CHICAGO & 931 & 0.0 & 1.0 & 0.52 & 0.50 \\
BOSTON & 931 & 0.0 & 1.0 & 0.19 & 0.39 \\
DETROIT & 931 & 0.0 & 1.0 & 0.29 & 0.45 \\
\hline
\end{tabular}


TABLE XXXI

SUMMARY STATISTICS FOR SUNBELT CITIES HOUSEHOLD MODEL

\begin{tabular}{||llllll||}
\hline VARIABLE & $\begin{array}{l}\text { N OF } \\
\text { CASES }\end{array}$ & MINIMUM & MAXIMUM & MEAN & $\begin{array}{l}\text { STD } \\
\text { DEV. }\end{array}$ \\
\hline VMT & 1531 & 0.0 & 130239 & 21104 & 16902 \\
DENSITY & 1531 & 0.08 & 46.88 & 5.08 & 11.8 \\
CITY LIMIT & 1531 & 0.0 & 1.0 & 0.42 & 0.49 \\
VEHICLES & 1531 & 0.0 & 9.0 & 1.86 & 0.95 \\
WORKERS & 1531 & 0.0 & 5.0 & 1.22 & 0.87 \\
HH SIZE & 1531 & 1.0 & 10.0 & 2.78 & 1.42 \\
HH LIFECYCLE & 1531 & 0.0 & 1.0 & 0.42 & 0.49 \\
AGE & 1531 & 3.0 & 88.0 & 43.5 & 16.0 \\
EDUCATION & 1531 & 0.0 & 32.0 & 18.1 & 7.76 \\
D-TRANSIT & 1531 & 0.0 & 1.0 & 0.69 & 0.48 \\
LOS ANGELES & 1531 & 0.0 & 1.0 & 0.51 & 0.50 \\
HOUSTON & 1531 & 0.0 & 1.0 & 0.13 & 0.34 \\
SAN FRANCISCO & 1531 & 0.0 & 1.0 & 0.22 & 0.41 \\
DENVER & 1531 & 0.0 & 1.0 & 0.09 & 0.28 \\
PORTLAND & 1531 & 0.0 & 1.0 & 0.06 & 0.23 \\
\hline
\end{tabular}


APPENDIX C

RESULTS OF AUXILIARY HOUSEHOLD MODELS 
TABLE XXXII

RESULTS OF THE HOUSEHOLD MODEL FOR METROPOLITAN CHICAGO

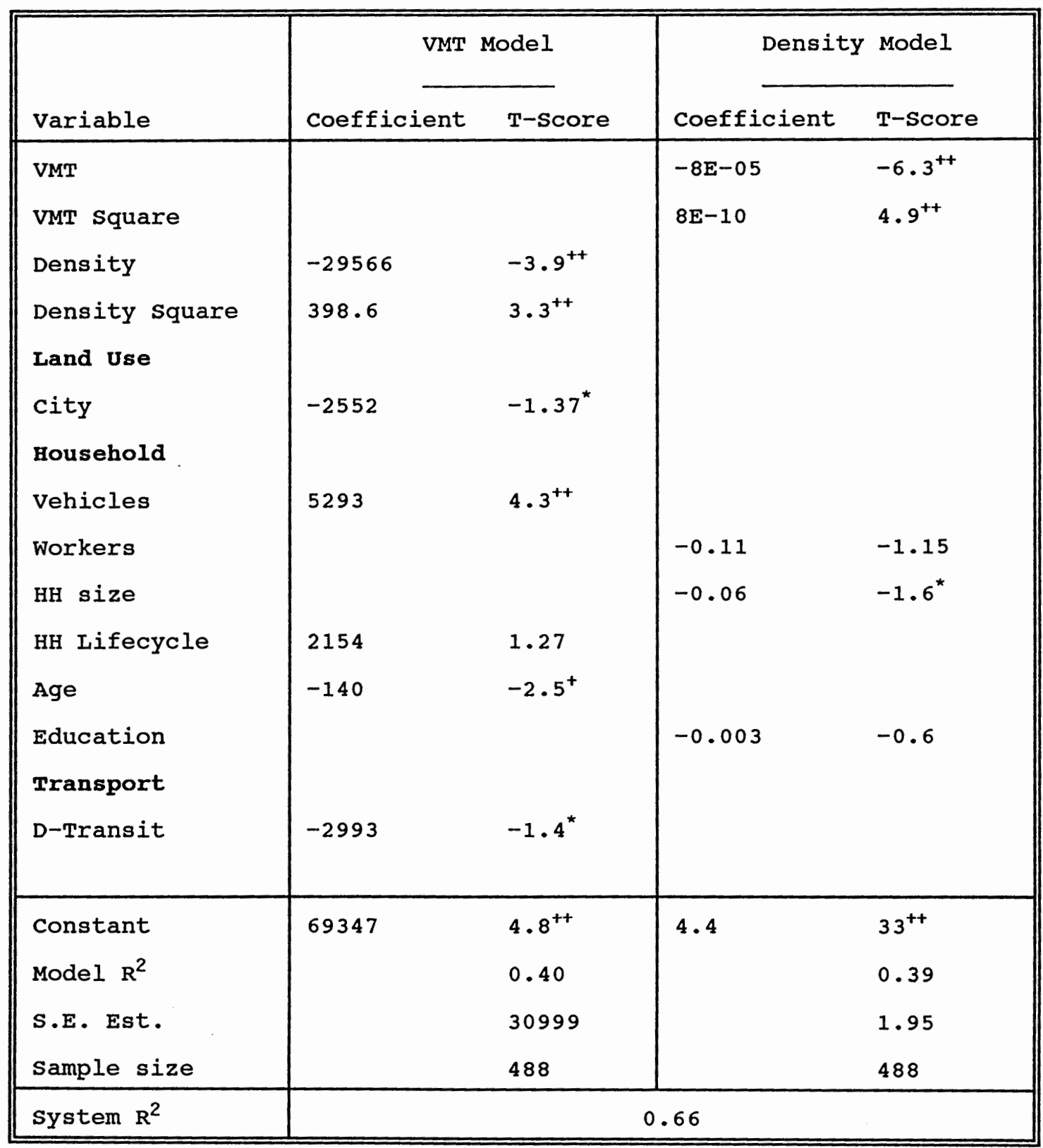

* Significant at the 0.05 level (one-tailed)

+ Significant at the 0.05 level (two-tailed)

++ significant at the 0.01 level (two-tailed) 
TABLE XXXIII

RESULTS OF THE HOUSEHOLD MODEL FOR METROPOLITAN BOSTON

\begin{tabular}{|c|c|c|c|c|}
\hline \multirow[b]{2}{*}{ Variable } & \multicolumn{2}{|c|}{ VMT Model } & \multicolumn{2}{|c|}{ Density Model } \\
\hline & Coefficient & T-Score & Coefficient & T-Score \\
\hline VMT & & & $-5 E-06$ & $-2.2^{+}$ \\
\hline VMT square & & & $4 E-11$ & $1.8^{\star}$ \\
\hline Density & $-1 E+05$ & $-2 \cdot 4^{+}$ & & \\
\hline Density square & 7808 & $1.3^{\star}$ & & \\
\hline Land Use & & & & \\
\hline city & 495.2 & 0.17 & & \\
\hline Household & & & & \\
\hline Vehicles & 10388 & $6.0^{++}$ & & \\
\hline Workers & & & 0.003 & 0.23 \\
\hline $\mathrm{HH}$ size & & & -0.006 & $-1.0^{\star}$ \\
\hline Hн Iifecycle & -2000 & -0.74 & & \\
\hline Age & -343.7 & $-2.74^{++}$ & & \\
\hline Education & & & -0.003 & $-2 \cdot 9^{+t}$ \\
\hline Transport & & & & \\
\hline D-Transit & -4218 & $-1.4^{\star}$ & & \\
\hline Constant & 116390 & $2.8^{t+}$ & 0.9 & $22^{++}$ \\
\hline Model $\mathrm{R}^{2}$ & & 0.35 & & 0.33 \\
\hline s.E. Est. & & 38832 & & 0.21 \\
\hline sample size & & 176 & & 176 \\
\hline system $\mathrm{R}^{2}$ & & & 63 & \\
\hline
\end{tabular}

* Significant at the 0.05 level (one-tailed)

+ Significant at the 0.05 level (two-tailed)

++ significant at the 0.01 level (two-tailed) 
TABLE XXXIV

RESULTS OF THE HOUSEHOLD MODEL FOR METROPOLITAN LOS ANGELES

\begin{tabular}{|c|c|c|c|c|}
\hline \multirow[b]{2}{*}{ Variable } & \multicolumn{2}{|c|}{ VMT Model } & \multicolumn{2}{|c|}{ Density Model } \\
\hline & Coefficient & $\mathbf{T}$-Score & Coefficient & T-Score \\
\hline VMT & & & $-5 E-05$ & $-5 \cdot 5^{++}$ \\
\hline VMT square & & & $5 E-10$ & $4.1^{++}$ \\
\hline Density & -7981 & -1.5 & & \\
\hline Density square & 66.4 & 0.8 & & \\
\hline Land Use & & & & \\
\hline city & -276 & -0.3 & & \\
\hline Household & & & & \\
\hline Vehicles & 9913 & $16^{++}$ & & \\
\hline Workers & & & 0.03 & 0.6 \\
\hline HH size & & & -0.05 & $-2 \cdot 3^{+}$ \\
\hline HH Lifecycle & -517 & -0.4 & & \\
\hline Age & & & & \\
\hline Education & & & -0.03 & $-5.7^{++}$ \\
\hline Transport & & & & \\
\hline D-Transit & 1466 & $1.2^{\star}$ & & \\
\hline Constant & 24062 & $2.3^{+}$ & 3.9 & $37^{++}$ \\
\hline Model $\mathrm{R}^{2}$ & & 0.55 & & 0.41 \\
\hline s.E. Est. & & 25432 & & 1.7 \\
\hline Sample size & & 779 & & 779 \\
\hline system $\mathrm{R}^{2}$ & & & .74 & \\
\hline
\end{tabular}

* significant at the 0.05 level (one-tail)

+ significant at the 0.05 level (two-tailed)

++ Significant at the 0.01 level (two-tailed) 
TABLE XXXV

Results OF THE HOUSEHOLD MODEL FOR METROPOLITAN HOUSTON

\begin{tabular}{|c|c|c|c|c|}
\hline \multirow[b]{2}{*}{ Variable } & \multicolumn{2}{|c|}{ VMT Model } & \multicolumn{2}{|c|}{ Density Model } \\
\hline & Coefficient & T-Score & Coefficient & T-Score \\
\hline VMT & & & $-1 E-05$ & $-3 \cdot 2^{+t}$ \\
\hline VMT square & & & $1 \mathrm{E}-10$ & $2.35^{+}$ \\
\hline Density & -62700 & -1.5 & & \\
\hline Density square & 3083 & 0.6 & & \\
\hline Land Use & & & & \\
\hline city & -30.6 & -0.01 & & \\
\hline Household & & & & \\
\hline Vehicles & 5041 & $2.96^{+t}$ & & \\
\hline workers & & & 0.02 & 0.9 \\
\hline HH size & & & -0.004 & $-0.4^{+}$ \\
\hline HH Lifecycle & -1021 & -0.4 & & \\
\hline Age & -19.7 & -0.2 & & \\
\hline Education & & & -0.004 & $-2.1^{+}$ \\
\hline Transport & & & & \\
\hline D-Transit & -2650 & -0.94 & & \\
\hline Constant & 72080 & 1.8 & 1.21 & $26^{++}$ \\
\hline Model $\mathrm{R}^{2}$ & & 0.30 & & 0.34 \\
\hline S.E. Est. & & 34000 & & 0.32 \\
\hline Sample size & & 195 & & 195 \\
\hline system $R^{2}$ & & & .71 & \\
\hline
\end{tabular}

* Significant at the 0.05 level (one-tailed)

+ Significant at the 0.05 level (two-tailed)

++ Significant at the 0.01 level (two-tailed) 
TABLE XXXVI

RESULTS OF THE HOUSEHOLD MODEL FOR METROPOLITAN PORTLAND

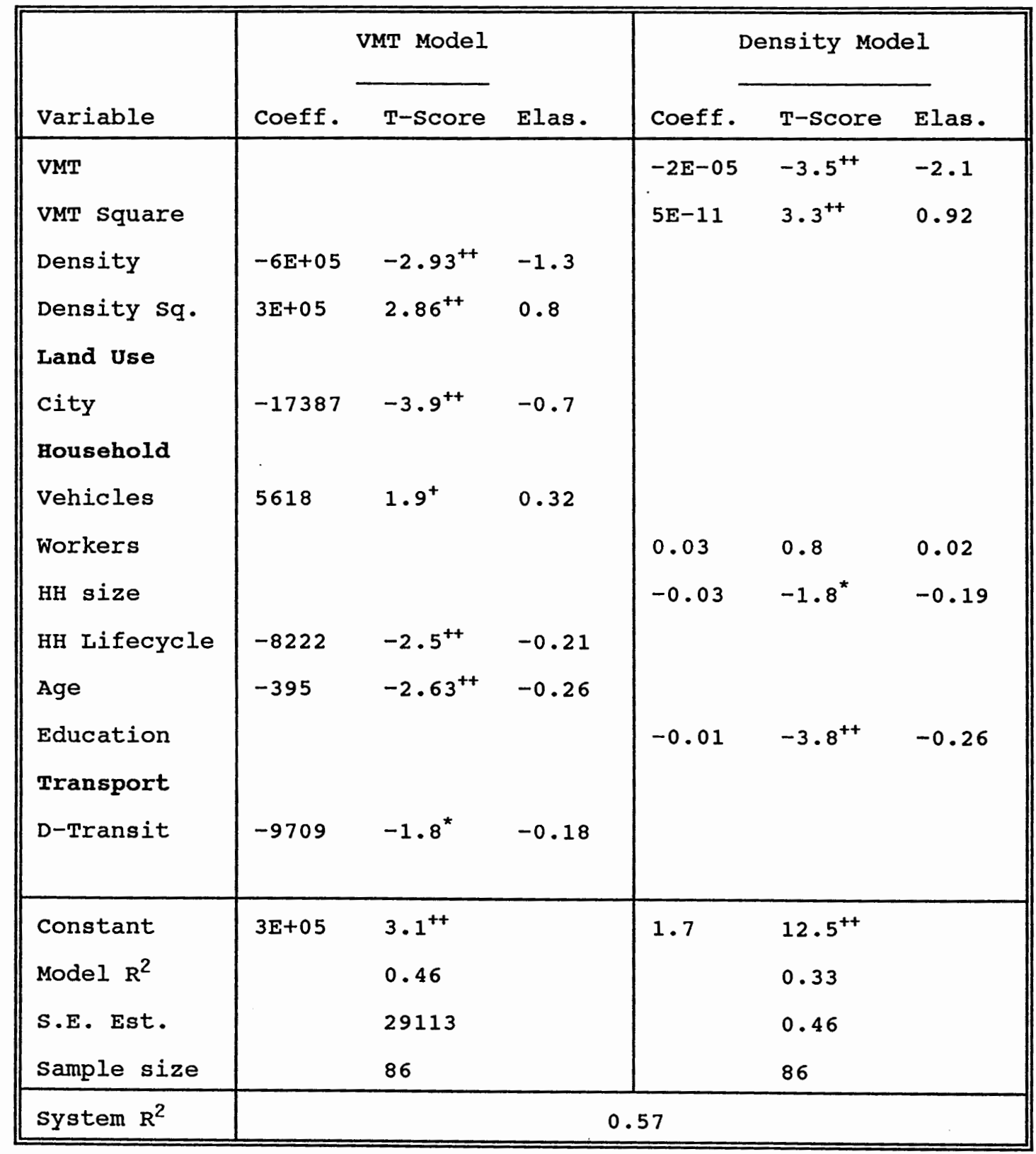

* Significant at the 0.05 level (one-tailed)

+ significant at the 0.05 level (two-tailed)

++ significant at the 0.01 level (two-tailed) 